\title{
Sex differences in steroid levels and steroidogenesis in the nervous system: Physiopathological role
}

\author{
Silvia Giatti ${ }^{\mathrm{a}}$, Silvia Diviccaro ${ }^{\mathrm{a}}$, Melania Maria Serafini ${ }^{\mathrm{a}}$, Donatella Caruso ${ }^{\mathrm{a}}$, \\ Luis Miguel Garcia-Segura ${ }^{b, c}$, Barbara Viviani ${ }^{a}$, Roberto C. Melcangi ${ }^{a, *}$ \\ ${ }^{a}$ Dipartimento di Scienze Farmacologiche e Biomolecolari, Università degli Studi di Milano, Milano, Italy \\ ${ }^{\mathrm{b}}$ Instituto Cajal, Consejo Superior de Investigaciones Científicas (CSIC), Madrid, Spain

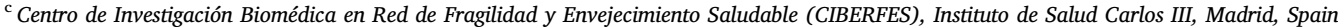

\section{A R T I C L E I N F O}

\section{Keywords:}

Affective disorders

Alzheimer's disease

Diabetic neuropathy

LXR ligands

Multiple sclerosis

Parkinson's disease

$5 \alpha$-Reductase

Traumatic brain injury

Stroke

TSPO ligands

\begin{abstract}
A B S T R A C T
The nervous system, in addition to be a target for steroid hormones, is the source of a variety of neuroactive steroids, which are synthesized and metabolized by neurons and glial cells. Recent evidence indicates that the expression of neurosteroidogenic proteins and enzymes and the levels of neuroactive steroids are different in the nervous system of males and females. We here summarized the state of the art of neuroactive steroids, particularly taking in consideration sex differences occurring in the synthesis and levels of these molecules. In addition, we discuss the consequences of sex differences in neurosteroidogenesis for the function of the nervous system under healthy and pathological conditions and the implications of neuroactive steroids and neurosteroidogenesis for the development of sex-specific therapeutic interventions.
\end{abstract}

\section{Introduction}

Steroidogenesis (Fig. 1) is particularly prominent in the peripheral glands that synthesize hormonal steroids, such as the adrenals and the gonads. However, it is a more generalized phenomenon than the synthesis of steroid hormones and is not restricted to the steroidogenic glands. Thus, cells in many tissues metabolize cholesterol to produce steroids for local actions. For instance, in the nervous system, neurons and glial cells synthesize steroids that regulate neural function by autocrine and paracrine mechanisms. These local steroid actions are exerted in parallel, but with independence, of the endocrine signaling by steroid hormones. Baulieu and his collaborators were the first to identify steroidogenic activity in the nervous system and termed "neurosteroids" the steroids produced by neural cells (Corpechot et al., 1981).

Steroidogenic activity is now well-documented in fish, reptiles, birds and mammals (Cascio et al., 2015; Diotel et al., 2018; GarciaSegura and Melcangi, 2006; Melcangi et al., 2008; Panzica and Melcangi, 2008; Pelletier, 2010; Porcu et al., 2016; Spanic et al., 2015; Weger et al., 2018). Consequently, significant levels of steroids are detected in the nervous system and these levels do not necessarily reflect those in plasma and cerebrospinal fluid (CSF) (Caruso et al., 2013b; Kancheva et al., 2011; Kancheva et al., 2010; Melcangi et al., 2011). However, the identification of a given steroid in the brain, the spinal cord or the peripheral nerves does not provide direct information on its site of synthesis. Indeed, both neurosteroids and steroid hormones contribute to determine the steroid levels in neural tissue. Therefore, in this paper we use the more general term "neuroactive steroids", which currently refers to steroids that have an activity in the nervous system, with preference to the name neurosteroids.

The accumulated information on the synthesis, metabolism, levels and actions of neuroactive steroids in the nervous system in recent years calls for a critical analysis of the implication of these molecules for brain function under physiological and pathological conditions. Thus, in the next sections, we will review sex differences in the levels of neuroactive steroids and in the expression of steroidogenic molecules in CNS and PNS under both physiological and pathological conditions. We will also discuss the available information on the physiopathological consequences of such sex differences in neuroactive steroid levels and neurosteroidogenesis for CNS physiology and for the manifestation of neurodegenerative and psychiatric disorders. In this regard, the opportunity offered by neuroactive steroids and neurosteroidogenesis for the development of neuroprotective interventions will be examined.

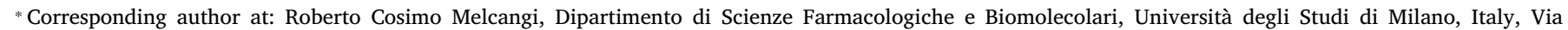
Balzaretti 9, 20133 Milano, Italy.

E-mail address: roberto.melcangi@unimi.it (R.C. Melcangi). 


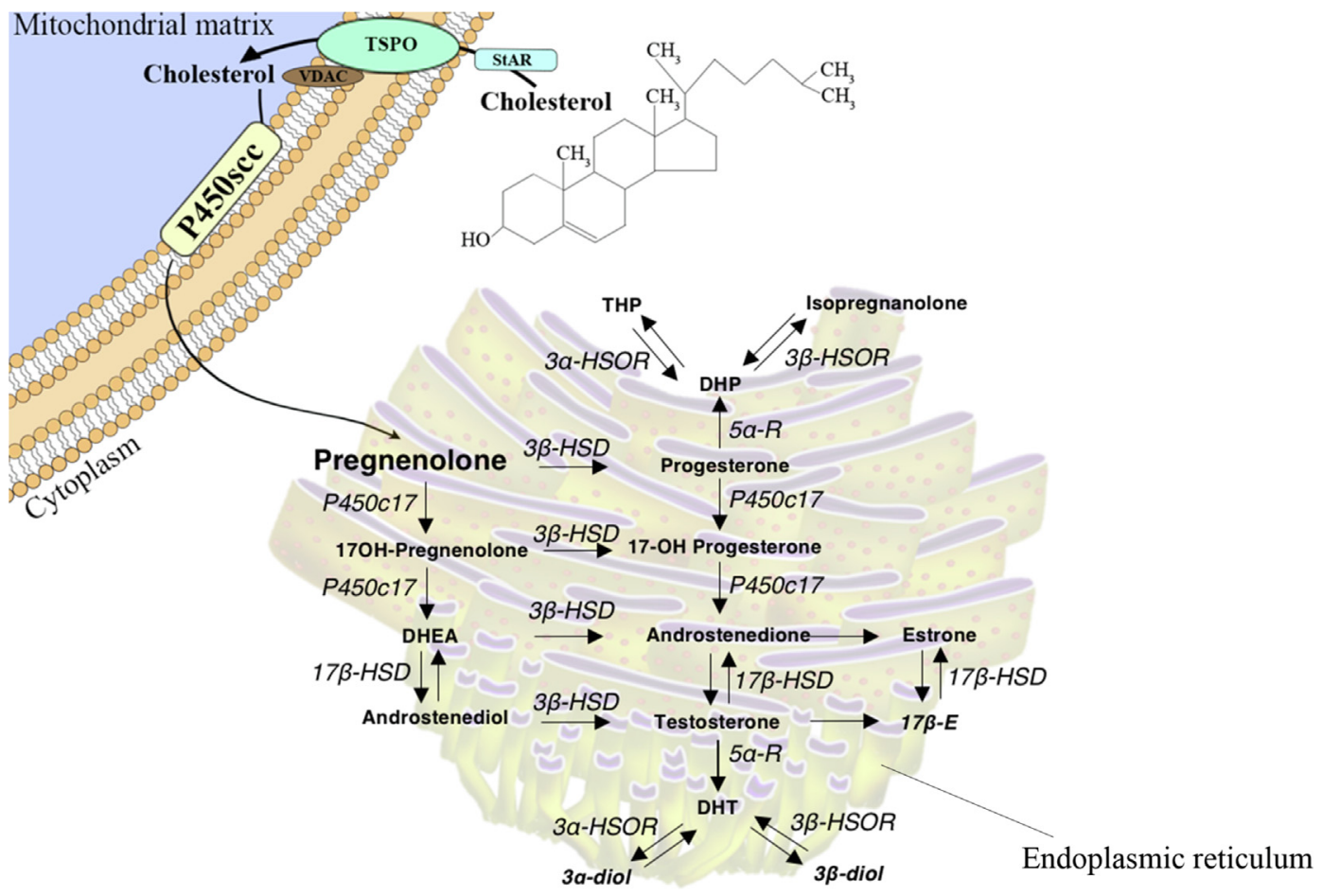

Fig. 1. Steroidogenic pathways. Formation of PREG from free cholesterol, occurring in the mitochondria, represents the first step of steroidogenesis. Translocation of free cholesterol into mitochondria is regulated by a molecular complex composed by several proteins (i.e., TSPO, StAR and the voltage-dependent anion channel protein, VDAC). Formation of PREG occurs by the action of the enzyme P450scc. This neuroactive steroid is then converted in the endoplasmic reticulum into PROG by the enzyme 3ß-HSD or into DHEA by the enzyme cytochrome P450c17. DHEA is the substrate for the synthesis of androgens, such as T. This neuroactive steroid is metabolized into 17 $\beta$-E by the action of the enzyme aromatase or into DHT by the action of the enzyme $5 \alpha$-R, which also converts PROG into DHP. DHT and DHP are

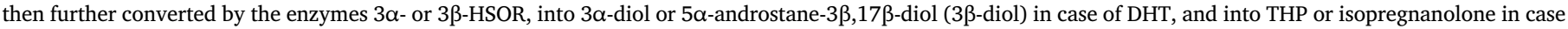
of DHP. Abbreviations in the text. The arrows and bidirectional arrows indicate the irreversible and reversible reactions respectively.

Finally, we will discuss neuroinflammation as a possible functional target for sex-specific therapies based on neuroactive steroids.

\section{Influence of sex and gonadal hormones on neurosteroidogenesis under physiological conditions}

\subsection{Sex differences in neurosteroidogenesis}

An important aspect of neurosteroidogenesis is that it is a sexually differentiated process. For instance, brain progesterone (PROG) levels and its metabolites are higher in pseudopregnant female rats than in males (Meffre et al., 2007) and neuroactive steroid levels in different brain regions show basal sex differences (Caruso et al., 2013b) (Fig. 2).

Sex differences in neuroactive steroid levels are probably due in part to differences in neurosteroidogenic machinery. For instance, sex differences are observed in the frog brain, where steroidogenic acute regulatory protein (StAR) gene expression increases during the reproductive phase in male but not in female brain (Santillo et al., 2017). In the brain of catfish Heteropneustes fossilis, the levels of 3beta-hydroxysteroid dehydrogenase (3ß-HSD) show sex differences depending on the seasonal phase and brain regions considered (Mishra and Chaube, 2017). 33-HSD expression is higher in brain slices from juvenile zebra finch females than in the corresponding brain slices from males (Tam and Schlinger, 2007). In green anole lizards, there is a higher gene expression of an isoform of 5alpha-reductase ( $5 \alpha-R)$ (i.e., the type 2 ) in the brain of females than in males (Cohen and Wade, 2010). In the quail brain, aromatase also shows sex differences, with higher enzymatic activity in males than in females (Balthazart et al., 2011).

Similarly, in rodents, aromatase gene expression and protein levels are higher in male amygdala neuronal cultures (Cisternas et al., 2017) as well as in vivo (Cisternas et al., 2015). Further observations indicate a higher aromatase expression in the bed nucleus of the stria terminalis and medial amygdaloid nucleus of male animals (Stanic et al., 2014).

Sex differences in other steroidogenic molecules have been also detected in the rodent brain. For instance, StAR gene expression in the adult rat cerebellum is significantly higher in proestrus females (i.e., data in other phases of the estrous cycle are not available) than in males (Giatti et al., 2019; Lavaque et al., 2006a; Lavaque et al., 2006b). The basal mRNA levels of 3alpha-hydroxysteroid oxidoreductase (3 $\alpha$ HSOR) are also significantly higher in females, at the proestrus day, than in males. On the contrary, the mRNA levels of translocator protein of $18 \mathrm{kDa}$ (TSPO) and $5 \alpha-\mathrm{R}$ are significantly higher in males. In the cerebral cortex, the mRNA expression of StAR, TSPO, P450 side chain cleavage (P450scc), 3 3 -HSD, $5 \alpha-\mathrm{R}$ and $3 \alpha-\mathrm{HSOR}$ is similar in males and females (Giatti et al., 2019). It is interesting to note that not only the neurosteroidogenic machinery shows sex differences, but also the homeostasis of cholesterol, the substrate of steroidogenesis, is different in male and female rats in brain regions such as the hippocampus and prefrontal cortex (Segatto et al., 2013).

\subsection{Influence of sex steroid hormones on neurosteroidogenesis}

One of the possible causes of sex differences in the levels of neuroactive steroids and in the expression of steroidogenic molecules in the nervous system is the different gonadal hormone environment in males and females. Indeed, several studies have shown that the nervous system adapts the local levels of neuroactive steroids to the physiological changes in steroid hormones coming from sex peripheral glands. Thus, there is a relationship between gonadal hormones and the nervous levels of neuroactive steroids. Indeed, our previous observations have indicated that gonadectomy affects the levels of neuroactive steroids in the CNS and the PNS (Caruso et al., 2010b). Interestingly, the changes in neuroactive steroid levels in the nervous system after gonadectomy present regional specificity between the different CNS 


\begin{tabular}{|lll|}
\multicolumn{1}{l}{ Female (diestrus) } & Male \\
\hline Plasma & PREG; DHP; THP; isopreg & T; DHT \\
CSF & PROG; isopreg; DHEA & PREG; THP; T; DHT \\
Hippocampus & DHP; THP; DHEA & PREG; T; DHT \\
Cerebral Cortex & DHP; THP; isopreg; DHEA & PREG; PROG; T; DHT \\
Cerebellum & DHP; isopreg & PREG; PROG; T; DHT \\
Spinal cord & PREG; DHP; isopreg & T; DHT \\
Sciatic nerve & PREG; DHP; THP; DHEA & isopreg; T; DHT \\
\hline
\end{tabular}

Fig. 2. Sex differences in the levels of neuroactive steroids in physiological conditions. Neuroactive steroid levels in different compartments of male and female rats. Higher level in females (pink box) or in males (light blue box) with respect to the other sex. Pregnenolone (PREG) levels in the cerebrospinal fluid (CSF), hippocampus, cerebral cortex and cerebellum are higher in males than in diestrus females (data in other phases of the estrous cycle are not available). On the contrary, levels of this neuroactive steroid in plasma, spinal cord and sciatic nerve are higher in diestrus females than in males. The levels of its metabolite, progesterone (PROG), are higher in the male cerebral cortex and cerebellum, while its CSF levels are higher in diestrus females. Higher levels of the PROG metabolite, dihydroprogesterone (DHP), are detected in plasma, hippocampus, cerebral cortex, cerebellum, spinal cord and sciatic nerve of diestrus females compared to males. Similarly, in plasma, hippocampus, cerebral cortex and sciatic nerve, the levels of the DHP metabolite, tetrahydroprogesterone (THP) also known as allopregnanolone, are higher in diestrus females, while in the CSF the levels of THP are higher in males. The levels of another metabolite of DHP, isopregnanolone, are higher in the CSF, plasma, cerebral cortex, cerebellum and spinal cord of females, while in the sciatic nerve isopregnanolone levels are higher in male animals. The levels of androgenic precursor dehydroepiandrosterone (DHEA), show higher levels in CSF, hippocampus, cerebral cortex and sciatic nerve of females but those of testosterone (T) and dihydrotestosterone (DHT) are higher in plasma, CSF, CNS areas and sciatic nerve of male animals. (For interpretation of the references to colour in this figure legend, the reader is referred to the web version of this article.)

areas and between the CNS and the PNS and do not necessarily reflect the changes in plasma steroid levels. Moreover, the effects of gonadectomy are different in males and females and depend on the duration of gonadal hormone deprivation (i.e., short or long-term castration) (Caruso et al., 2010b).

Recent results indicate that, at least in some cases, the sex specific effects of long-term gonadectomy are associated with alterations in the expression of the neurosteroidogenic machinery. For instance, in female rats the expression of $3 \beta-H S D$ in the cerebral cortex and the expression of $3 \alpha$-HSOR in the cerebellum are decreased after long-term ovariectomy, while the expression of P450scc and TSPO in the cerebral cortex and the expression of StAR in the cerebellum are increased by the same experimental procedure (Giatti et al., 2019). In contrast, longterm orchidectomy induces an increase in the expression of TSPO and a decrease in the expression of $5 \alpha-\mathrm{R}$ in male cerebellum (Giatti et al., 2019).

In this context, it is also important to highlight that other factors, such as ligands of TSPO (Da Pozzo et al., 2016; Wolf et al., 2015) or PPAR- $\alpha$ (Locci and Pinna, 2019), vitamin D (Emanuelsson et al., 2018), D-aspartate (Di Fiore et al., 2018) and vasotocin (Nagarajan et al., 2015) are able to stimulate neurosteroidogenesis. In addition, maternal fructose consumption during gestation and lactation affects neurosteroidogenesis in the offspring hippocampus, with an increase in the gene expression of P450(11ß)-2, 11ß-hydroxysteroid dehydrogenase type 2 and $17 \beta$ - hydroxysteroid dehydrogenase type 1 and a decrease in StAR, TSPO and 17 $\beta$ - hydroxysteroid dehydrogenase type 3 (Ohashi et al., 2015). However, the possible sex specific effects of these molecules remain to be determined.

\section{Neuroactive steroid levels under pathological conditions}

\subsection{Alzheimer's disease}

Recent studies indicate that different neuropathological events affect the synthesis and levels of neuroactive steroids. For example, altered levels of neuroactive steroids as well as of neurosteroidogenic enzymes are detected in post-mortem brain tissue of Alzheimer's disease (AD) patients (Hasanpour et al., 2018; Luchetti et al., 2011a; Luchetti et al., 2011b; Marx et al., 2006; Rosario et al., 2011; Yue et al., 2005). Changes in brain neuroactive steroid levels have been detected also in $\mathrm{AD}$ mouse models, such as the 3xTg-AD mouse, in which the levels of dihydroprogesterone (DHP), its metabolite isopregnanolone and 17beta-estradiol (17 $\beta$-E) are significantly increased in the limbic region compared to wild type mice (Caruso et al., 2013a). In addition, the bilateral injection of amyloid $\beta$ 25-35 into the hippocampal CA1 region induces a decrease in PREG and PROG levels as well as an increase in $17 \beta$-E levels in this brain area. Altered levels of PROG and $17 \beta-E$ in the prefrontal cortex are also detected in this animal model (Liu et al., 2013).

\subsection{Parkinson's disease}

A decrease of DHP has been reported also in the CSF of Parkinson's disease (PD) patients (di Michele et al., 2003). In addition, the expression of the $5 \alpha$-R type 1 enzyme is downregulated in the substantia nigra, while that of $3 \alpha$-HSOR type 3 is upregulated in the caudate nucleus of PD patients (Luchetti et al., 2010). Neuroactive steroid levels are also altered in PD rodent models. For instance, the total brain levels of dihydrotestosterone (DHT) are increased by injection with 1-methyl4-phenyl-1,2,3,6-tetrahydropyridine (Bourque et al., 2016), while the striatal levels of PREG and DHP are decreased and those of isopregnanolone increased, by injection with 6-hydroxydopamine (Melcangi et al., 2012).

\subsection{Multiple sclerosis}

Effects of Multiple Sclerosis (MS) on neurosteroidogenesis in humans are suggested by the demonstration that the expression of aromatase and of 3 3 -HSD is increased respectively in MS lesions of male and female MS patients (Luchetti et al., 2014). In addition, altered levels of neuroactive steroids are detected in MS patients. For instance, increased levels of PREG, isopregnanolone and $5 \alpha$-androstane-3 $3,17 \beta$ diol ( $3 \alpha$-diol), and decreased levels of DHP, DHT, tetrahydroprogesterone (THP) and 17ß-E have been detected in the CSF of Relapsing Remitting (RR)-MS male adult patients (Caruso et al., 2014). THP levels are also significantly decreased in brain samples of male MS patients (Noorbakhsh et al., 2011). In addition, as recently observed in brain tissue of MS patients and of experimental autoimmune encephalomyelitis (EAE) mouse model, the pathology induces a decrease in the levels of DHEA and in the expression of its synthesizing enzyme 


\section{(i.e., CYP17A1) (Boghozian et al., 2017).}

The brain levels of other neuroactive steroids, such as PREG and PROG are also affected in EAE rat at the acute and chronic phases of the disease (Caruso et al., 2010a; Giatti et al., 2010). It is important to highlight that the observed effects on PREG levels are not detected in plasma, suggesting a specific effect of EAE on neurosteroidogenesis (Caruso et al., 2010a; Giatti et al., 2010).

The hippocampus and cerebral cortex show decreased expression levels of StAR, P450scc and 5 $\alpha-\mathrm{R}$ in a demyelination mouse model induced by the injection of cuprizone (Leicaj et al., 2018). Neuroactive steroid levels are also altered in an experimental model of amyotrophic lateral sclerosis. Thus, in male wobbler mouse, the levels of PROG, DHP and THP are increased in the brain and spinal cord in association with a decrease in testosterone (T) levels (Gonzalez Deniselle et al., 2016).

\subsection{Traumatic CNS injury and stroke}

Traumatic brain injury (TBI) in rodents modifies the brain levels of PREG, PROG, THP, isopregnanolone, T, DHT and 17ß-E (LopezRodriguez et al., 2015; Lopez-Rodriguez et al., 2016; Meffre et al., 2007). Spinal cord transection also affects neuroactive steroid levels. Indeed, an increase in PREG, PROG and its metabolites, DHP and THP, is observed in the injured spinal cord of adult male rats (Labombarda et al., 2006b). In addition, altered neuroactive steroid levels have been also reported in stroke and ischemia models. Levels of PROG and of its metabolite, DHP, are significantly increased by six hours after middle cerebral artery occlusion in mice (Liu et al., 2012). In addition, the levels of $17 \beta-E$ are increased in hippocampal reactive astrocytes in a global cerebral ischemia model (Zhang et al., 2014).

\subsection{Peripheral neuropathy}

The levels of neuroactive steroids are also affected in peripheral nerves by diabetes (i.e., diabetic peripheral neuropathy) (Giatti et al., 2018b; Pesaresi et al., 2011a; Pesaresi et al., 2010b), crush injury (Roglio et al., 2008), and Charcot-Marie-Tooth disease type 1A (CMT1A) (Caruso et al., 2008) in animal models. In addition, altered levels of neuroactive steroids have been observed in peripheral nerve of sterol regulatory element binding protein-1C knockout mice (Mitro et al., 2017), which exhibits peripheral neuropathy (Cermenati et al., 2015).

\subsection{Diabetic encephalopathy}

In addition to the well-characterized effects of diabetes on peripheral nerves and the retina, brain function may also be altered in this pathology. Diabetic encephalopathy induces also changes in the levels of neuroactive steroids in animal models (Calabrese et al., 2014; Giatti et al., 2018b; Pesaresi et al., 2010a; Pesaresi et al., 2010b). Interestingly, a reduction in PREG levels in the hippocampus, but not in plasma, was reported in an experimental model of type 1 diabetes (i.e., by injection of streptozotocin), suggesting a direct effect of diabetes on neurosteroidogenesis (Romano et al., 2017). This concept is supported by the decreased expression of StAR and P450scc, the alteration in the synthesis and metabolism of cholesterol, the substrate for steroidogenesis, and the impaired functionality of mitochondria (i.e., the subcellular organelles where PREG synthesis occurs) in the hippocampus of this animal model (Romano et al., 2017). It is interesting to highlight that diabetes has specific effects on neurosteroidogenic mechanisms depending on the brain region considered. Indeed, the same analysis performed in cerebral cortex showed that, even if also in this brain area the decrease of PREG is associated with alteration in cholesterol homeostasis and mitochondrial functionality, the mechanisms responsible of these effects are different (Romano et al., 2018).

\subsection{Affective and psychiatric disorders}

Affective and psychiatric disorders, like for instance depression, anxiety, premenstrual dysphoric disorder, postpartum depression, posttraumatic stress, schizophrenia and impulsive aggression, also affect the levels of neuroactive steroids (Backstrom et al., 2014; Maguire, 2019; Marx et al., 2011; Marx et al., 2009; Romeo et al., 1998; Rupprecht et al., 2010; Schule et al., 2014; Uzunova et al., 1998). Estradiol-withdrawal, monoamines and neural plasticity seems to have a role in depressive responses (Frokjaker et al., 2015; Galea et al., 2001; Sacher et al., 2010). In addition, anxiety-like behavior and depression are mainly associated with decreased plasma and/or CSF levels of the $5 \alpha$-reduced metabolites of PROG and T, which are able to interact with GABA-A receptor (Frye et al., 2008; Maguire, 2019; Romeo et al., 1998; Rupprecht and Holsboer, 1999; Rupprecht et al., 2010; Schule et al., 2014; Walf and Frye, 2012). In agreement, the expression levels of $5 \alpha-R$ type 1 enzyme are downregulated in prefrontal cortex Brodmamn's area 9 of depressed patients (Agis-Balboa et al., 2014). A relationship between $\mathrm{T}$ levels and depression has been reported in both men (McHenry et al., 2014; McIntyre et al., 2006; Shores et al., 2004) and women (Kumsar et al., 2014) and a significant association between single nucleotide polymorphisms rs523349 (Leu89Val) located in SRD5A2 gene encoding $5 \alpha$-R type 2 and autism has been also reported (Zettergren et al., 2013).

An extensive literature is also available for the effects of ethanol on neuroactive steroid levels and neurosteroidogenesis in humans (Finn and Jimenez, 2018; Porcu et al., 2016; Ramachandran et al., 2015). Indeed, plasma levels of THP are decreased in human alcoholics during alcohol withdrawal and return to normal levels upon recovery (Romeo et al., 1996). In agreement, risk of alcohol dependence is associated with polymorphic variation in the enzymes $5 \alpha-\mathrm{R}$ and $3 \alpha$-HSOR (Milivojevic et al., 2011).

Modifications in the levels of neuroactive steroids have been detected also in male rodents showing depressive-like behavior after exposure from preconception until lactation to bisphenol $\mathrm{A}$, an endocrine disruptor. In particular, these animals show decreased plasma levels of DHEA (Xin et al., 2018). In addition, knockout mice for $5 \alpha$-R type 2 enzyme show reduced dominance-related behaviors, as well as deficits of novelty-seeking and risk-taking responses (Mosher et al., 2018).

\subsection{Other disorders}

Changes in neuroactive steroid levels have been also recently reported in migraine and cluster headache. Indeed, THP plasma levels are increased in episodic or chronic migraine and reduced in cluster headache, while the levels of DHEA and its sulfate form are reduced in the plasma of patients affected by chronic migraine (Koverech et al., 2019).

Medication used to treat pain or to induce anesthesia may also affect the levels of neuroactive steroids. For instance, in primary culture of cortical neurons, ketamine increases the levels of $\mathrm{T}$ and decreases the levels of 17ß-E (Li et al., 2016), while in cultures of rat neural stem cells, morphine treatment increases the levels of DHT and 17ß-E (Feizy et al., 2016) as well as the expression of $5 \alpha-\mathrm{R}$ and aromatase (Abdyazdani et al., 2017).

\section{Influence of sex on neurodegenerative and psychiatric disorders}

\subsection{Sex differences in the incidence of the disease}

Several neurodegenerative and psychiatric disorders show sex differences in incidence. For instance, the incidence of AD (Andersen et al., 1999; Fratiglioni et al., 1997) and MS (Dooley and Hogan, 2003; Gleicher and Barad, 2007; Jacobson et al., 1997) is higher in females, while that of PD (Benito-Leon et al., 2003; de Lau et al., 2004; Van Den 
Eeden et al., 2003; Wooten et al., 2004) and stroke (Reeves et al., 2008; Turtzo and McCullough, 2008) is higher in males. However, in stroke, after 85 years of age, the incidence in the two sexes is the opposite (Rosamond et al., 2007).

The incidence of autism is higher in boys than in girls (Fombonne, 1999, 2003). Depressive disorders (Hankin and Abramson, 1999), anxiety disorders (Afifi, 2007; Foot and Koszycki, 2004), including social phobia, post-traumatic stress disorders, panic disorders, as well as eating disorders (Kaye, 2008), such as anorexia and bulimia, are more frequent in females than in males.

Diabetic encephalopathy is associated with cognitive deficits and increased risk of dementia, stroke, cerebrovascular disease, AD and psychiatric disorders, such as depression and eating disorders, which, as mentioned above, show sex-specific features (Biessels et al., 2008; Biessels et al., 2002; Gispen and Biessels, 2000; Jacobson et al., 2002; Kodl and Seaquist, 2008). Therefore, diabetic encephalopathy shows sex differences in the incidence, progression and severity, depending on the associated pathology (Andersen et al., 1999; Farace and Alves, 2000; Fratiglioni et al., 1997; Kaye, 2008; Marcus et al., 2008; Niemeier et al., 2007; Simonds and Whiffen, 2003). For instance, boys, but not girls, with type 1 diabetes perform poorly in school compared to healthy classmates, showing reduced performance and intelligence quotient (Schoenle et al., 2002). In addition, females with type 2 diabetes have smaller hippocampal volumes in comparison to male patients (Hempel et al., 2012).

The incidence of PNS alterations shows also sex differences. For instance, females are more predisposed than males to peripheral neuropathy associated with chronic alcoholism (Ammendola et al., 2000). In contrast, diabetic peripheral neuropathy is more frequent in men than in women (Basit et al., 2004; Booya et al., 2005).

\subsection{Sex differences in the manifestation of the pathological alterations}

\subsubsection{Alzheimer's disease}

Sex differences are not only observed in the incidence of neurodegenerative and psychiatric disorders but also in their neurological outcomes. For instance, in $\mathrm{AD}$, sex influences $\beta$-amyloid plaque distribution in the human temporal cortex (Kraszpulski et al., 2001) and $\beta$ amyloid deposition in the brain of AD transgenic mice (Callahan et al., 2001; Lewis et al., 2001). Analysis of visuospatial episodic memory in $\mathrm{AD}$ patients shows better performance in men than in women (Beinhoff et al., 2008). However, in an experimental model of AD (i.e., 3xTg-AD mice), female animals perform worse than males at 6 months of age (Clinton et al., 2007).

\subsubsection{Parkinson's disease}

In $\mathrm{PD}$, women tend to be older than men at symptom onset and have more a tremor dominant form of disease, which in turn is associated with a slower disease progression (Haaxma et al., 2007). In experimental models of this disease, male animals show higher depletion of dopamine than females and also the pattern of proinflammatory molecules show sex differences (Czlonkowska et al., 2006).

\subsubsection{Multiple sclerosis}

Most commonly MS female patients show relapsing-remitting-type symptomatology and the course of the disease is more benign in comparison to men (Hawkins and McDonnell, 1999), which are affected in older age and develop a more severe pathology, reaching faster a severe disability (Confavreux et al., 2003), with more destructive lesions than women (Pozzilli et al., 2003). Cognitive decline is also more predominant in men than in women (Parmenter et al., 2007; Savettieri et al., 2004). Inflammatory responses show also sex differences in MS patients (Moldovan et al., 2008; Pelfrey et al., 2002) as well as in animal models (Bebo et al., 1999a; Matarese et al., 2001; Reddy et al., 2005). Observations in EAE model suggest also a sex difference in markers of myelination, such as myelin basic protein (MBP) and platelet-derived growth factor alpha receptor (PDGF $\alpha \mathrm{R}$ ), in spinal cord (Massella et al., 2012).

\subsubsection{Traumatic CNS injury and stroke}

TBI results in higher mortality and poor outcomes in females than in males (Farace and Alves, 2000; Kraus et al., 2000; Ng et al., 2006). However, other studies suggest that women have better overall responses to rehabilitation therapy (Groswasser et al., 1998), better performance on cognitive outcome measures (Ratcliff et al., 2007), and that men have greater level of injury (Slewa-Younan et al., 2004). In females, the outcomes of moderate-to-severe TBI are significantly better after menopause, but not before menopause, in comparison to men (Davis et al., 2006). In addition, the CSF of female patients show smaller oxidative damage load than males after TBI (Wagner et al., 2004). However, women have a poorer recovery from stroke than men (Holroyd-Leduc et al., 2000; Kapral et al., 2005; Niewada et al., 2005; Reeves et al., 2008; Roquer et al., 2003; Turtzo and McCullough, 2008). Although some studies suggest increased long-term mortality in females in comparison to males, other studies indicate the opposite (Devroey et al., 2003; Eriksson et al., 2008; Kimura et al., 2005; Reeves et al., 2008; Rosamond et al., 2007; Turtzo and McCullough, 2008).

In animal models of stroke, adult females show reduced lesions than adult males, but this difference reverts with aging (Alkayed et al., 1998; Hall et al., 1991; Manwani et al., 2013; Selvamani et al., 2014). Sex differences have been also observed in the epigenetic modifications of astrocytes after cerebral ischemia (Chisholm et al., 2015; Chisholm and Sohrabji, 2015).

\subsubsection{Peripheral neuropathy}

Diabetic peripheral neuropathy also shows sex differences. For instance, male diabetic patients develop this secondary effect of diabetes earlier than female patients (Aaberg et al., 2008). In addition, male patients show with higher frequency muscle weakness and atrophy (Kiziltan and Benbir, 2008), as well as motor nerve conduction abnormalities, ulnar nerve involvement (Kiziltan and Benbir, 2008; Kiziltan et al., 2007), lower amplitudes and conduction velocities and longer latencies with respect to female patients (Albers et al., 1996). On the contrary, female patients show more often neuropathic pain and negative sensory symptoms (Kiziltan and Benbir, 2008). Observations in the STZ-experimental model indicate the same sex specific effects (Joseph and Levine, 2003). Interestingly, short-term diabetes in STZ rat model affects axonal transport and mitochondrial function in male, but not in female animals (Pesaresi et al., 2018). As reported in an experimental model of type 2 diabetes, such as BTBR $o b / o b$ mice, intraepidermal nerve fiber loss is higher in males than in females (O'Brien et al., 2016). A possible explanation might be the more robust increase in metabolic perturbations (i.e., hypertriglyceridemia) observed in male animals (Hudkins et al., 2010; O'Brien et al., 2016). Observations performed in $\mathrm{db} / \mathrm{db}$ mice (i.e., a genetic model of type 2 diabetes) also support a higher peripheral neurovascular dysfunction in males (Fan et al., 2018).

\subsubsection{Diabetic encephalopathy}

Short term diabetes in the streptozotocin (STZ) experimental rat model induces a decrease of alpha 1 subunit of $\mathrm{Na}^{+}, \mathrm{K}^{+}$-ATPase in the cerebellum of male, but not female rats. In contrast, long-term diabetes causes a decrease in the expression of this subunit only in females (Kalocayova et al., 2017). In db/db mouse, males develop a greater extent of cognition deficits than females (Fan et al., 2018) and in the same diabetic animal model, experimental stroke induces a higher mortality and bigger infarction size in males than in females (Vannucci et al., 2001). However, in an another experimental model of type 2 diabetes, such as the KKAy mouse model, ischemic brain injury induces a much larger ischemic area as well as higher cerebral NADPH oxidase activity in females in comparison to males (Sakata et al., 2011). In this experimental model, female animals also show higher impairment in 
cognitive function, greater insulin resistance, lower expression of peroxisome proliferators-activated receptor gamma and higher superoxide production (Sakata et al., 2010). In Goto-Kakizaki rats (i.e., a non-obese model that spontaneously develops type 2 diabetes), middle-aged females were less vulnerable than males to oxidative damage and less prone to the accumulation of AD-like neuropathological markers (Candeias et al., 2017).

\subsubsection{Affective and psychiatric disorders}

Autistic male patients are more susceptible to alterations in genes related with synaptic plasticity (Mottron et al., 2015). In a rat model of autism, such as that induced by the prenatal exposure to valproic acid, males show lower sensitivity to pain, elevated anxiety, decreased level of social interactions, decreased thymus weight, decreased splenocyte proliferative response to mitogenic stimulation, increased production of NO by peritoneal macrophages and increased basal level of corticosterone in comparison to females (Schneider et al., 2008). In another experimental model of autism, the reeler mice, heterozygous males at variance to females, show a reduced number of Purkinje cells (Doulazmi et al., 1999; Hadj-Sahraoui et al., 1996).

Even if the incidence of schizophrenia is comparable in men and women, males usually experience the first onset of schizophrenia between 15 and 24 years, 3-4 years earlier than females. In addition, females may experience schizophrenia at the beginning of the menopause (Hafner, 2003; Halbreich and Kahn, 2003; Rao and Kolsch, 2003; Riecher-Rossler and Hafner, 2000). Generally, males show more severe negative symptoms, but paranoid and disorganized subtype of the disease is more predominant in females (Goldstein and Link, 1988; Moriarty et al., 2001). Moreover, antipsychotic and electroconvulsive therapies are more effective in women than in men (Bloch et al., 2005; Szymanski et al., 1995). Furthermore, women perform better on tests of attention, verbal memory and executive function, while men perform better on tests of spatial memory and visual processing (Goldstein, 2006; Goldstein et al., 1998; Seidman et al., 1997). Sex differences in brain structures in schizophrenic patients have also been reported (Andreasen et al., 1990; Andreasen et al., 1994; Bryant et al., 1999; Goldstein et al., 2007; Goldstein et al., 2002; Gur et al., 2004; Pariante et al., 2004; Reite et al., 1997; Takahashi et al., 2003). For instance, schizophrenic male patients have larger ventricles and smaller frontal and temporal lobe volumes (Andreasen et al., 1990; Andreasen et al., 1994; Bryant et al., 1999; Reite et al., 1997), while women have an increased hypothalamic volume (Goldstein et al., 2007).

\section{Sex differences in the levels of neuroactive steroids under pathological conditions}

Observations in patients (Fig. 3) and in experimental models of neurodegenerative and psychiatric disorders have shown sex-specific alterations in neuroactive steroid levels and are here summarized.

\subsection{Alzheimer's disease}

The neuroactive steroid environment could be one of the factors that contribute to the sex differences reported in the incidence and/or manifestation of neurodegenerative and psychiatric disorders. Several recent observations, obtained from different laboratories, seem to support this concept. For instance, as reported by a recent meta-analysis, low plasma $\mathrm{T}$ levels are significantly associated with increased risk of $\mathrm{AD}$ in elderly men (Lv et al., 2016). In addition, higher free $\mathrm{T}$ levels in females are associated with lower cerebral $A \beta$ positivity, while in males delay the progression of neurodegeneration (Lee et al., 2017). This is confirmed by assessment in postmortem brain tissue. Indeed, a decrease in brain levels of T occurs in male AD patients while, not only $\mathrm{T}$ but also 17 $\beta$-E levels are decreased in females (Rosario et al., 2011). A male/female comparison of the levels of neuroactive steroids in experimental models of $\mathrm{AD}$ is still necessary.

\subsection{Parkinson's disease}

To our knowledge, there is not available information on a male/ female comparison of neuroactive steroid levels in human or animal models of PD.

\subsection{Multiple sclerosis}

Studies in EAE rodent model of MS have shown sex-specific effects in the levels of neuroactive steroids in the CNS. Among other changes, PREG levels are decreased in the cerebral cortex, cerebellum and spinal cord of EAE Dark-Agouti (DA) male rats at the acute (i.e., 14 days postimmunization) and chronic (i.e., 40 days post-immunization) phases of the disease, but are not modified in female animals (Caruso et al., 2010a; Giatti et al., 2010).

\subsection{Traumatic CNS injury and stroke}

Male TBI patients show lower plasma levels of T and PROG compared with healthy patients, while female patients show in addition lower plasma levels of estradiol (Zhong et al., 2019).

Neuroactive steroid plasma levels are also affected by acute ischemic stroke in a sex specific way. Thus, an increase in $17 \beta-E$ plasma levels occurs in women but not in men (Casas et al., 2017).

Sex-specific effects of CNS injury and stroke on neuroactive steroids have been observed also in animal models. For instance, TBI in male rats, results in an increase, after six hours, in PREG and PROG brain levels and a decrease in T levels, while in pseudopregnant female rats an increase of isopregnanolone levels occurs (Meffre et al., 2007). Longer time of TBI in female mice (i.e., $24 \mathrm{~h}, 72 \mathrm{~h}$ and 2 weeks) induces a significant decrease in the brain levels of PROG (at all times considered), THP (after $72 \mathrm{~h}$ and 2 weeks), isopregnanolone (after $24 \mathrm{~h}$ and 2 weeks), T (after $24 \mathrm{~h}$ ) and 17 $\beta$-E (after 2 weeks) (Lopez-Rodriguez et al., 2015). On the contrary, a decrease of PREG and DHT levels, associated with an increase in T levels, is observed by 2 weeks after TBI in the brain of male mice (Lopez-Rodriguez et al., 2016).

In mice, gonadectomy in females, but not in males, increases ischemic stroke sensitivity. This effect is mediated by gonadal secretions, as demonstrated by the use of the four core genotype mouse model, in which the testes determining Sry gene is located in an autosome and allows to differentiate between gonadal effects and chromosome effects on sex differences (Manwani et al., 2015). Female astrocytes are less susceptible than males to oxygen-glucose deprivation and this is probably due to an enhanced aromatase activity in these cells. Indeed, expression and activity of this enzyme is higher in female than in male astrocytes. In addition, aromatase inhibitors, like for instance arimidex, abolish the sex difference in oxygen-glucose deprivation-induced cell death (Liu et al., 2007). Moreover, the cerebral levels of PROG and DHP are rapidly upregulated in male, but not in female mice, in response to ischemic stroke, as recently demonstrated in an experimental model of middle cerebral artery occlusion (Zhu et al., 2017).

\subsection{Peripheral neuropathy}

To knowledge authors there is not available information on a male/ female comparison of neuroactive steroid levels in patients. However, in animal models of diabetic peripheral neuropathy, long-term diabetes (i.e., three months after the induction) induces a decrease of PREG, T, DHT and $3 \alpha$-diol levels in the male rat sciatic nerve, while in females a decrease in the levels of PROG, THP and isopregnanolone occur (Pesaresi et al., 2010b). Short-term diabetes (i.e., one month after the induction) induces a different sex pattern of changes in the sciatic nerve. Thus, in the nerve of male rat, T and DHT levels are decreased in association with an increase in THP levels, while the levels of all neuroactive steroids assessed are unaffected in the female sciatic nerve (Pesaresi et al., 2018). Diabetes also differentially affects the expression 


\begin{tabular}{|c|c|c|}
\hline Pathology & & \\
\hline$A D$ & $\downarrow$ T and $17 \beta-E$ levels in brain* & $\downarrow$ T levels in brain* \\
\hline TBI & $\begin{array}{l}\checkmark \text { T, PROG and 17ß-E levels } \\
\text { in plasma* }\end{array}$ & $\downarrow_{\text {T, PROG levels in plasma* }}$ \\
\hline Stroke & A $17 \beta-E$ levels in plasma\# & \\
\hline Schizophrenia & $\begin{array}{l}\text { T levels in plasma (stable } \\
\text { multi-episode patients)* }\end{array}$ & $\begin{array}{l}\sqrt{ } \text { PREG, DHEA levels in plasma* } \\
V_{\text {multi-episode patients) }}^{*}\end{array}$ \\
\hline MDD & & $\checkmark$ T levels in plasma* \\
\hline PTSD & $\downarrow$ THP levels in CSF * & \\
\hline Alcohol use disorder & & TTHP in pmSN" \\
\hline
\end{tabular}

Fig. 3. Sex differences in the levels of neuroactive steroids of patients under pathological conditions. Increase or decrease of neuroactive steroid levels in female (pink box) or male (light blue box) patients in comparison to healthy subjects (*) or to the other sex (\#). Alzheimer's disease (AD): both T and 17ß-estradiol (17ß-E) levels are decreased in the brain of female AD patients. Testosterone (T) levels are decreased in the brain of male AD patients. Traumatic brain injury (TBI): female patients show lower plasma levels of T, progesterone (PROG) and 17 $\beta$-E compared to healthy subjects. Male TBI patients show lower plasma levels of T and PROG compared with healthy subjects. Stroke: $17 \beta$-E plasma levels are increased in women after stroke, but not in men. Schizophrenia: plasma levels of T are reduced in women with stable multi-episode schizophrenia compared to healthy subjects. Decreased levels of pregnenolone (PREG) and dehydroepiandrosterone (DHEA) have been found in the plasma of male schizophrenic patients. In addition, plasma levels of total $\mathrm{T}$ are reduced in stable multi-episode schizophrenia male patients. Major depressive disorders (MDD): plasma levels of $\mathrm{T}$ are decreased in men with MDD. Posttraumatic stress disorders (PTSD): cerebrospinal fluid (CSF) levels of tetrahydroprogesterone (THP) are decreased in men with PTSD. Alcohol use disorder: THP immunoreactivity is increased in the substantia nigra pars medialis (pmSN) of men with alcohol use disorder. (For interpretation of the references to colour in this figure legend, the reader is referred to the web version of this article.)

of steroidogenic enzymes in the PNS. For instance, the expression of aromatase is altered by long-term diabetes in a sex specific way. Indeed, the expression of this enzyme is increased in the sciatic nerve of female but not of male rats (Burul-Bozkurt et al., 2010).

In an animal model of the Charcot-Marie-Tooth disease type $1 \mathrm{~A}$ (CMT1A) inherited peripheral neuropathy, sexual differences in the levels of some neuroactive steroids have also been identified. Indeed, the levels of isopregnanolone and $3 \alpha$-diol are decreased in female and male sciatic nerve, respectively (Caruso et al., 2008).

\subsection{Diabetic encephalopathy}

To our knowledge, there is not available information on a male/ female comparison of neuroactive steroid levels in diabetic patients. However, in experimental model of diabetes, neuroactive steroid levels in the brain are modified depending on the sex. For instance, an increase in DHEA and T levels, in association with a decrease in 17 $\beta$-E levels, occur in the brain of female Goto-Kakizaki rats. On the contrary, only an increase of $\mathrm{T}$ occurs in the male brain (Candeias et al., 2017). The effects of diabetes on CNS neuroactive steroid levels also show regional differences. Thus, PROG and isopregnanolone levels are decreased in the cerebellum of long-term diabetic female rats, but not in the cerebellum of males, while the opposite occurs in DHP levels. In addition, the levels of THP in the spinal cord are decreased in male animals but not in females (Pesaresi et al., 2010b). Furthermore, $\mathrm{T}$ and DHT levels are significantly decreased in male cerebral cortex, cerebellum and spinal cord of male but not of female animals (Pesaresi et al., 2010b). In addition, sex-specific changes in the brain levels of neuroactive steroids in diabetic rats show variations that depend on the duration of the pathology. For instance, PREG levels decrease in the cerebral cortex and hippocampus of male rats (Romano et al., 2017; Romano et al., 2018) but not in females after short-term diabetes (cerebral cortex: controls $1.19 \pm 0.26$ vs STZ $0.50 \pm 0.20$; hippocampus: controls $2.67 \pm 0.43$ vs STZ $2.86 \pm 1.00$; data were obtained by LC-MS/MS and expressed as pg/mg of tissue \pm SEM, $n=6$ ). After long-term diabetes, the levels of this neuroactive steroids are decreased in the cerebral cortex of both sexes (Pesaresi et al., 2010b).

Some neuroactive steroids show similar changes in the brain of male and female diabetic animals. For instance, the levels of PROG show a similar decrease in male (Romano et al., 2017; Romano et al., 2018) and female cerebral cortex (controls $3.90 \pm 0.71$ vs STZ $0.48 \pm 0.09$; data are expressed as $\mathrm{pg} / \mathrm{mg}$ of tissue \pm SEM, $\mathrm{n}=6, \mathrm{p}=0.0007$, data were obtained by LC-MS/MS and analyzed by Student's $t$ test) and hippocampus (controls $3.84 \pm 0.84$ vs STZ $0.58 \pm 0.13$; data are expressed as $\mathrm{pg} / \mathrm{mg}$ of tissue $\pm \mathrm{SEM}, \mathrm{n}=6, \mathrm{p}=0.0034$, data were obtained by LC-MS/MS and analyzed by Student's $t$ test) after short-term diabetes and in the cerebral cortex after long-term diabetes (Pesaresi et al., 2010b), in spite of the fact that the plasma levels of this neuroactive steroid are significantly decreased in female short-term diabetic animals (controls $10.27 \pm 1.63$ vs STZ $1.38 \pm 0.17$; data are expressed as $\mathrm{pg} / \mu \mathrm{l}$ of plasma \pm SEM, $\mathrm{n}=6, \mathrm{p}=0.0003$, data were obtained by LC-MS/MS and analyzed by Student's $t$ test) but not in the males (Romano et al., 2017; Romano et al., 2018). The decrease in PROG plasma levels in diabetic female rats is in agreement with the well-characterized alterations in the reproductive axis at the gonadal and neuroendocrine levels in female diabetic patients (Giatti et al., 2018b). Furthermore, the observed sex differences in plasma levels of PROG in diabetic animals but not in the cerebral cortex and 
hippocampus indicate that sex differences in peripheral steroid levels induced by diabetes do not necessarily reflect similar sex differences in the brain. Indeed, diabetes affects the expression of steroidogenic enzymes in the brain in a sex specific way. Thus, the expression of aromatase is increased in the hippocampus of female but not of male rats (Burul-Bozkurt et al., 2010).

\subsection{Affective and psychiatric disorders}

Men with major depressive disorder show lower T plasma levels, while the levels of this neuroactive steroid in women are unaffected (Giltay et al., 2017). In addition, studies in patients with posttraumatic stress disorders have shown a decrease in the CSF levels of THP that are associated with an impairment of $3 \alpha$-HSOR in females (Rasmusson et al., 2006) and of $5 \alpha-\mathrm{R}$ in males (Rasmusson et al., 2019).

To our knowledge, there is not available information on a male/ female comparison of neuroactive steroid levels in autism. However, sex differences have been detected in the levels of neuroactive steroids in plasma of schizophrenic patients. In particular, the plasma levels of PREG and DHEA are significantly decreased in male, but not in female patients (Huang et al., 2017). In addition, a recent meta-analysis indicates that plasma levels of total $\mathrm{T}$ are reduced in stable multi-episode schizophrenia male patients and increased in female patients (Misiak et al., 2018).

It has been ascertained by a recent postmortem study that THP immunoreactivity in substantia nigra pars medialis, but not in other brain regions, is significantly higher in men than in women diagnosed with alcohol use disorder (Hasirci et al., 2017). Alcohol exposure during fetal life also affects the levels of neuroactive steroids with sex differences. For instance, sex differences occur in white matter microstructure in children and adolescent affected by prenatal alcohol exposure, with girls and boys exhibiting lower and higher fractional anisotropy in brain white matter, respectively, compared to control individuals (Uban et al., 2017). A relationship with neuroactive steroids also occurs in these patients. Indeed, a positive association between fractional anisotropy and T or DHEA levels is observed in girls, but not in boys, with prenatal alcohol exposure (Uban et al., 2017).

It is known that alterations in the stress system are related with depressive disorders (Maguire, 2019; Maydych, 2019; Park et al., 2019; Patel et al., 2019) and recent evidence suggests that neurosteroidogenesis may contribute to sex differences in the stress axis. Low levels of $\mathrm{T}$ in males and low levels of $17 \beta-\mathrm{E}$ and PROG in females are associated with increased depressive-like behaviors in rodents (Calmarza-Font et al., 2012; Diz-Chaves et al., 2012; Lagunas et al., 2010; Osborne et al., 2009; Walf and Frye, 2010, 2014; Walf et al., 2009). In addition, sex (with higher response in female animals) and brain regional differences in the neuroactive steroid levels, and particularly in the $5 \alpha$-reduced metabolites, occur after acute stress in rats (Sze et al., 2018). For instance, the levels of DHP increase in the frontal cortex and brainstem of male and female rats following stress. In addition, a significant increase in the levels of these neuroactive steroids is also detected in the hypothalamus, amygdala and hippocampus in females, but not in males. Furthermore, the levels of THP, a metabolite of DHP, are increased in all female brain regions analyzed, but only in the frontal cortex of male animals (Sze et al., 2018). Interestingly, shortterm treatment of rats with an antidepressant drug such as fluoxetine (i.e., a selective serotonin reuptake inhibitor), increases THP levels in the brain of females, but not in the brain of males. This effect seems to be due to an inhibition of THP retro-conversion into DHP (Fry et al., 2014).

Stressful conditions not only cause sex differences in brain neuroactive steroid levels, but also differentially affect the expression of brain steroidogenic molecules in males and females. For instance, environmental stress in rats caused by artificial light, immobility in a small space and excessive heat, results in increased gene expression and protein levels of $5 \alpha-R$ type 2 enzyme in the brain of adult males, but decreased expression in females (Sanchez et al., 2009).

THP levels are decreased in the male, but not in the female brain in a mouse model of autism spectrum disorder-like behavior induced by the treatment with SKF105111, an inhibitor of the enzyme $5 \alpha$-R type 1 and 2 (Ebihara et al., 2017). In another experimental model of autism (i.e., the heterozygous reeler mouse) the levels of $\mathrm{T}$ and $17 \beta-\mathrm{E}$ are increased, while the levels of DHT are decreased, at postnatal day 5 in the male, but not in the female cerebellum (Biamonte et al., 2009).

In mice, exposure to predator odor stress (i.e., an experimental model of traumatic stress) increases ethanol intake and has a synergistic interaction with prior binge drinking in a sexually specific way (i.e., in male but not in female animals) (Devaud et al., 2018). Interestingly, in this experimental model brain regional and sex differences occur in neurosteroidogenesis and in neuroactive steroid levels. For instance, expression of P450scc in the prefrontal cortex is significantly decreased in males, but increased in females, vs the corresponding controls. On the contrary, the expression of this enzyme in hippocampus is increased in females but not in male animals (Devaud et al., 2018). Assessment of plasma neuroactive steroids shows a significant increase in the levels of PREG and DHEA in male but not in female animals (Devaud et al., 2018).

\subsection{Other disorders}

Sex specific features are also observed in association with mitochondrial dynamin like GTPase (OPA1) mutations, which induce degeneration of retinal ganglion cells (i.e., autosomal dominant optic atrophy). As demonstrated in an animal model (i.e., OPA1 ${ }^{\text {delTTAG }}$ ), the levels of PREG and 17 $\beta$-E are significantly increased in the retina and plasma of female but not male animals in comparison to wild-type mice. Interestingly, in retina of female OPA $1^{\text {delTTAG }}$ there is also an increase in the expression of the steroidogenic molecules P450scc and 3ß-HSD (Sarzi et al., 2017), suggesting modifications in neurosteroidogenesis.

Gestational deficiency in methyl donors (e.g., vitamin B12 and folate) produces hyperhomocysteinemia associated with impairment of cerebellar synaptic plasticity and neurogenesis, together with cognitive and motor disorders. This deficiency is associated with an impairment of neurosteroidogenesis. Indeed, decreased levels of PREG and 17ß-E and expression of StAR and aromatase occur in the cerebellum of female rats, but not in males (El Hajj Chehadeh et al., 2014).

\section{Neuroactive steroids as physiological modulators of neural function}

Neuroactive steroids act in the nervous system by binding to classical steroid receptors, such as PROG (PR), androgen (AR) and estrogen (ER) receptors, as well as through non-classical steroid receptors, such as G-protein coupled estrogen receptor (GPER), membrane-associated protein PGRMC1 (also known as 25-Dx), the membrane PRs (mPR), gamma-amino butyric acid (GABA) A and B receptors, N-methyl-D-aspartate (NMDA) receptor, $\alpha$-amino-3-hydroxy-5-methyl-4-isoxazolepropionic acid (AMPA) receptor, dopamine 1 (D1) receptor, the nicotine receptors, the $\alpha-1$ adrenergic receptor, the sigma- 1 receptor and L-type $\mathrm{Ca}^{2+}$ channels (Giatti et al., 2015a; Giatti et al., 2016b; Hadjimarkou and Vasudevan, 2018; Singh et al., 2013; Vega-Vela et al., 2017).

Neuroactive steroids regulate neural function during all life stages. For instance, developmental actions of $17 \beta$-E include effects on neurogenesis (Martinez-Cerdeno et al., 2006), neuronal survival (Chowen et al., 1992), neuritogenesis (Arevalo et al., 2012a), synaptogenesis (Bender et al., 2010) and differentiation of glial cells (Garcia-Segura et al., 1989; McCarthy et al., 2008; McCarthy et al., 2003; TorresAleman et al., 1992). PROG regulates the development of Purkinje cells of the cerebellum (Tsutsui et al., 2011) and together with its metabolites also modulates oligodendrocyte differentiation (Ghoumari et al., 2005; Ghoumari et al., 2003; Jung-Testas et al., 1996), the myelination 
program (Guennoun et al., 2001; Magnaghi et al., 2007; Mercier et al., 2001), the expression of myelin proteins (Ghoumari et al., 2003; Melcangi et al., 2005; Melcangi et al., 1999) as well as myelin formation (Chan et al., 1998; Chan et al., 2000). T metabolites have similar effects on myelin (Magnaghi et al., 2004; Magnaghi et al., 1999; Melcangi et al., 2005).

During adult life, T, 17 $\beta$-E and PROG act in specific brain regions to regulate reproduction. Indeed, in males $\mathrm{T}$ acts as a negative regulator of GnRH and LH pulse and frequency (Jackson et al., 1991; Steiner et al., 1982), while in females $17 \beta$-E and PROG regulate GnRH pulsatility (Skinner et al., 1998) and estrous responsiveness in the hypothalamus (Barfield et al., 1984). These effects of PROG in females depend both on its changes in plasma levels during the ovarian cycle and on its synthesis by hypothalamic astrocytes after their stimulation by $17 \beta-\mathrm{E}$ (Micevych and Sinchak, 2008).

T, $17 \beta$-E and PROG also regulate synaptic plasticity (Arevalo et al., 2015b; Baudry et al., 2013; Foy et al., 2008; Frankfurt and Luine, 2015; Garcia-Segura et al., 1994; Kramar et al., 2013; McEwen and Woolley, 1994; Murphy and Segal, 2000; Ooishi et al., 2012), cytoskeletal proteins, the morphology of neurons and astrocytes (Garcia-Segura et al., 1994; Guerra-Araiza et al., 2007; Kramar et al., 2013; Luquin et al., 1993; Reyna-Neyra et al., 2002; Velazquez-Zamora et al., 2012), adult neurogenesis (Bowers et al., 2010; Galea, 2008; Wang et al., 2008) and cognition (Arevalo et al., 2015b; Celec et al., 2015; Colciago et al., 2015; Frankfurt and Luine, 2015; Kramar et al., 2013; VelazquezZamora et al., 2012). In addition, estrogens and androgens have complementary effects on synaptic changes in the hippocampus. Thus, $17 \beta-$ $\mathrm{E}$ is responsible for the full expression of long-term potentiation, while DHT for its conversion into long-term depression (Di Mauro et al., 2015).

\section{Neuroactive steroids as protective agents for the nervous system}

\subsection{Estradiol, progesterone and progesterone metabolites}

An extensive literature showing protective effects of neuroactive steroids in several experimental models of CNS and PNS pathologies is available. Indeed, 17ß-E and PROG are protective in experimental models of AD (Pike et al., 2009; Wang et al., 2008), PD (Bourque et al., 2009; Callier et al., 2001; Rodriguez-Perez et al., 2013), Huntington's disease (Kumar et al., 2014; Tunez et al., 2006), epilepsy (Frye et al., 2009; Frye and Scalise, 2000; Veliskova, 2006), excitotoxicity (Azcoitia et al., 1999; Ciriza et al., 2006), stroke (Sayeed et al., 2007; Sohrabji, 2015), motoneuron degeneration (Gonzalez Deniselle et al., 2002; Huppenbauer et al., 2005; Platania et al., 2005; Yu, 1989), MS and demyelination (Garay et al., 2007; Garay et al., 2010; Ibanez et al., 2003; Spence and Voskuhl, 2012; Taylor et al., 2010), TBI (Cutler et al., 2007; Day et al., 2013; Djebaili et al., 2005; Lopez Rodriguez et al., 2011) and spinal cord injury (Elkabes and Nicot, 2014; Labombarda et al., 2006a; Mosquera et al., 2014; Siriphorn et al., 2012), among others.

An important target of the neuroprotective effects of PROG is the myelin compartment. For instance, this neuroactive steroid increases MBP expression in a model of spinal cord injury (Labombarda et al., 2006a; Labombarda et al., 2009) and promotes repair in the cuprizone demyelinating experimental model, increasing the density of oligodendrocyte progenitor cells and mature oligodendrocytes and the expression of proteolipid protein (PLP) and MBP (El-Etr et al., 2015). PROG, administered together with 17ß-E, also promotes MBP expression in this model (Acs et al., 2009).

Effects of PROG are in part mediated by its metabolites. Indeed, both DHP and THP are protective against excitotoxicity (Ciriza et al., 2006) and THP reduce seizures (Frye and Scalise, 2000) and protect against stroke (Sayeed et al., 2006), oxygen-glucose deprivation (Ardeshiri et al., 2006) and TBI (Djebaili et al., 2005). This neuroactive steroid is also a potential candidate for the treatment of mood and anxiety disorders (Wirth, 2011).

PROG and its derivatives are also able to counteract the damage induced by the aging process on peripheral nerves. Indeed, these neuroactive steroids increase the expression of glycoprotein zero (P0) and peripheral myelin protein 22 (PMP22) (Melcangi et al., 2003; Melcangi et al., 1998; Melcangi et al., 2000b), and exert a beneficial effects on the number and shape of myelinated fibers, reducing the frequency of myelin abnormalities (Azcoitia et al., 2003; Melcangi et al., 2003). Neuroprotective actions of PROG or DHP have been also reported in different experimental models of peripheral nerve damage, such as transection (Melcangi et al., 2000a), cryolesion (Koenig et al., 1995) and guided regeneration of the facial nerve (Chavez-Delgado et al., 2005), crush (Roglio et al., 2008) and docetaxel-induced peripheral neurotoxicity (Roglio et al., 2009).

The metabolites of PROG also exert a variety of neuroprotective effects in diabetic encephalopathy and diabetic peripheral neuropathy. For instance, PROG and DHP counteract the decreased expression of peripheral myelin proteins, such as P0 and PMP22 (Leonelli et al., 2007) and the increase in the number of fibers with myelin infoldings in the sciatic nerve of STZ diabetic rats (Veiga et al., 2006). In an ex-vivo model of hyperglycemia (i.e., dorsal root ganglia cultures exposed to high levels of glucose), these neuroactive steroids show similar protective effects (Giatti et al., 2018b). DHP also increases the expression of another myelin protein, such as MBP, in the spinal cord of STZ diabetic rats (Pesaresi et al., 2010a).

Lipid components of the peripheral myelin are also a target for the protective effects of neuroactive steroids. Thus, DHP, by promoting fatty acid desaturation altered by diabetes, reduces myelin structural alterations in sciatic nerve (Mitro et al., 2014) and restores the lipid profile of myelin in the cerebral cortex of STZ-rats (Cermenati et al., 2017).

In STZ experimental model, PROG is also able to counteract the increased CNS and PNS expression levels of vascular endothelial growth factor, a marker of angiogenesis, interleukin-6, a marker of inflammation, and CD11, NG2, COX2 and matrix metalloproteinase-2, markers of tissue injury (Atif et al., 2017). THP improves nerve conduction velocity (NCV), thermal threshold and skin innervation density, while its precursor, DHP, in addition to these parameters, also improves alterations in $\mathrm{Na}^{+}, \mathrm{K}^{+}$-ATPase activity (Leonelli et al., 2007). Other protective effects of 17ß-E, PROG and its metabolites include the regulation of proapoptotic and anti-apoptotic proteins (Arevalo et al., 2015a; Djebaili et al., 2005), the decrease of oxidative stress (Liu et al., 2011; Mosquera et al., 2014; Ozacmak and Sayan, 2009; Zhang et al., 2009) and of lipid peroxidation (Ishihara et al., 2014; Roof and Hall, 2000; Zhu et al., 2012).

In addition, THP ameliorates diabetic-induced thermal hyperalgesia and prevents cell apoptosis in spinal cord in the STZ model (Afrazi et al., 2014). The mechanisms of action of neuroactive steroids on neuropathic pain have been also characterized in other experimental models (Mensah-Nyagan et al., 2009; Patte-Mensah et al., 2014), where they regulate molecules involved in pain signaling, such as T-type calcium channels, GABA-A channels, P2X3 receptors, voltage-gated sodium channels and bradykinin signaling (Ayoola et al., 2014; Cho and Chaban, 2012). The inhibition of the local synthesis of THP in the spinal cord enhances neuropathic pain induced by sciatic nerve injury (PatteMensah et al., 2014). In addition, this neuroactive steroid and its precursor, DHP, suppress neuropathic symptoms (allodynia/hyperalgesia) evoked by antineoplastic drugs such as vincristine (Meyer et al., 2010) and oxaliplatin (Meyer et al., 2011).

\subsection{Androgens}

Androgens are also neuroprotective agents. Indeed, T and DHT exert protective effects in PD animal models (Bourque et al., 2009; Khasnavis et al., 2013), in EAE models (Bebo et al., 1999b; Dalal et al., 1997; 
Giatti et al., 2015b; Palaszynski et al., 2004b), in MS patients (Kurth et al., 2014; Sicotte et al., 2007) and in an experimental model of TBI (Barreto et al., 2007). The effect of androgens on stroke is still unclear, since both protective and deleterious effects have been reported (Quillinan et al., 2014). A possible hypothesis is that the effect depends on the dosage applied. Indeed, positive effects are obtained with low doses and in middle-aged and older animals (Quillinan et al., 2014). DHT is able to counteract the male hippocampal neuronal loss after kainic acid injection (Ramsden et al., 2003). Moreover, T or DHT protect hippocampal neurons form apoptosis caused by $\beta$-amyloid, staurosporine, Apoptosis Activator II (Nguyen et al., 2010; Zhang et al., 2004) or serum deprivation (Hammond et al., 2001). In experimental models of $\mathrm{AD}$, T decreases $\beta$-amyloid (Rosario et al., 2012) and reduces pathological alterations (Rosario et al., 2010). In addition, T and DHT are protective factors for motoneurons (Huppenbauer et al., 2005).

Androgens are also protective agents in the PNS. Thus, T and DHT induce a faster regeneration and functional recovery of injured nerves (Huppenbauer et al., 2005; Jones et al., 2001; Tanzer and Jones, 2004; Vita et al., 1983; Yu, 1982) and its precursor, DHEA, decreases the extent of denervation atrophy and induces an earlier onset of axonal regeneration after sciatic nerve transection in rats (Ayhan et al., 2003). In addition, DHT stimulates $\mathrm{Na}^{+}, \mathrm{K}^{+}$-ATPase activity and P0 expression in the sciatic nerve of STZ diabetic rats (Roglio et al., 2007) and counteracts the impairment of NCV, thermal sensitivity and skin innervation density induced by diabetes (Roglio et al., 2007). In the same experimental model, the further metabolite of DHT, 3 $\alpha$-diol, also improves NCV, thermal sensitivity and skin innervation density (Roglio et al., 2007) and reduces myelin structural alterations and the accumulation of myelin saturated fatty acids in the sciatic nerve (Mitro et al., 2014). In addition, the androgen precursor DHEA prevents neuronal (Pesaresi et al., 2011b) and vascular dysfunction (Yorek et al., 2002).

Androgens exert also beneficial effects on neuropathic pain occurring in diabetes mellitus. For instance, in the STZ model, DHT counteracts the effect of diabetes on mechanical nociceptive threshold while $3 \alpha$-diol is effective on tactile allodynia (Calabrese et al., 2014).

\section{Sex differences in the physiological and protective actions of neuroactive steroids}

\subsection{Sex differences in the expression of steroid receptors}

\subsubsection{Physiological conditions}

As mentioned above, neuroactive steroids may exert their effects by classical and non-classical steroid receptors. Some observations indicate the existence of sex differences in the pattern expression of these receptors. For instance, in developing primary hippocampal neurons, the expression of ERs (ER $\alpha, E R \beta$ and GPER) is higher in female cultures and the expression of AR is higher in male cultures (Ruiz-Palmero et al., 2016). In comparison to males, the expression of $E R \alpha$ is higher in the bed nucleus of the stria terminalis and in the medial preoptic area of female animals while that of AR is higher in the anteroventral periventricular nucleus, in the ventrolateral part of the ventromedial hypothalamic nucleus and in the arcuate nucleus. In addition, a higher AR expression is detected in the bed nucleus of the stria terminalis and in the medial preoptic area of male animals (Brock et al., 2015). Further observations indicate that during the perinatal period the gene expression of AR is higher in the hypothalamus and prefrontal cortex of male animals. In addition, the expression of ER $\alpha$ is higher in the hypothalamus and hippocampus of male animals before birth. On the contrary, the gene expression of ER $\beta$ is higher in the prefrontal cortex of female animals immediately after birth (Mogi et al., 2015). Kisspeptin 1 neurons of anteroventral periventricular nucleus express higher levels of ER $\alpha$ and PR in females than in males (Poling et al., 2017). Classical genomic effects of neuroactive steroids also imply coactivators, like for instance the steroid receptor coactivator-1. Assessment of its immunoreactivity in the rodent brain shows higher levels in males than in females (Bian et al., 2011).

\subsubsection{Pathological conditions}

Sex specific changes in the pattern expression of steroid receptors also occur under pathological conditions. For instance, as demonstrated in MS patients, the expression of ER $\beta$ is increased in lesions of men, while that of PR in those of women (Luchetti et al., 2014). In addition, impairment in cerebellar synaptic plasticity and neurogenesis together with cognitive and motor disorders observed in hyperhomocysteinemia is associated with a decreased expression of ER $\alpha$ and ER $\beta$ in the rat cerebellum of female rats (El Hajj Chehadeh et al., 2014).

\subsection{Sex differences in the actions of neuroactive steroids under physiological conditions}

Among the variety of the physiological effects exerted by neuroactive steroids, some of them show sex specific features. For instance, the expression of the isoform PR-A is induced by $17 \beta-E$ in the cerebellum of male rats, but not in females (Guerra-Araiza et al., 2002). In addition, treatments with 17ß-E or DHT increase the gene expression and protein levels of aromatase in female, but not in male neuronal cultures (Cisternas et al., 2017).

The role of $17 \beta-E$ on synaptic plasticity also shows sex specific features in the hippocampus (Vierk et al., 2014; Vierk et al., 2012) and basolateral amygdala (Bender et al., 2017). For instance, long term potentiation in the hippocampus of female and male mice is impaired by the systemic administration of an inhibitor of aromatase, but the effect was particularly prominent in females (Vierk et al., 2012). Inhibition of aromatase activity in the hippocampus also results in a decreased number of hippocampal synapses, but only in females (Vierk et al., 2014; Vierk et al., 2012). In addition, systemic treatment with letrozole (i.e., an inhibitor of aromatase) reduces spine synapse density in basolateral amygdala of adult female but not of male animals and the same occurs in organotypic corticoamygdalar cultures from immature animals (Bender et al., 2017).

$17 \beta$-E suppresses GABAergic inhibition in the hippocampus of females by a mechanism implying $\mathrm{ER} \alpha$, mGluR and endocannabinoiddependent mechanism. However, this does not occur in male animals (Tabatadze et al., 2015). This neuroactive steroid also potentiates glutamatergic synaptic transmission in the hippocampus, however the mechanism involves distinct ER subtypes in each sex (Oberlander and Woolley, 2016). A similar situation occurs for the effects of 17ß-E on hippocampal memory. Thus, actions of this neuroactive steroid in the hippocampus exerts beneficial effects on memory consolidation in both sexes, however at variance to what is observed in females, activation of extracellular signal-regulated kinase is not necessary in male animals (Koss et al., 2018).

Local synthesis of $17 \beta-E$ also contributes to sex differences in neuritogenesis. Indeed, neuronal synthesis of this neuroactive steroid promotes higher expression of the neuritogenic factor Neurogenin 3 (Ngn3) and increased neuritogenesis in developing female primary hippocampal neurons compared to male neurons. In contrast, treatment with T or DHT increases the expression of Ngn3 and neuritogenesis in male hippocampal neurons and reduced these parameters in female neurons (Ruiz-Palmero et al., 2016).

As mentioned above, the myelin compartment is a target for PROG and its metabolites. Interestingly, some effects exerted by these neuroactive steroids on PNS myelin proteins (i.e., P0, PMP22, MAG and MAL) are sex specific (Magnaghi et al., 2006). In addition, sex differences in the effects of PROG have also been reported in Schwann cell proliferation (Fex Svenningsen and Kanje, 1999). Finally, it is interesting to note that, as recently demonstrated, the sex difference observed in oligodendrocyte density and myelin proteins (Cerghet et al., 2006) are related with a postnatal increase of androgens and AR signaling (Abi Ghanem et al., 2017). 


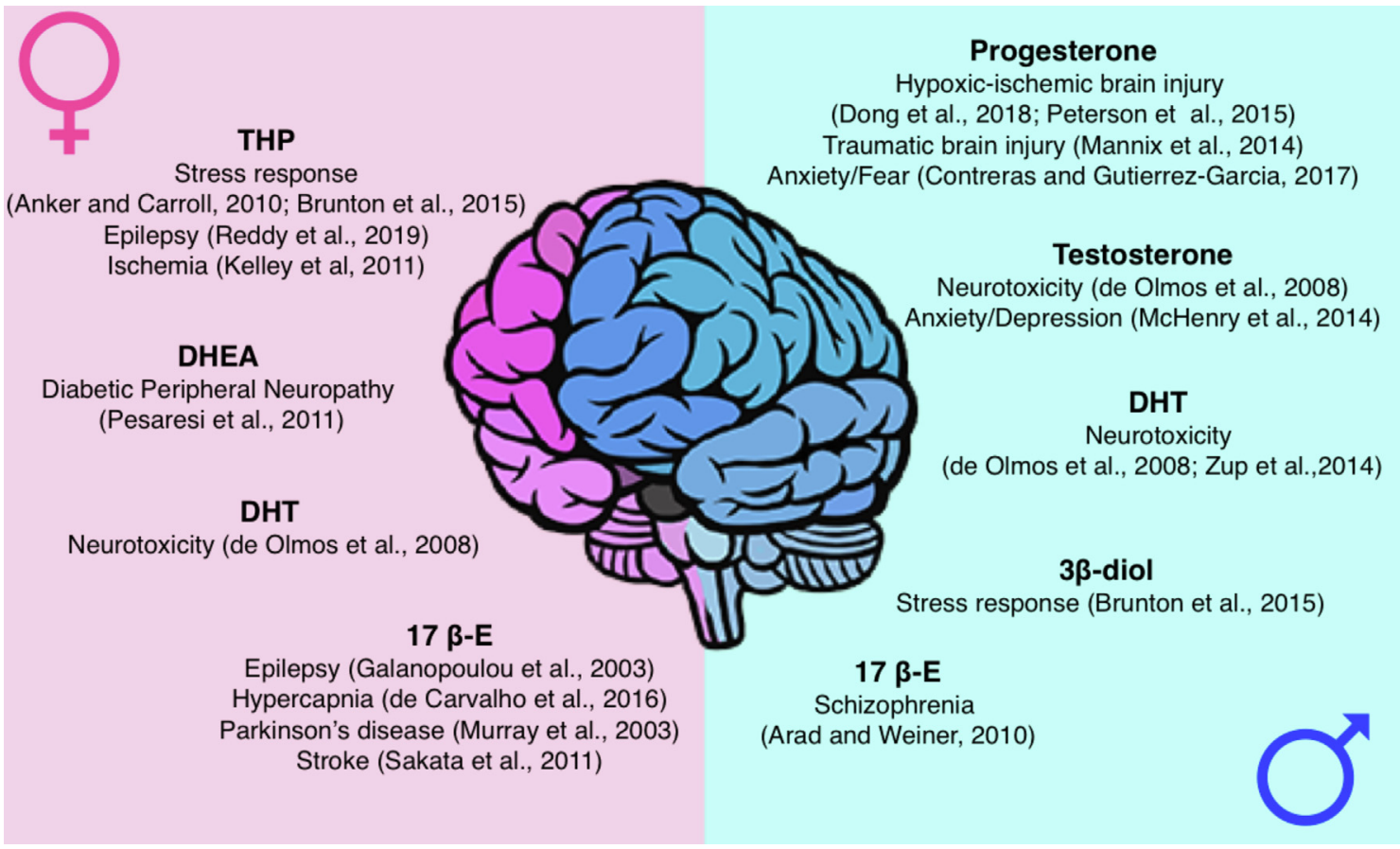

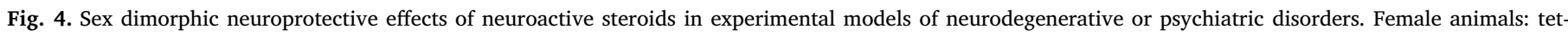

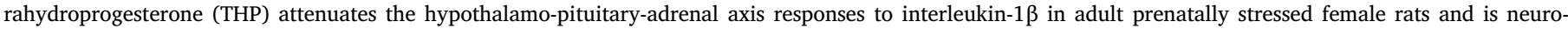

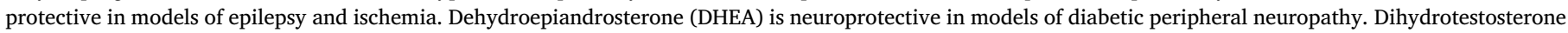

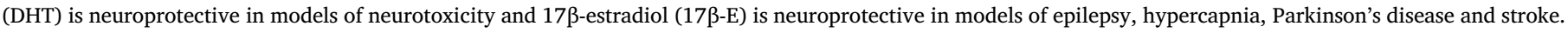

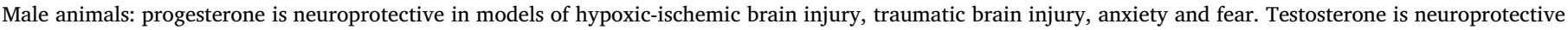

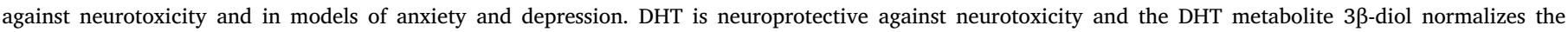

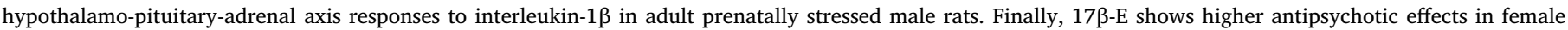
animals.

\subsection{Sex differences in the actions of neuroactive steroids under pathological conditions}

As mentioned above, several neuroprotective effects of neuroactive steroids have been reported (see section 8). However, most of the studies present in the literature have been conducted only in one sex. Thus, the possible influence of the sex in the protective effects of neuroactive steroids in animal models of neurodegeneration and psychiatric alterations has been poorly considered so far. Some examples of sex differences in the neuroprotective actions of neuroactive steroids are discussed in the following sections (Fig. 4).

\subsubsection{Parkinson's disease}

$17 \beta$-E has been shown to reduce lesion size in a PD animal model, but only in gonadectomized females. On the contrary, it increases damage in gonadectomized males (Murray et al., 2003). Thus, in this experimental model of PD, estrogens are neuroprotective in females but neurotoxic in males (Gillies et al., 2004). In agreement, T enhances dopamine depletion induced by methamphetamine in male, but not in female animals (Lewis and Dluzen, 2008). Interestingly, the gene parkin seems to have a role in the sex specific effects of $17 \beta$-E. Indeed, using parkin null mice (i.e., an animal model of PD), some of the neuroprotective effects exerted by this neuroactive steroid disappear in this experimental model (Rodriguez-Navarro et al., 2008).

Neuroprotective effects of $17 \beta-E$ on PD and other neurodegenerative diseases may be also exerted by protection on mitochondria (Vina et al., 2003). Indeed, as observed in sex specific cultures of rodent mesencephalic neurons exposed to a mitochondrion-toxin such as 6OHDA (i.e., an in vitro model of PD), treatment with this neuroactive steroid induces a more prominent neuroprotective effect (i.e., reduced free radical production and cell death) in female than in male neurons (Misiak et al., 2010).

\subsubsection{Traumatic CNS injury and stroke}

Numerous studies have shown that PROG exerts protective actions after traumatic CNS injury in rodents. Sex differences in the neuroprotective action of PROG have been reported in adolescent mice. Thus, PROG promotes motor recovery in adolescent male, but not in female mice after controlled TBI (Mannix et al., 2014).

Excitotoxicity is one of the main causes of secondary neuronal death in traumatic CNS injury and stroke. In cultured hippocampal neurons, DHT exerts a protective effect against apoptosis induced by glutamate in male, but not female cells (Zup et al., 2014). A non-competitive NMDA receptor-antagonist, such as MK801, produces a sex specific neurotoxic effect (i.e., females are markedly more sensitive than males) that is affected by neuroactive steroid treatment. Indeed, in gonadectomized male rats, either T or DHT reduce brain damage, while in gonadectomized females only DHT is effective. In addition, in this model DHT is partially protective in intact females while in males 17ß-E is neurotoxic. Thus, a possible conclusion could be that non-aromatizable androgens are neuroprotective while estrogens counteract this effect (de Olmos et al., 2008).

The metabolite of PROG, THP, exerts dose-dependent sex-specific neuroprotective actions in ischemic models. Indeed, a low dose of this neuroactive steroid provides higher neuroprotection from ischemic damage in females than in males, while a higher dose is beneficial in both sexes (Kelley et al., 2011). As reported in an experimental model of neonatal hypoxic/ischemic brain injury, treatment with PROG is protective in males but not in female animals (Dong et al., 2018). Similar sex differences have been reported in an animal model of neonatal hypoxic-ischemic encephalopathy (Peterson et al., 2015). In an experimental model of hypercapnia-induced activation of the locus coeruleus, $17 \beta$-E reduces the activation of noradrenergic neurons in female but not in male rats (de Carvalho et al., 2016). Finally, in an experimental model of type 2 diabetes (i.e., the KKAy mouse) female 
animals exhibit a more severe ischemic brain damage after stroke than males and $17 \beta-E$ treatment induced an attenuation of oxidative stress (Sakata et al., 2011).

\subsubsection{Peripheral neuropathy}

In a rat model of diabetes type 1 (i.e., STZ injection), gonadectomy protects females, but not males, from diabetic peripheral neuropathy by increasing DHEA levels in the sciatic nerve (Pesaresi et al., 2011a). Indeed, the efficacy of the DHEA treatment was higher in gonadally intact diabetic females than in intact diabetic males (Pesaresi et al., 2011b).

\subsubsection{Diabetic encephalopathy}

DHEA may also alter in a sex-specific way the glucose metabolism in the CNS. Thus, this neuroactive steroid decreases glucose uptake and increases glycogen content in cerebral cortex and olfactory bulb of male, but not of female animals (Vieira-Marques et al., 2017). In hypoglicemic animals, ER $\alpha$ and ER $\beta$ enhance astrocyte AMPK and glycogen synthase expression together with an inhibition of glycogen phosphorylase in female animals, while activation of ER $\beta$ suppresses these proteins in male animals (Hasan Mahmood et al., 2018).

\subsubsection{Affective and psychiatric disorders}

Neuroactive steroids also show sex specific effects in psychiatric disorders. For instance, in a model of schizophrenia, 17ß-E shows antipsychotic effect in both sexes, but is more effective in males than in females (Arad and Weiner, 2010). The KO of GPER1 produces sex differences in behavioral responses. Thus, GPER1 KO male mice express a marked increase of exploratory drive in elevated plus maze and lightdark choice test to variance of female animals that displayed a less pronounced phenotype. Thus, this estrogen membrane receptor seems to be involved in anxiety and stress control in a sex specific way (Kastenberger and Schwarzer, 2014). In addition, as recently demonstrated, endogenous $\mathrm{T}$ production in males plays an important role in the sex differences in anxiety that have been reported in aged rats (Domonkos et al., 2017). Indeed, several clinical and preclinical studies suggest that $\mathrm{T}$ is strongly beneficial in males against anxiety and depression (McHenry et al., 2014).

Amygdala-medial frontal cortex connections regulate anxiety as well as fear. As recently demonstrated, PROG decreases the responsivity to amygdala stimulation, particularly in males (Contreras and Gutierrez-Garcia, 2017). Interestingly, a significant association of anxiety with two intronic single nucleotide polymorphisms (rs3930965 and rs41314625) located in the AKR1C1 gene, which plays an important role in the regulation of PROG effects (El-Kabbani et al., 2011), has been reported in female patients with panic disorders (Quast et al., 2014). In addition, the PROG metabolite THP attenuates in adult prenatally stressed rats the hypothalamo-pituitary-adrenal axis responses to interleukin- $1 \beta$ only in females, while $3 \beta$-diol normalized these responses in males (Brunton et al., 2015). This neuroactive steroid is also able in females, but not in males, to block the stress-induced reinstatement of cocaine-seeking behavior induced by yohimbine (i.e., a pharmacological stressor) (Anker and Carroll, 2010).

\subsubsection{Other disorders}

In an epilepsy animal model, $17 \beta$-E treatment reduces hippocampal injury but only in ovariectomized females (Galanopoulou et al., 2003). In addition, the PROG metabolite THP, shows greater antiseizure potency in females than in males and this effect seems to be related with a greater abundance of extrasynaptic $\delta$-subunit of GABA-A receptors in females (Reddy et al., 2019).
9. Targeting neurosteroidogenesis as a possible pharmacological approach for neuroprotection

\subsection{Translocator protein ligands}

As mentioned above, neuroactive steroids represent promising protective agents for neurodegenerative and psychiatric disorders. One possible therapeutic strategy could be to induce neurosteroidogenesis by ligands of TSPO. As shown in Fig. 1, TSPO is one of the component of the molecular complex able to translocate cholesterol into mitochondria. Although this protein may not be essential for steroidogenesis, it is necessary for the proper regulation of the steroidogenic process (Morohaku et al., 2014; Papadopoulos et al., 2018; Selvaraj and Stocco, 2015; Selvaraj et al., 2015). Thus, activation of TSPO stimulates PREG synthesis and consequently increases neuroactive steroid levels (Papadopoulos, 2014; Papadopoulos et al., 2018).

In addition, TSPO ligands regulate mitochondrial respiration, permeability transition pore opening, apoptosis and cell proliferation. On the other hand, TSPO is also related with neuroinflammation (i.e., it is a marker of microglial activation). Interestingly, total distribution volume of TSPO is related with the duration of untreated major depressive disorder (Setiawan et al., 2018) and with first-episode psychosis and schizophrenia (Plavén-Sigray et al., 2018). In addition, TSPO distribution shows sex differences in healthy patients (Tuisku et al., 2019).

Acting through the mechanisms mentioned above, some TSPO ligands exert a beneficial effect in different experimental models of neuropathology (Arbo et al., 2015; Cheng et al., 2016; Da Pozzo et al., 2015; Giatti et al., 2015a; Giatti et al., 2015c; Ishikawa et al., 2016; Leva et al., 2017; Ma et al., 2016; Santoro et al., 2016). For instance, TSPO activation ameliorates the behavioral deficits of post-traumatic stress disorder (Miao et al., 2014) and protects from MS (Daugherty et al., 2013), AD (Barron et al., 2013), diabetic encephalopathy (Mitro et al., 2012), diabetic peripheral neuropathy (Giatti et al., 2009), aginginduced peripheral neuropathy (Leonelli et al., 2005) and peripheral nerve injury (Ferzaz et al., 2002; Girard et al., 2012; Girard et al., 2008).

\subsection{Liver $X$ receptor ligands}

Another possible strategy to increase neuroactive steroid levels and consequently to exert protective effects is represented by activation of the liver X receptors (LXRs). In adrenal glands, LXRs regulate StAR and induce the expression of genes involved in cholesterol homeostasis (Cummins and Mangelsdorf, 2006; Cummins et al., 2006). Protective effects of the activation of LXRs have been reported in cerebral ischemia (Cheng et al., 2010), MS, AD and PD (Xu et al., 2013). In addition, the induction of neurosteroidogenesis associated to the neuroprotective effects of LXR ligands has been reported in diabetic peripheral neuropathy (Cermenati et al., 2010) and diabetic encephalopathy (Mitro et al., 2012).

\section{3. $5 \alpha$-reductase inhibitors}

As mentioned above $5 \alpha-\mathrm{R}$ represents a key enzyme for the metabolism of PROG and T. Therefore, inhibitors of this enzyme, such as finasteride or dutasteride, exert beneficial effects in experimental models of neurodegeneration. For instance, finasteride treatment exerts neuroprotective effects in ischemic brain injury induced in aged male rats (Tanaka et al., 2019), while dutasteride is protective in an experimental model of PD (Litim et al., 2015, 2017). In addition, several observations suggest that these $5 \alpha$-R inhibitors have therapeutic efficacy in behavioral disorders and specifically those associated with dopaminergic hyperfunction, such as Tourette syndrome and dyskinetic manifestations (Bortolato et al., 2008; Fanni et al., 2019; Frau and Bortolato, 2019). Finally, dutasteride reduces subsequent alcohol consumption in subjects classified as heavy drinkers (Covault et al., 2014). 
Therefore, the pharmacological modulation of this enzyme may represent a useful therapeutic approach for alcoholism, as well as for other neurological or psychiatric diseases. On this point of view, the comparison, still lacking, of the effects in male and female subjects will be extremely important. However, a word of caution is necessary for the use of these inhibitors. Indeed, it is important also to highlight that these $5 \alpha-\mathrm{R}$ inhibitors may have, in case of androgenetic alopecia, serious endocrine and neuropsychiatric side effects, such as erectile and ejaculatory dysfunctions, loss of libido, depression, anxiety, suicidal thoughts and sleep problems, which may persist despite treatment withdrawal (Giatti et al., 2018a; Irwig, 2012a,b; Traish et al., 2015). Indeed, both clinical (Basaria et al., 2016; Caruso et al., 2015; Chiriaco et al., 2016; Melcangi et al., 2013, 2017) and experimental studies (Diviccaro et al., 2019; Giatti et al., 2016a) have recently supported the existence of a so called "Post-Finasteride Syndrome".

\section{Neuroinflammation as a possible target for sex-specific therapy based on neuroactive steroids}

Immune surveillance of the CNS is a multifaceted dynamical process based on the recruitment of different cells and structures in precise time windows. Its peculiarity resides in the microenvironment of the CNS, strictly ruled by anatomical barriers that separate the CNS from the circulation. The blood brain barrier (BBB), the blood-CSF barrier and the meninges provide a highly selective gateway for peripheral circulating immune cells but also represent immunologically active niches accommodating perivascular, choroid plexus and meningeal macrophages, together with dendritic cells (DCs) and granulocytes (Brown and Weinberg, 2018; Herz et al., 2017). All these cells differently contribute to both physiological and pathological pathways in a close relationship with the resident microglia and astrocytes (Fig. 5).

Neuroinflammation is a common treat characterizing several different pathologies. Immune cell populations are differentially recruited in function of the type of insult and play beneficial or detrimental roles depending on the persistence of an aggressive phenotype M1/Th1, regarded as pro-inflammatory and that may potentially enhance tissue damage, vs the M2/Th2 phenotype, which is considered immunomodulatory and pro-reparative (Mantovani et al., 2005).

Possibly, the most complex involvement of immune cells in the CNS occurs in autoimmune diseases, of which MS is the most common. Myeloid cells (macrophages, monocytes and dendritic cells) are among the most prominent of the immune infiltrates in MS. These cells act in concert with T-cells by attracting them to the CNS parenchyma and contribute to lesion formation. In particular, myeloid cells located at the perivascular and meningeal spaces recruit and reactivate infiltrating autoreactive T-cells to undergo expansion and enter the parenchyma (Brown and Weinberg, 2018). Moreover, release of inflammatory cytokines alters the integrity of the BBB at an early stage of the disease (Brown and Weinberg, 2018). Compared to aggressive monocytes, resident microglia clear tissue debris and contribute to recovery, although the phenotypic similarity with monocytes makes difficult to resolve their behavior. The same difficulty is faced in neurodegenerative diseases, where the immune contribution seems to essentially rely on microglia, while the role of monocytes is questionable (Herz et al., 2017).

Both microglia and myeloid cells contribute to repairing (i.e. promoting angiogenesis, axonal regeneration) and/or to secondary degeneration after CNS injury (Herz et al., 2017). It has been hypothesized that the reconstructing or detrimental action of these immune cells probably rely on timing and route of infiltration, whether from the choroid plexus or blood vasculature, after injury (Herz et al., 2017).

Hormonal environment is one of the factors that determine sex differences in the immune response. Indeed, in autoimmune diseases such as MS, females represent the highest percentage of cases (Jacobson et al., 1997), possibly due to reduced androgen levels. The observation that MS onset occurs later in males than in females, in coincidence with the decline in bioavailable T (Weinshenker, 1994), and that castration of male mice increases EAE susceptibility, underline the sensitivity to $\mathrm{T}$ modulation (Palaszynski et al., 2004b). Similar results are observed in other autoimmune disorders such as rheumatoid arthritis, extending the role of $\mathrm{T}$ to different autoimmune syndromes (Harbuz et al., 1995).

The presence of nuclear, membrane-bound and G-protein coupled sex steroid receptors in lymphocytes and myeloid cells (Blasko et al., 2009; Kovats et al., 2010) renders them sensitive to a wide plethora of neuroactive steroids, beside $\mathrm{T}$, indicating a complex sex-dependent immune modulation under hormonal control. As such, androgens/T, $17 \beta-E$ and PROG are known to influence the functioning of immune cells in different pathological contexts.

\subsection{Neuroimmune control by androgens}

The experimental findings commented above suggest mainly an anti-inflammatory role for $\mathrm{T}$ that is supported by observations obtained in vitro and in vivo, both in animal models and in clinical studies. This effect seems to be independent on the type of insult suffered from the nervous system and involves different cell types recruited in the inflammatory response.

Reduction of pro-inflammatory profile towards an anti-inflammatory one has been observed upon androgens/T administration in MS animal models (Bebo et al., 1999b; Dalal et al., 1997) and humans (Gold et al., 2008), following TBI (Barreto et al., 2007; Garcia-Estrada et al., 1993), and in animal models of neurodegenerative diseases (Tomas-Camardiel et al., 2002; Yao et al., 2017).

Sex-dependent polarization in T-cell response is observed upon mice immunization with encephalitogenic peptide so that T-cells from male mice have a lower interferon-gamma (IFN- $\gamma$ )/ interleukin-10 (IL-10) ratio then T-cells from female mice (Bebo et al., 1999b). Female T-cells show an inverse response, increasing IL-10 production over IFN- $\gamma$, upon ex-vivo exposure to physiologic concentration of DHT or T (Bebo et al., 1999b). Accordingly, T reduces differentiation of T-cells towards autoreactive pro-inflammatory Th1 and Th17 phenotype both in vivo in an EAE model and in vitro in murine splenic T-cells under polarizing conditions (Massa et al., 2017). These observations have a counterpart at clinical level, where $\mathrm{T}$ treatment of male MS patients induces a shift in peripheral lymphocyte composition by decreasing $\mathrm{CD} 4+\mathrm{T}$ cell percentage (TH1 phenotype) and increasing natural killer (NK) cells (suggested to promote regulatory T-cells and enhance Th2-response) (Gold et al., 2008).

Androgens can thus alter the development of effector T-cells and may play a relevant role in governing gender differences in the immune response ruling the susceptibility to autoimmune disorders. In this context, emerging data suggest also a protective role of $\mathrm{T}$ through its action on mast cells in EAE by favoring the production of IL-33, a cytokine that promotes a Th2 protective response (Brown and Weinberg, 2018). Accordingly, immunized SJL females, prone to develop aggressive EAE, exhibit reduced IL-33 compared to more protected male mice (Brown and Weinberg, 2018); prevention of the disease in females is obtained upon IL-33 administration prior to immunization (Russi et al., 2018).

Androgens also reduce reactive microglia and astroglia after stab wound injury (Barreto et al., 2007; Garcia-Estrada et al., 1993), demyelination by cuprizone (Hussain et al., 2013), neurotoxic insults by 1-methyl-4-phenylpyridinium (MPP +) (Tomas-Camardiel et al., 2002) and suppress pro-inflammatory cytokines expression induced by $\mathrm{A} \beta$ in vitro and in vivo (Yao et al., 2017).

Experimental approaches used to test androgens anti-inflammatory activity are usually performed in females or gonadectomized males, suggesting that androgens potential therapeutic effect might be unveiled when depleted. 


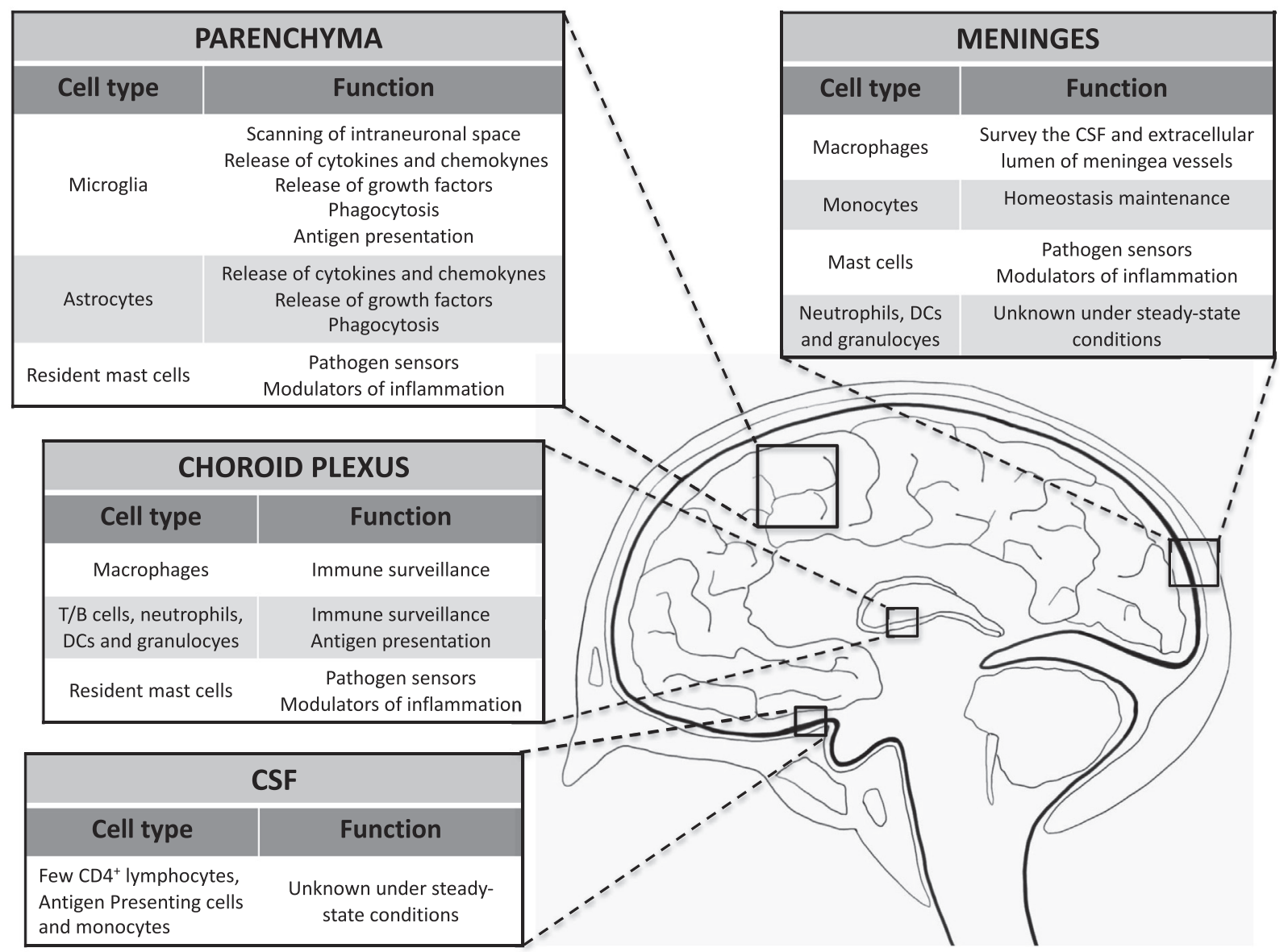

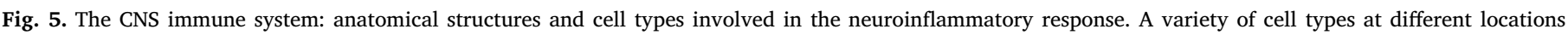

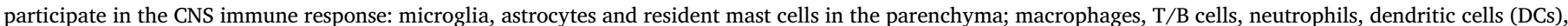

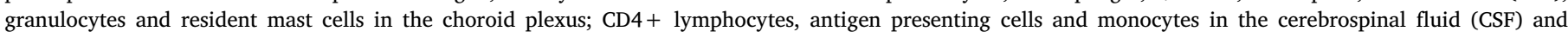
macrophages, monocytes, mast cells, neutrophils, DCs and granulocytes in the meninges.

\subsection{Neuroimmune control by estrogens, progesterone and progesterone metabolites.}

Differently from $\mathrm{T}$, which generally depresses immune response, estradiol shows immunostimulatory responses at physiological levels to became immunosuppressive at supraphysiological levels (Kovacs et al., 2002). Concerning the CNS, this dual activity seems also to be dependent on regional and astrocyte-type differences (Larson, 2018).

Estrogens and progestins exert as well an anti-inflammatory action in different pathological contests ranging from autoimmune to neurodegenerative diseases and TBI (Arevalo et al., 2012b). Four main features are affected: morphological glial activation and proliferation, cytokine production and release, differentiation of myeloid cells and lymphocytes and migration of immune cells.

Both exogenous and endogenous PROG reduce the number of activated microglia and astrocytes, as measured based on ionized calciumbinding adapter molecule 1 (Iba1) and glial fibrillary acidic protein (GFAP) expression, after middle cerebral artery occlusion (Dang et al., 2011; Wali et al., 2016; Zhu et al., 2017), spinal cord transection (Labombarda et al., 2011) and demyelination (Garay et al., 2009). Similar effects are reproduced by $17 \beta-E$ (Barreto et al., 2007; Dang et al., 2011; Sribnick et al., 2005; Vegeto et al., 2001; Viviani et al., 2002). Accordingly, reduced glia activation is reflected in a decreased production of inflammatory factors such as pro-inflammatory cytokines, chemokines and nitric oxide, as observed upon lipopolysaccharide (LPS) exposure of astrocytes or microglia in the presence of PROG or 17ß-E (Cerciat et al., 2010; Dodel et al., 1999; Drew and Chavis, 2000;
Kipp et al., 2007; Vegeto et al., 2001). This effect relies on decreasing nuclear factor $\mathrm{kB}$ (NFkB) nuclear translocation both for PROG or 17ß-E (Dodel et al., 1999; Ghisletti et al., 2005; Lei et al., 2014; Vegeto et al., 2001) that is extended also to macrophages, monocytes and neutrophils (Kramer et al., 2004; Miller et al., 2004; Murphy et al., 2010). In addition, 17 $\beta$-E inhibition of NFkB induced by IL-1 $\beta$ in endothelial cells correlates with the decreased expression of adhesion molecules like intercellular adhesion molecule 1 (ICAM1), opposing to penetration of circulating cells in the CNS due to the role in transmigration of leukocytes across the BBB. 17ß-E reduction of the chemokine receptor C-X-C Motif Chemokine Receptor 2 (CXCR2) in monocyte and neutrophils also contributes to limit circulating cells chemotaxis after cytokine stimulation or injury (Geraldes et al., 2006; Lei et al., 2003; Miller et al., 2004).

Finally, estrogenic anti-inflammatory action and recovery of the damaged tissue is prompted by $17 \beta-\mathrm{E}$ promotion of Treg cells (Palaszynski et al., 2004a) and estriol increased expression of anti-inflammatory cytokines (IL-10 and TGF- $\beta$ ) at expenses of pro-inflammatory ones (IL-12 and IL-6) (Douin-Echinard et al., 2008). It is important also to highlight that metabolites of PROG and DHT also affect neuroinflammation (Giatti et al., 2012). For instance, in EAE model, THP treatment reduces immunoreactivity for Iba1, a monocytoid cell marker, and for $\mathrm{CD} 3 \varepsilon$, a lymphocytic marker, in the lumbar spinal cord (Noorbakhsh et al., 2011). In this experimental model, the metabolite of T, DHT, is also able to reduce gliosis (Giatti et al., 2015b). In TBI experimental model, THP decreases the expression of IL-1 $\beta$ and TNF- $\alpha$ (He et al., 2004) and increases the expression of a potent 
inhibitor of the complement convertases that are activators of the inflammatory cascade, such as CD55 (VanLandingham et al., 2007).

It is important to bear in mind that neuroinflammation is physiologically needed to counteract infection and favors maintenance and recovery of the nervous tissue upon abnormal challenges, such as toxins exposure or endogenous protein deposition. In addition, activation of specific immune cells, like microglia, is required in specific developmental windows to shape neuronal circuits. Indeed, a successful immune response has to be tightly regulated to avoid an excessive or an undue response, possibly leading to the damage of the surrounding tissue. The switch from a pro-inflammatory to an anti-inflammatory phenotype operated by sex hormones is undoubtedly an advantage. This mode of action, in fact, not only turns off the aggressive phase of neuroinflammation but also promotes the recovering phase.

\subsection{Sex-dependent features of immune cells that might impact on} dimorphic inflammatory response in the adult brain

Immune surveillance relies on specific features of the cells involved that allow to organize the best response, i.e. expression of pathogen- or damage-associated molecular patterns (PAMPs and DAMPs), changes in cell number and changes in morphology. Sex differences of these features are part of the brain sexual differentiation and, although their functional role is so far unclear, might represent a molecular basis to understand the different incidence of neurological diseases in males and females (Hanamsagar and Bilbo, 2016).

Sex differences in number, morphology and gene expression start since the early postnatal stages and evolve along development, contributing to sex-specific organization of the brain and behavior (Fig. 6)
(Nelson et al., 2019). In the adult brain, a higher number of astrocytes has been observed in male than female hippocampus, medial amygdala and suprachiasmatic nucleus (Acaz-Fonseca et al., 2016) and astrocytes display a more complex morphology in male than female medial amygdala and arcuate nucleus of the hypothalamus (Acaz-Fonseca et al., 2016). In contrast, in the early adulthood (P60, rat) females have more microglia with thick and long processes than males in the hippocampus, amygdala and parietal cortex (Schwarz et al., 2012).

The pattern of expression of cytokines, chemokines and their receptors is also different in female and male adult brain. Thus, IL-10 and its receptor antagonist, IL-6, IL- $1 \alpha$, cluster of differentiation molecule $11 \mathrm{~b}$ (CD-11b) and Toll-interacting protein (TOLLIP) gene expression is increased in females, while males display higher IL-18, CC motif Chemokine Receptor 4 (CCR4) and CC motif ligand 22 (CCL22) gene expression (Schwarz et al., 2012). A recent study (Villa et al., 2018) indicates a higher expression of genes associated to inflammatory processes, including regulation of cell migration and cytokine production, in male than female microglia isolated from the whole adult brain. Although the functional significance of most of these differences remains to be investigated, this last study provides indication that female microglia is better adapted than male microglia to limit ischemic damage independently from the hormonal environment (Villa et al., 2018).

In addition to astrocytes and microglia, resident macrophages have higher Toll Like Receptors (TLRs) expression and phagocytic activity in females than males (Scotland et al., 2011). Since TLRs are components of the innate immune system that respond to infectious ligand and endogenous molecule released upon brain tissue producing inflammatory cytokines, it has been hypothesized that this sex-dependent

\begin{tabular}{|c|c|c|c|}
\hline \multirow[b]{2}{*}{ Cell type } & \multicolumn{3}{|c|}{ CNS IMMUNE CELLS KNOWN SEX DIFFERENCES } \\
\hline & $\bigcirc^{\pi}$ Male & † Female & $\begin{array}{l}\text { Steroid receptor } \\
\text { expression }\end{array}$ \\
\hline Microglia & $\begin{array}{l}\text { amount in the early postnatal } \\
\text { development } \\
\text { IL-18, CCR4, CCL22 expression }\end{array}$ & $\begin{array}{l}\text { amount in adulthood in } \\
\text { hippocampus, amygdala and } \\
\text { parietal cortex } \\
\text { IL-10, IL-10ra, IL-16, IL-1 } \alpha, \text { IL-1 } \\
\text { expression } \\
\text { Ticker and longer processes } \\
\text { Higher primed/ramified ratio }\end{array}$ & $\begin{array}{c}E R \alpha, \beta \\
A R \\
P R\end{array}$ \\
\hline
\end{tabular}

amount in adulthood in

hippocampus, medial amygdala and Less complex morphology in medial ER $\quad$ L,$\beta$ suprachiasmatic nucleus amygdala and hypothalamus

Astrocytes

IL-6, TNF- $\alpha$ and IL-1 $\beta$ expression

\begin{tabular}{|c|c|c|c|}
\hline Resident macrophages & amount in the medial preoptic area & $\begin{array}{l}\text { Toll-like receptors expression } \\
\text { and phagocytic activity }\end{array}$ & Unknown \\
\hline $\begin{array}{l}\text { T/B cells, granulocytes, } \\
\text { monocytes and DCs }\end{array}$ & Unknown & Unknown & $\begin{array}{c}\mathrm{ER} \alpha(\mathrm{T} / \mathrm{B} \text { cells }) \\
\operatorname{ER} \beta(\mathrm{DCs})\end{array}$ \\
\hline
\end{tabular}

Fig. 6. Sex differences in immuno-competent cell types. Sex differences in cell number, cell morphology and/or in the molecular and cellular responses of microglia, astrocytes and resident macrophages have been detected in different models of neuroinflammation. 
feature might contribute to a greater response in females.

As discussed in this section, neuroinflammation is a common treat characterizing several different pathologies, thus identifying the molecular basis ruling sex differences might represent a unique challenge to develop a sex-targeted therapy based on neuroactive steroids.

\section{Conclusions and perspectives}

As here reviewed, the capability of the nervous system to synthesize and metabolize neuroactive steroids is a well-ascertained concept. Furthermore, recent studies have shown that the levels of neuroactive steroids in the nervous system show sex differences that do not necessarily reflect similar sex differences in plasma levels, suggesting a specific effect on neurosteroidogenesis. This is particularly evident under pathological conditions in which not only the levels of neuroactive steroids but also the expression of steroidogenic molecules and enzymes are differentially affected in the nervous system of males and females. Given its neuroprotective actions, the sex-dimorphic modifications in the levels of neuroactive steroids in the nervous system under pathological conditions may contribute to further generate sex differences in the manifestation of the pathological alterations. However, it remains to be determined in which conditions sex differences in neuroactive steroid levels are causal agents in the generation of the sex differences in neurodegenerative and psychiatric disorders or when are a consequence of such sex differences in pathology. Indeed, the literature on these aspects is still poor and most of the data have been obtained in only one sex. In particular, further research is needed to determine the implications of sex differences in neurosteroidogenesis for brain healthy aging and the diseases of the nervous system associated with aging.

Systematic analyses of sex differences in the neuroactive steroid field are important to determine the possibility for sex-specific diagnostics and therapy based on these molecules. Further studies should also characterize functional targets of neuroactive steroids, such as the regulation of neuroinflammation, that may contribute to identify sexspecific therapeutic interventions. In addition, to avoid possible side effects of the systemic treatment with neuroactive steroids or their synthetic ligands, future therapeutic strategies may be oriented to target specifically in each sex the neurosteroidogenesis by molecules modulating cholesterol availability, cholesterol transport or the activity of key steroidogenic enzymes.

\section{Acknowledgements}

We acknowledge support from MIUR Progetto Eccellenza and Intramural Grant Line-B from Università degli Studi di Milano to Silvia Giatti. We also acknowledge support from Agencia Estatal de Investigación, Spain (grant number BFU2017-82754-R), Centro de Investigación Biomédica en Red de Fragilidad y Envejecimiento Saludable (CIBERFES), Instituto de Salud Carlos III, Madrid, Spain and Fondos Feder.

\section{References}

Aaberg, M.L., Burch, D.M., Hud, Z.R., Zacharias, M.P., 2008. Gender differences in the onset of diabetic neuropathy. J. Diabetes Complications 22, 83-87.

Abdyazdani, N., Nourazarian, A., Nozad Charoudeh, H., Kazemi, M., Feizy, N., Akbarzade, M., Mehdizadeh, A., Rezaie, J., Rahbarghazi, R., 2017. The role of morphine on rat neural stem cells viability, neuro-angiogenesis and neuro-steroidgenesis properties. Neurosci. Lett. 636, 205-212.

Abi Ghanem, C., Degerny, C., Hussain, R., Liere, P., Pianos, A., Tourpin, S., Habert, R., Macklin, W.B., Schumacher, M., Ghoumari, A.M., 2017. Long-lasting masculinizing effects of postnatal androgens on myelin governed by the brain androgen receptor. PLoS Genet. 13, e1007049.

Acaz-Fonseca, E., Avila-Rodriguez, M., Garcia-Segura, L.M., Barreto, G.E., 2016. Regulation of astroglia by gonadal steroid hormones under physiological and pathological conditions. Prog. Neurobiol. 144, 5-26.

Acs, P., Kipp, M., Norkute, A., Johann, S., Clarner, T., Braun, A., Berente, Z., Komoly, S., Beyer, C., 2009. 17beta-estradiol and progesterone prevent cuprizone provoked demyelination of corpus callosum in male mice. Glia 57, 807-814.

Afifi, M., 2007. Gender differences in mental health. Singapore Med. J. 48, 385-391.

Afrazi, S., Esmaeili-Mahani, S., Sheibani, V., Abbasnejad, M., 2014. Neurosteroid allopregnanolone attenuates high glucose-induced apoptosis and prevents experimental diabetic neuropathic pain: in vitro and in vivo studies. J. Steroid Biochem. Mol. Biol. 139, 98-103.

Agis-Balboa, R.C., Guidotti, A., Pinna, G., 2014. 5alpha-reductase type I expression is downregulated in the prefrontal cortex/Brodmann's area 9 (BA9) of depressed patients. Psychopharmacology 231, 3569-3580.

Albers, J.W., Brown, M.B., Sima, A.A., Greene, D.A., 1996. Nerve conduction measures in mild diabetic neuropathy in the Early Diabetes Intervention Trial: the effects of age, sex, type of diabetes, disease duration, and anthropometric factors. Tolrestat Study Group for the Early Diabetes Intervention Trial. Neurology 46, 85-91.

Alkayed, N.J., Harukuni, I., Kimes, A.S., London, E.D., Traystman, R.J., Hurn, P.D., 1998. Gender-linked brain injury in experimental stroke. Stroke 29, 159-165 discussion 166.

Ammendola, A., Gemini, D., Iannaccone, S., Argenzio, F., Ciccone, G., Ammendola, E. Serio, L., Ugolini, G., Bravaccio, F., 2000. Gender and peripheral neuropathy in chronic alcoholism: a clinical-electroneurographic study. Alcohol Alcohol. 35, 368-371.

Andersen, K., Launer, L.J., Dewey, M.E., Letenneur, L., Ott, A., Copeland, J.R., Dartigues, J.F., Kragh-Sorensen, P., Baldereschi, M., Brayne, C., Lobo, A., Martinez-Lage, J.M., Stijnen, T., Hofman, A., 1999. Gender differences in the incidence of AD and vascular dementia: The EURODEM Studies. EURODEM Incidence Research Group. Neurology 53, 1992-1997.

Andreasen, N.C., Ehrhardt, J.C., Swayze 2nd, V.W., Alliger, R.J., Yuh, W.T., Cohen, G., Ziebell, S., 1990. Magnetic resonance imaging of the brain in schizophrenia. The pathophysiologic significance of structural abnormalities. Arch. Gen. Psychiatry 47, 35-44.

Andreasen, N.C., Flashman, L., Flaum, M., Arndt, S., Swayze 2nd, V., O'Leary, D.S., Ehrhardt, J.C., Yuh, W.T., 1994. Regional brain abnormalities in schizophrenia measured with magnetic resonance imaging. JAMA 272, 1763-1769.

Anker, J.J., Carroll, M.E., 2010. Sex differences in the effects of allopregnanolone on yohimbine-induced reinstatement of cocaine seeking in rats. Drug Alcohol Depend. $107,264-267$.

Arad, M., Weiner, I., 2010. Sex-dependent antipsychotic capacity of 17beta-estradiol in the latent inhibition model: a typical antipsychotic drug in both sexes, atypical antipsychotic drug in males. Neuropsychopharmacology 35, 2179-2192.

Arbo, B.D., Benetti, F., Garcia-Segura, L.M., Ribeiro, M.F., 2015. Therapeutic actions of translocator protein $(18 \mathrm{kDa})$ ligands in experimental models of psychiatric disorders and neurodegenerative diseases. J. Steroid Biochem. Mol. Biol. 154, 68-74.

Ardeshiri, A., Kelley, M.H., Korner, I.P., Hurn, P.D., Herson, P.S., 2006. Mechanism of progesterone neuroprotection of rat cerebellar Purkinje cells following oxygen-glucose deprivation. Eur. J. Neurosci. 24, 2567-2574.

Arevalo, M.A., Azcoitia, I., Garcia-Segura, L.M., 2015a. The neuroprotective actions of oestradiol and oestrogen receptors. Nat. Rev. Neurosci. 16, 17-29.

Arevalo, M.A., Azcoitia, I., Gonzalez-Burgos, I., Garcia-Segura, L.M., 2015b. Signaling mechanisms mediating the regulation of synaptic plasticity and memory by estradiol. Horm. Behav.

Arevalo, M.A., Ruiz-Palmero, I., Scerbo, M.J., Acaz-Fonseca, E., Cambiasso, M.J., GarciaSegura, L.M., 2012a. Molecular mechanisms involved in the regulation of neuritogenesis by estradiol: Recent advances. J. Steroid Biochem. Mol. Biol. 131, 52-56.

Arevalo, M.A., Santos-Galindo, M., Acaz-Fonseca, E., Azcoitia, I., Garcia-Segura, L.M., 2012 b. Gonadal hormones and the control of reactive gliosis. Horm. Behav. 63, $216-221$.

Atif, F., Prunty, M.C., Turan, N., Stein, D.G., Yousuf, S., 2017. Progesterone modulates diabetes/hyperglycemia-induced changes in the central nervous system and sciatic nerve. Neuroscience 350, 1-12.

Ayhan, S., Markal, N., Siemionow, K., Araneo, B., Siemionow, M., 2003. Effect of subepineurial dehydroepiandrosterone treatment on healing of transected nerves repaired with the epineurial sleeve technique. Microsurgery 23, 49-55.

Ayoola, C., Hwang, S.M., Hong, S.J., Rose, K.E., Boyd, C., Bozic, N., Park, J.Y., Osuru, H.P., DiGruccio, M.R., Covey, D.F., Jevtovic-Todorovic, V., Todorovic, S.M., 2014 Inhibition of CaV3.2 T-type calcium channels in peripheral sensory neurons contributes to analgesic properties of epipregnanolone. Psychopharmacology 231, 3503-3515.

Azcoitia, I., Leonelli, E., Magnaghi, V., Veiga, S., Garcia-Segura, L.M., Melcangi, R.C., 2003. Progesterone and its derivatives dihydroprogesterone and tetrahydroprogesterone reduce myelin fiber morphological abnormalities and myelin fiber loss in the sciatic nerve of aged rats. Neurobiol. Aging 24, 853-860.

Azcoitia, I., Sierra, A., Garcia-Segura, L.M., 1999. Neuroprotective effects of estradiol in the adult rat hippocampus: interaction with insulin-like growth factor-I signalling. J. Neurosci. Res. 58, 815-822.

Backstrom, T., Bixo, M., Johansson, M., Nyberg, S., Ossewaarde, L., Ragagnin, G., Savic, I., Stromberg, J., Timby, E., van Broekhoven, F., van Wingen, G., 2014. Allopregnanolone and mood disorders. Prog. Neurobiol. 113, 88-94.

Balthazart, J., Charlier, T.D., Cornil, C.A., Dickens, M.J., Harada, N., Konkle, A.T., Voigt, C., Ball, G.F., 2011. Sex differences in brain aromatase activity: genomic and nongenomic controls. Front Endocrinol (Lausanne) 2, 34.

Barfield, R.J., Glaser, J.H., Rubin, B.S., Etgen, A.M., 1984. Behavioral effects of progestin in the brain. Psychoneuroendocrinology 9, 217-231.

Barreto, G., Veiga, S., Azcoitia, I., Garcia-Segura, L.M., Garcia-Ovejero, D., 2007. Testosterone decreases reactive astroglia and reactive microglia after brain injury in male rats: role of its metabolites, oestradiol and dihydrotestosterone. Eur. J. Neurosci. 25, 3039-3046.

Barron, A.M., Garcia-Segura, L.M., Caruso, D., Jayaraman, A., Lee, J.W., Melcangi, R.C., 
Pike, C.J., 2013. Ligand for translocator protein reverses pathology in a mouse model of Alzheimer's disease. J. Neurosci. 33, 8891-8897.

Basaria, S., Jasuja, R., Huang, G., Wharton, W., Pan, H., Pencina, K., Li, Z., Travison, T.G., Bhawan, J., Gonthier, R., Labrie, F., Dury, A.Y., Serra, C., Papazian, A., O'Leary, M., Amr, S., Storer, T.W., Stern, E., Bhasin, S., 2016. Characteristics of Men Who Report Persistent Sexual Symptoms after Finasteride Use for Hair Loss. J. Clin. Endocrinol. Metab. 101, 4669-4680.

Basit, A., Hydrie, M.Z., Hakeem, R., Ahmedani, M.Y., Masood, Q., 2004. Frequency of chronic complications of type II diabetes. J. Coll. Physicians Surg. Pak. 14, 79-83.

Baudry, M., Bi, X., Aguirre, C., 2013. Progesterone-estrogen interactions in synaptic plasticity and neuroprotection. Neuroscience 239, 280-294.

Bebo Jr., B.F., Adlard, K., Schuster, J.C., Unsicker, L., Vandenbark, A.A., Offner, H., 1999a. Gender differences in protection from EAE induced by oral tolerance with a peptide analogue of MBP-Ac1-11. J. Neurosci. Res. 55, 432-440.

Bebo Jr., B.F., Schuster, J.C., Vandenbark, A.A., Offner, H., 1999b. Androgens alter the cytokine profile and reduce encephalitogenicity of myelin-reactive T cells. J. Immunol. 162, 35-40.

Beinhoff, U., Tumani, H., Brettschneider, J., Bittner, D., Riepe, M.W., 2008. Genderspecificities in Alzheimer's disease and mild cognitive impairment. J. Neurol. 255, 117-122.

Bender, R.A., Zhou, L., Vierk, R., Brandt, N., Keller, A., Gee, C.E., Schafer, M.K., Rune, G.M., 2017. Sex-dependent regulation of aromatase-mediated synaptic plasticity in the basolateral amygdala. J. Neurosci. 37, 1532-1545.

Bender, R.A., Zhou, L., Wilkars, W., Fester, L., Lanowski, J.S., Paysen, D., Konig, A., Rune, G.M., 2010. Roles of 17ss-estradiol involve regulation of reelin expression and synaptogenesis in the dentate gyrus. Cereb. Cortex 20, 2985-2995.

Benito-Leon, J., Bermejo-Pareja, F., Rodriguez, J., Molina, J.A., Gabriel, R., Morales, J.M., 2003. Prevalence of PD and other types of parkinsonism in three elderly populations of central Spain. Mov. Disord. 18, 267-274.

Biamonte, F., Assenza, G., Marino, R., D'Amelio, M., Panteri, R., Caruso, D., Scurati, S., Yague, J.G., Garcia-Segura, L.M., Cesa, R., Strata, P., Melcangi, R.C., Keller, F., 2009 Interactions between neuroactive steroids and reelin haploinsufficiency in Purkinje cell survival. Neurobiol. Dis. 36, 103-115.

Bian, C., Zhang, D., Guo, Q., Cai, W., Zhang, J., 2011. Localization and sex-difference of steroid receptor coactivator-1 immunoreactivities in the brain of adult female and male mice. Steroids 76, 269-279.

Biessels, G.J., Deary, I.J., Ryan, C.M., 2008. Cognition and diabetes: a lifespan perspective. Lancet Neurol. 7, 184-190.

Biessels, G.J., van der Heide, L.P., Kamal, A., Bleys, R.L., Gispen, W.H., 2002. Ageing and diabetes: implications for brain function. Eur. J. Pharmacol. 441, 1-14.

Blasko, E., Haskell, C.A., Leung, S., Gualtieri, G., Halks-Miller, M., Mahmoudi, M., Dennis, M.K., Prossnitz, E.R., Karpus, W.J., Horuk, R., 2009. Beneficial role of the GPR30 agonist G-1 in an animal model of multiple sclerosis. J. Neuroimmunol. 214, 67-77.

Bloch, Y., Ratzoni, G., Sobol, D., Mendlovic, S., Gal, G., Levkovitz, Y., 2005. Gender differences in electroconvulsive therapy: a retrospective chart review. J. Affect. Disord. 84, 99-102.

Boghozian, R., McKenzie, B.A., Saito, L.B., Mehta, N., Branton, W.G., Lu, J., Baker, G.B., Noorbakhsh, F., Power, C., 2017. Suppressed oligodendrocyte steroidogenesis in multiple sclerosis: Implications for regulation of neuroinflammation. Glia 65, 1590-1606.

Booya, F., Bandarian, F., Larijani, B., Pajouhi, M., Nooraei, M., Lotfi, J., 2005. Potential risk factors for diabetic neuropathy: a case control study. BMC Neurol. 5, 24.

Bortolato, M., Frau, R., Orru, M., Bourov, Y., Marrosu, F., Mereu, G., Devoto, P., Gessa, G.L., 2008. Antipsychotic-like properties of 5-alpha-reductase inhibitors. Neuropsychopharmacology 33, 3146-3156.

Bourque, M., Dluzen, D.E., Di Paolo, T., 2009. Neuroprotective actions of sex steroids in Parkinson's disease. Front. Neuroendocrinol. 30, 142-157.

Bourque, M., Morissette, M., Al Sweidi, S., Caruso, D., Melcangi, R.C., Di Paolo, T., 2016. Neuroprotective effect of progesterone in MPTP-treated male mice. Neuroendocrinology 103, 300-314.

Bowers, J.M., Waddell, J., McCarthy, M.M., 2010. A developmental sex difference in hippocampal neurogenesis is mediated by endogenous oestradiol. Biol. Sex Differ. 1,8 .

Brock, O., De Mees, C., Bakker, J., 2015. Hypothalamic expression of oestrogen receptor alpha and androgen receptor is sex-, age- and region-dependent in mice. J. Neuroendocrinol. 27, 264-276.

Brown, M.A., Weinberg, R.B., 2018. Mast cells and innate lymphoid cells: underappreciated players in CNS autoimmune demyelinating disease. Front. Immunol. 9, 514.

Brunton, P.J., Donadio, M.V., Yao, S.T., Greenwood, M., Seckl, J.R., Murphy, D., Russell, J.A., 2015. 5alpha-Reduced neurosteroids sex-dependently reverse central prenatal programming of neuroendocrine stress responses in rats. J. Neurosci. 35, 666-677.

Bryant, N.L., Buchanan, R.W., Vladar, K., Breier, A., Rothman, M., 1999. Gender differences in temporal lobe structures of patients with schizophrenia: a volumetric MRI study. Am. J. Psychiatry 156, 603-609.

Burul-Bozkurt, N., Pekiner, C., Kelicen, P., 2010. Diabetes alters aromatase enzyme levels in sciatic nerve and hippocampus tissues of rats. Cell. Mol. Neurobiol. 30, 445-451.

Calabrese, D., Giatti, S., Romano, S., Porretta-Serapiglia, C., Bianchi, R., Milanese, M., Bonanno, G., Caruso, D., Viviani, B., Gardoni, F., Garcia-Segura, L.M., Melcangi, R.C., 2014. Diabetic neuropathic pain: a role for testosterone metabolites. J. Endocrinol. 221, 1-13.

Callahan, M.J., Lipinski, W.J., Bian, F., Durham, R.A., Pack, A., Walker, L.C., 2001. Augmented senile plaque load in aged female beta-amyloid precursor protein-transgenic mice. Am. J. Pathol. 158, 1173-1177.

Callier, S., Morissette, M., Grandbois, M., Pelaprat, D., Di Paolo, T., 2001. Neuroprotective properties of 17beta-estradiol, progesterone, and raloxifene in MPTP
C57Bl/6 mice. Synapse 41, 131-138.

Calmarza-Font, I., Lagunas, N., Garcia-Segura, L.M., 2012. Antidepressive and anxiolytic activity of selective estrogen receptor modulators in ovariectomized mice submitted to chronic unpredictable stress. Behav. Brain Res. 227, 287-290.

Candeias, E., Duarte, A.I., Sebastiao, I., Fernandes, M.A., Placido, A.I., Carvalho, C., Correia, S., Santos, R.X., Seica, R., Santos, M.S., Oliveira, C.R., Moreira, P.I., 2017. Middle-aged diabetic females and males present distinct susceptibility to alzheimer disease-like pathology. Mol. Neurobiol. 54, 6471-6489.

Caruso, D., Abbiati, F., Giatti, S., Romano, S., Fusco, L., Cavaletti, G., Melcangi, R.C., 2015. Patients treated for male pattern hair with finasteride show, after discontinuation of the drug, altered levels of neuroactive steroids in cerebrospinal fluid and plasma. J. Steroid Biochem. Mol. Biol. 146, 74-79.

Caruso, D., Barron, A.M., Brown, M.A., Abbiati, F., Carrero, P., Pike, C.J., Garcia-Segura, L.M., Melcangi, R.C., 2013a. Age-related changes in neuroactive steroid levels in 3xTg-AD mice. Neurobiol. Aging 34, 1080-1089.

Caruso, D., D'Intino, G., Giatti, S., Maschi, O., Pesaresi, M., Calabrese, D., Garcia-Segura, L.M., Calza, L., Melcangi, R.C., 2010a. Sex-dimorphic changes in neuroactive steroid levels after chronic experimental autoimmune encephalomyelitis. J. Neurochem. 114, 921-932.

Caruso, D., Melis, M., Fenu, G., Giatti, S., Romano, S., Grimoldi, M., Crippa, D., Marrosu, M.G., Cavaletti, G., Melcangi, R.C., 2014. Neuroactive steroid levels in plasma and cerebrospinal fluid of male multiple sclerosis patients. J. Neurochem. 130, 591-597.

Caruso, D., Pesaresi, M., Abbiati, F., Calabrese, D., Giatti, S., Garcia-Segura, L.M., Melcangi, R.C., 2013b. Comparison of plasma and cerebrospinal fluid levels of neuroactive steroids with their brain, spinal cord and peripheral nerve levels in male and female rats. Psychoneuroendocrinology 38, 2278-2290.

Caruso, D., Pesaresi, M., Maschi, O., Giatti, S., Garcia-Segura, L.M., Melcangi, R.C. 2010b. Effects of short- and long-term gonadectomy on neuroactive steroid levels in the central and peripheral nervous system of male and female rats. J. Neuroendocrinol. 22, 1137-1147.

Caruso, D., Scurati, S., Roglio, I., Nobbio, L., Schenone, A., Melcangi, R.C., 2008. Neuroactive steroid levels in a transgenic rat model of CMT1A neuropathy. J. Mol. Neurosci. 34, 249-253

Casas, S., Gonzalez Deniselle, M.C., Gargiulo-Monachelli, G.M., Perez, A.F., Tourreilles, M., Mattiazzi, M., Ojeda, C., Lotero Polesel, D., De Nicola, A.F., 2017. Neuroactive steroids in acute ischemic stroke: association with cognitive, functional, and neurological outcomes. Horm. Metab. Res. 49, 16-22.

Cascio, C., Deidda, I., Russo, D., Guarneri, P., 2015. The estrogenic retina: The potential contribution to healthy aging and age-related neurodegenerative diseases of the retina. Steroids 103, 31-41.

Celec, P., Ostatnikova, D., Hodosy, J., 2015. On the effects of testosterone on brain behavioral functions. Front. Neurosci. 9, 12.

Cerciat, M., Unkila, M., Garcia-Segura, L.M., Arevalo, M.A., 2010. Selective estrogen receptor modulators decrease the production of interleukin- 6 and interferon-gammainducible protein-10 by astrocytes exposed to inflammatory challenge in vitro. Glia 58, 93-102.

Cerghet, M., Skoff, R.P., Bessert, D., Zhang, Z., Mullins, C., Ghandour, M.S., 2006. Proliferation and death of oligodendrocytes and myelin proteins are differentially regulated in male and female rodents. J. Neurosci. 26, 1439-1447.

Cermenati, G., Audano, M., Giatti, S., Carozzi, V., Porretta-Serapiglia, C., Pettinato, E., Ferri, C., D'Antonio, M., De Fabiani, E., Crestani, M., Scurati, S., Saez, E., Azcoitia, I., Cavaletti, G., Garcia-Segura, L.M., Melcangi, R.C., Caruso, D., Mitro, N., 2015. Lack of sterol regulatory element binding factor-1c imposes glial Fatty Acid utilization leading to peripheral neuropathy. Cell Metab. 21, 571-583.

Cermenati, G., Giatti, S., Audano, M., Pesaresi, M., Spezzano, R., Caruso, D., Mitro, N., Melcangi, R.C., 2017. Diabetes alters myelin lipid profile in rat cerebral cortex: Protective effects of dihydroprogesterone. J. Steroid Biochem. Mol. Biol. 168, 60-70.

Cermenati, G., Giatti, S., Cavaletti, G., Bianchi, R., Maschi, O., Pesaresi, M., Abbiati, F., Volonterio, A., Saez, E., Caruso, D., Melcangi, R.C., Mitro, N., 2010. Activation of the liver $\mathrm{X}$ receptor increases neuroactive steroid levels and protects from diabetes-induced peripheral neuropathy. J. Neurosci. 30, 11896-11901.

Chan, J.R., Phillips 2nd, L.J., Glaser, M., 1998. Glucocorticoids and progestins signal the initiation and enhance the rate of myelin formation. Proc. Natl. Acad. Sci. U. S. A. 95, 10459-10464.

Chan, J.R., Rodriguez-Waitkus, P.M., Ng, B.K., Liang, P., Glaser, M., 2000. Progesterone synthesized by Schwann cells during myelin formation regulates neuronal gene expression. Mol. Biol. Cell 11, 2283-2295.

Chavez-Delgado, M.E., Gomez-Pinedo, U., Feria-Velasco, A., Huerta-Viera, M., Castaneda, S.C., Toral, F.A., Parducz, A., Anda, S.L., Mora-Galindo, J., Garcia-Estrada, J., 2005 Ultrastructural analysis of guided nerve regeneration using progesterone- and pregnenolone-loaded chitosan prostheses. J. Biomed. Mater. Res. B Appl. Biomater. 74, $589-600$.

Cheng, O., Ostrowski, R.P., Liu, W., Zhang, J.H., 2010. Activation of liver X receptor reduces global ischemic brain injury by reduction of nuclear factor-kappaB. Neuroscience 166, 1101-1109.

Cheng, Q., Sun, G.J., Liu, S.B., Yang, Q., Li, X.M., Li, X.B., Liu, G., Zhao, J.N., Zhao, M.G., 2016. A novel translocator protein $18 \mathrm{kDa}$ ligand, ZBD-2, exerts neuroprotective effects against acute spinal cord injury. Clin. Exp. Pharmacol. Physiol. 43, 930-938.

Chiriaco, G., Cauci, S., Mazzon, G., Trombetta, C., 2016. An observational retrospective evaluation of 79 young men with long-term adverse effects after use of finasteride against androgenetic alopecia. Andrology 4, 245-250.

Chisholm, N.C., Henderson, M.L., Selvamani, A., Park, M.J., Dindot, S., Miranda, R.C., Sohrabji, F., 2015. Histone methylation patterns in astrocytes are influenced by age following ischemia. Epigenetics 10, 142-152.

Chisholm, N.C., Sohrabji, F., 2015. Astrocytic response to cerebral ischemia is influenced by sex differences and impaired by aging. Neurobiol. Dis. 
Cho, T., Chaban, V.V., 2012. Interaction between P2X3 and oestrogen receptor (ER) alpha/ERbeta in ATP-mediated calcium signalling in mice sensory neurones. J. Neuroendocrinol. 24, 789-797.

Chowen, J.A., Torres-Aleman, I., Garcia-Segura, L.M., 1992. Trophic effects of estradiol on fetal rat hypothalamic neurons. Neuroendocrinology 56, 895-901.

Ciriza, I., Carrero, P., Frye, C.A., Garcia-Segura, L.M., 2006. Reduced metabolites mediate neuroprotective effects of progesterone in the adult rat hippocampus. The synthetic progestin medroxyprogesterone acetate (Provera) is not neuroprotective. J. Neurobiol. 66, 916-928.

Cisternas, C.D., Cabrera Zapata, L.E., Arevalo, M.A., Garcia-Segura, L.M., Cambiasso, M.J., 2017. Regulation of aromatase expression in the anterior amygdala of the developing mouse brain depends on ERbeta and sex chromosome complement. Sci. Rep. 7, 5320 .

Cisternas, C.D., Tome, K., Caeiro, X.E., Dadam, F.M., Garcia-Segura, L.M., Cambiasso, M.J., 2015. Sex chromosome complement determines sex differences in aromatase expression and regulation in the stria terminalis and anterior amygdala of the developing mouse brain. Mol. Cell. Endocrinol. 414, 99-110.

Clinton, L.K., Billings, L.M., Green, K.N., Caccamo, A., Ngo, J., Oddo, S., McGaugh, J.L., LaFerla, F.M., 2007. Age-dependent sexual dimorphism in cognition and stress response in the 3xTg-AD mice. Neurobiol. Dis. 28, 76-82.

Cohen, R.E., Wade, J., 2010. Distribution of two isozymes of 5alpha-reductase in the brains of adult male and female green anole lizards. Brain Behav. Evol. 76, 279-288.

Colciago, A., Casati, L., Negri-Cesi, P., Celotti, F., 2015. Learning and memory: Steroids and epigenetics. J. Steroid Biochem. Mol. Biol. 150, 64-85.

Confavreux, C., Vukusic, S., Adeleine, P., 2003. Early clinical predictors and progression of irreversible disability in multiple sclerosis: an amnesic process. Brain 126, 770-782.

Contreras, C.M., Gutierrez-Garcia, A.G., 2017. Progesterone modifies the responsivity of the amygdala-mPFC connection in male but not female Wistar rats. Neurosci. Lett. $649,1-6$

Corpechot, C., Robel, P., Axelson, M., Sjovall, J., Baulieu, E.E., 1981. Characterization and measurement of dehydroepiandrosterone sulfate in rat brain. Proc. Natl. Acad. Sci. U. S. A. 78, 4704-4707.

Covault, J., Pond, T., Feinn, R., Arias, A.J., Oncken, C., Kranzler, H.R., 2014. Dutasteride reduces alcohol's sedative effects in men in a human laboratory setting and reduces drinking in the natural environment. Psychopharmacology 231, 3609-3618.

Cummins, C.L., Mangelsdorf, D.J., 2006. Liver X receptors and cholesterol homoeostasis: spotlight on the adrenal gland. Biochem. Soc. Trans. 34, 1110-1113.

Cummins, C.L., Volle, D.H., Zhang, Y., McDonald, J.G., Sion, B., Lefrancois-Martinez, A.M., Caira, F., Veyssiere, G., Mangelsdorf, D.J., Lobaccaro, J.M., 2006. Liver X receptors regulate adrenal cholesterol balance. J. Clin. Invest. 116, 1902-1912.

Cutler, S.M., Cekic, M., Miller, D.M., Wali, B., VanLandingham, J.W., Stein, D.G., 2007. Progesterone improves acute recovery after traumatic brain injury in the aged rat. J. Neurotrauma 24, 1475-1486.

Czlonkowska, A., Ciesielska, A., Gromadzka, G., Kurkowska-Jastrzebska, I., 2006. Gender differences in neurological disease: role of estrogens and cytokines. Endocrine 29, 243-256.

Da Pozzo, E., Giacomelli, C., Barresi, E., Costa, B., Taliani, S., Passetti Fda, S., Martini, C., 2015. Targeting the $18-\mathrm{kDa}$ translocator protein: recent perspectives for neuroprotection. Biochem. Soc. Trans. 43, 559-565.

Da Pozzo, E., Giacomelli, C., Costa, B., Cavallini, C., Taliani, S., Barresi, E., Da Settimo, F., Martini, C., 2016. TSPO PIGA ligands promote neurosteroidogenesis and human astrocyte well-being. Int. J. Mol. Sci. 17.

Dalal, M., Kim, S., Voskuhl, R.R., 1997. Testosterone therapy ameliorates experimental autoimmune encephalomyelitis and induces a T helper 2 bias in the autoantigenspecific T lymphocyte response. J. Immunol. 159, 3-6.

Dang, J., Mitkari, B., Kipp, M., Beyer, C., 2011. Gonadal steroids prevent cell damage and stimulate behavioral recovery after transient middle cerebral artery occlusion in male and female rats. Brain Behav. Immun. 25, 715-726.

Daugherty, D.J., Selvaraj, V., Chechneva, O.V., Liu, X.B., Pleasure, D.E., Deng, W., 2013. A TSPO ligand is protective in a mouse model of multiple sclerosis. EMBO Mol. Med. 5, 891-903.

Davis, D.P., Douglas, D.J., Smith, W., Sise, M.J., Vilke, G.M., Holbrook, T.L., Kennedy, F., Eastman, A.B., Velky, T., Hoyt, D.B., 2006. Traumatic brain injury outcomes in preand post- menopausal females versus age-matched males. J. Neurotrauma 23, $140-148$.

Day, N.L., Floyd, C.L., D'Alessandro, T.L., Hubbard, W.J., Chaudry, I.H., 2013. 17betaestradiol confers protection after traumatic brain injury in the rat and involves activation of G protein-coupled estrogen receptor 1. J. Neurotrauma 30, 1531-1541.

de Carvalho, D., Marques, D.A., Bernuci, M.P., Leite, C.M., Araujo-Lopes, R., AnselmoFranci, J., Bicego, K.C., Szawka, R.E., Gargaglioni, L.H., 2016. Role of sex hormones in hypercapnia-induced activation of the locus coeruleus in female and male rats. Neuroscience 313, 36-45.

de Lau, L.M., Giesbergen, P.C., de Rijk, M.C., Hofman, A., Koudstaal, P.J., Breteler, M.M., 2004. Incidence of parkinsonism and Parkinson disease in a general population: the Rotterdam study. Neurology 63, 1240-1244.

de Olmos, S., Bueno, A., Bender, C., Lorenzo, A., de Olmos, J., 2008. Sex differences and influence of gonadal hormones on MK801-induced neuronal degeneration in the granular retrosplenial cortex of the rat. Brain Struct. Funct. 213, 229-238.

Devaud, L.L., Alavi, M., Jensen, J.P., Helms, M.L., Nipper, M.A., Finn, D.A., 2018. Sexually divergent changes in select brain proteins and neurosteroid levels after a history of ethanol drinking and intermittent PTSD-like stress exposure in adult C57BL/6J mice. Alcohol.

Devroey, D., Van Casteren, V., Buntinx, F., 2003. Registration of stroke through the Belgian sentinel network and factors influencing stroke mortality. Cerebrovasc. Dis. 16, 272-279.
Di Fiore, M.M., Santillo, A., Falvo, S., Chieffi Baccari, G., Venditti, M., Di Giacomo Russo, F., Lispi, M., D'Aniello, A., 2018. Sex hormone levels in the brain of d-aspartatetreated rats. C R Biol. 341, 9-15.

Di Mauro, M., Tozzi, A., Calabresi, P., Pettorossi, V.E., Grassi, S., 2015. Neo-synthesis of estrogenic or androgenic neurosteroids determine whether long-term potentiation or depression is induced in hippocampus of male rat. Front. Cell. Neurosci. 9, 376.

di Michele, F., Longone, P., Romeo, E., Lucchetti, S., Brusa, L., Pierantozzi, M., Bassi, A., Bernardi, G., Stanzione, P., 2003. Decreased plasma and cerebrospinal fluid content of neuroactive steroids in Parkinson's disease. Neurol. Sci. 24, 172-173.

Diotel, N., Charlier, T.D., Lefebvre d'Hellencourt, C., Couret, D., Trudeau, V.L., Nicolau, J.C., Meilhac, O., Kah, O., Pellegrini, E., 2018. Steroid transport, local synthesis, and signaling within the brain: roles in neurogenesis, neuroprotection, and sexual behaviors. Front. Neurosci. 12, 84

Diviccaro, S., Giatti, S., Borgo, F., Barcella, M., Borghi, E., Trejo, J.L., Garcia-Segura, L.M., Melcangi, R.C., 2019. Treatment of male rats with finasteride, an inhibitor of 5alphareductase enzyme, induces long-lasting effects on depressive-like behavior, hippocampal neurogenesis, neuroinflammation and gut microbiota composition. Psychoneuroendocrinology 99, 206-215.

Diz-Chaves, Y., Kwiatkowska-Naqvi, A., Von Hulst, H., Pernia, O., Carrero, P., GarciaSegura, L.M., 2012. Behavioral effects of estradiol therapy in ovariectomized rats depend on the age when the treatment is initiated. Exp. Gerontol. 47, 93-99.

Djebaili, M., Guo, Q., Pettus, E.H., Hoffman, S.W., Stein, D.G., 2005. The neurosteroids progesterone and allopregnanolone reduce cell death, gliosis, and functional deficits after traumatic brain injury in rats. J. Neurotrauma 22, 106-118.

Dodel, R.C., Du, Y., Bales, K.R., Gao, F., Paul, S.M., 1999. Sodium salicylate and 17betaestradiol attenuate nuclear transcription factor NF-kappaB translocation in cultured rat astroglial cultures following exposure to amyloid A beta(1-40) and lipopolysaccharides. J. Neurochem. 73, 1453-1460.

Domonkos, E., Borbelyova, V., Csongova, M., Bosy, M., Kacmarova, M., Ostatnikova, D., Hodosy, J., Celec, P., 2017. Sex differences and sex hormones in anxiety-like behavior of aging rats. Horm. Behav. 93, 159-165.

Dong, S., Zhang, Q., Kong, D., Zhou, C., Zhou, J., Han, J., Zhou, Y., Jin, G., Hua, X., Wang, J., Hua, F., 2018. Gender difference in the effect of progesterone on neonatal hypoxic/ischemic brain injury in mouse. Exp. Neurol. 306, 190-198.

Dooley, M.A., Hogan, S.L., 2003. Environmental epidemiology and risk factors for autoimmune disease. Curr. Opin. Rheumatol. 15, 99-103.

Douin-Echinard, V., Laffont, S., Seillet, C., Delpy, L., Krust, A., Chambon, P., Gourdy, P., Arnal, J.F., Guery, J.C., 2008. Estrogen receptor alpha, but not beta, is required for optimal dendritic cell differentiation and [corrected] CD40-induced cytokine production. J. Immunol. 180, 3661-3669.

Doulazmi, M., Frederic, F., Lemaigre-Dubreuil, Y., Hadj-Sahraoui, N., Delhaye-Bouchaud, N., Mariani, J., 1999. Cerebellar Purkinje cell loss during life span of the heterozygous staggerer mouse (Rora(+)/Rora(sg)) is gender-related. J. Comp. Neurol. 411 267-273.

Drew, P.D., Chavis, J.A., 2000. Female sex steroids: effects upon microglial cell activation. J. Neuroimmunol. 111, 77-85.

Ebihara, K., Fujiwara, H., Awale, S., Dibwe, D.F., Araki, R., Yabe, T., Matsumoto, K., 2017. Decrease in endogenous brain allopregnanolone induces autism spectrum disorder (ASD)-like behavior in mice: a novel animal model of ASD. Behav. Brain Res. $334,6-15$.

El Hajj Chehadeh, S., Dreumont, N., Willekens, J., Canabady-Rochelle, L., Jeannesson, E., Alberto, J.M., Daval, J.L., Gueant, J.L., Leininger-Muller, B., 2014. Early methyl donor deficiency alters cAMP signaling pathway and neurosteroidogenesis in the cerebellum of female rat pups. Am. J. Physiol. Endocrinol. Metab. 307, E1009-E1019.

El-Etr, M., Rame, M., Boucher, C., Ghoumari, A.M., Kumar, N., Liere, P., Pianos, A., Schumacher, M., Sitruk-Ware, R., 2015. Progesterone and nestorone promote myelin regeneration in chronic demyelinating lesions of corpus callosum and cerebral cortex. Glia 63, 104-117.

El-Kabbani, O., Dhagat, U., Hara, A., 2011. Inhibitors of human 20alpha-hydroxysteroid dehydrogenase (AKR1C1). J. Steroid Biochem. Mol. Biol. 125, 105-111.

Elkabes, S., Nicot, A.B., 2014. Sex steroids and neuroprotection in spinal cord injury: a review of preclinical investigations. Exp. Neurol. 259, 28-37.

Emanuelsson, I., Almokhtar, M., Wikvall, K., Gronbladh, A., Nylander, E., Svensson, A.L., Fex Svenningsen, A., Norlin, M., 2018. Expression and regulation of CYP17A1 and 3beta-hydroxysteroid dehydrogenase in cells of the nervous system: Potential effects of vitamin D on brain steroidogenesis. Neurochem. Int. 113, 46-55.

Eriksson, M., Norrving, B., Terent, A., Stegmayr, B., 2008. Functional outcome 3 months after stroke predicts long-term survival. Cerebrovasc. Dis. 25, 423-429.

Fan, B., Liu, X.S., Szalad, A., Wang, L., Zhang, R., Chopp, M., Zhang, Z.G., 2018. Influence of sex on cognition and peripheral neurovascular function in diabetic mice. Front. Neurosci. 12, 795 .

Fanni, S., Scheggi, S., Rossi, F., Tronci, E., Traccis, F., Stancampiano, R., De Montis, M.G., Devoto, P., Gambarana, C., Bortolato, M., Frau, R., Carta, M., 2019. 5alpha-reductase inhibitors dampen L-DOPA-induced dyskinesia via normalization of dopamine D1 receptor signaling pathway and D1-D3 receptor interaction. Neurobiol. Dis. 121, 120-130.

Farace, E., Alves, W.M., 2000. Do women fare worse: a metaanalysis of gender differences in traumatic brain injury outcome. J. Neurosurg. 93, 539-545.

Feizy, N., Nourazarian, A., Rahbarghazi, R., Nozad Charoudeh, H., Abdyazdani, N., Montazersaheb, S., Narimani, M., 2016. Morphine inhibited the rat neural stem cell proliferation rate by increasing neuro steroid genesis. Neurochem. Res. 41, 1410-1419.

Ferzaz, B., Brault, E., Bourliaud, G., Robert, J.P., Poughon, G., Claustre, Y., Marguet, F., Liere, P., Schumacher, M., Nowicki, J.P., Fournier, J., Marabout, B., Sevrin, M., George, P., Soubrie, P., Benavides, J., Scatton, B., 2002. SSR180575 (7-chloro-N, N,5- 
trimethyl-4-oxo-3-phenyl-3,5-dihydro-4H-pyridazino[4,5-b]i ndole-1-acetamide), a peripheral benzodiazepine receptor ligand, promotes neuronal survival and repair. J. Pharmacol. Exp. Ther. 301, 1067-1078.

Fex Svenningsen, A., Kanje, M., 1999. Estrogen and progesterone stimulate Schwann cell proliferation in a sex- and age-dependent manner. J. Neurosci. Res. 57, 124-130.

Finn, D.A., Jimenez, V.A., 2018. Dynamic adaptation in neurosteroid networks in response to alcohol. Handb. Exp. Pharmacol. 248, 55-78.

Fombonne, E., 1999. The epidemiology of autism: a review. Psychol. Med. 29, 769-786.

Fombonne, E., 2003. Epidemiological surveys of autism and other pervasive developmental disorders: an update. J. Autism Dev. Disord. 33, 365-382.

Foot, M., Koszycki, D., 2004. Gender differences in anxiety-related traits in patients with panic disorder. Depress Anxiety 20, 123-130.

Foy, M.R., Akopian, G., Thompson, R.F., 2008. Progesterone regulation of synaptic transmission and plasticity in rodent hippocampus. Learn. Mem. 15, 820-822.

Frankfurt, M., Luine, V., 2015. The evolving role of dendritic spines and memory: in teraction(s) with estradiol. Horm. Behav.

Fratiglioni, L., Viitanen, M., von Strauss, E., Tontodonati, V., Herlitz, A., Winblad, B., 1997. Very old women at highest risk of dementia and Alzheimer's disease: incidence data from the Kungsholmen Project, Stockholm. Neurology 48, 132-138.

Frau, R., Bortolato, M., 2019. Repurposing steroidogenesis inhibitors for the therapy of neuropsychiatric disorders: Promises and caveats. Neuropharmacology 147, 55-65.

Frokjaer, V.G., Pinborg, A., Holst, K.K., Overgaard, A., Henningsson, S., Heede, M., Larsen, E.C., Jensen, P.S., Agn, M., Nielsen, A.P., Stenbaek, D.S., da Cunha-Bang, S., Lehel, S., Siebner, H.R., Mikkelsen, J.D., Svarer, C., Knudsen, G.M., 2015. Role of serotonin transporter changes in depressive responses to sex-steroid hormone manipulation: a positron emission tomography study. Biol. Psychiatry 78, 534-543.

Fry, J.P., Li, K.Y., Devall, A.J., Cockcroft, S., Honour, J.W., Lovick, T.A., 2014. Fluoxetine elevates allopregnanolone in female rat brain but inhibits a steroid microsomal dehydrogenase rather than activating an aldo-keto reductase. Br. J. Pharmacol. 171, $5870-5880$

Frye, C.A., Koonce, C.J., Edinger, K.L., Osborne, D.M., Walf, A.A., 2008. Androgens with activity at estrogen receptor beta have anxiolytic and cognitive-enhancing effects in male rats and mice. Horm. Behav. 54, 726-734.

Frye, C.A., Ryan, A., Rhodes, M., 2009. Antiseizure effects of 3alpha-androstanediol and/ or 17beta-estradiol may involve actions at estrogen receptor beta. Epilepsy Behav. 16, 418-422.

Frye, C.A., Scalise, T.J., 2000. Anti-seizure effects of progesterone and 3alpha,5alpha-THP in kainic acid and perforant pathway models of epilepsy. Psychoneuroendocrinology 25, 407-420.

Galanopoulou, A.S., Alm, E.M., Veliskova, J., 2003. Estradiol reduces seizure-induced hippocampal injury in ovariectomized female but not in male rats. Neurosci. Lett. 342, 201-205.

Galea, L.A., Wide, J.K., Barr, A.M., 2001. Estradiol alleviates depressive-like symptoms in a novel animal model of post-partum depression. Behav. Brain Res. 122, 1-9.

Galea, L.A., 2008. Gonadal hormone modulation of neurogenesis in the dentate gyrus of adult male and female rodents. Brain Res. Rev. 57, 332-341.

Garay, L., Deniselle, M.C., Lima, A., Roig, P., De Nicola, A.F., 2007. Effects of progesterone in the spinal cord of a mouse model of multiple sclerosis. J. Steroid Biochem. Mol. Biol. 107, 228-237.

Garay, L., Deniselle, M.C., Meyer, M., Costa, J.J., Lima, A., Roig, P., Denicola, A.F., 2009. Protective effects of progesterone administration on axonal pathology in mice with experimental autoimmune encephalomyelitis. Brain Res. 1283, 177-185.

Garay, L., Gonzalez Deniselle, M.C., Gierman, L., Lima, A., Roig, P., De Nicola, A.F., 2010 Pharmacotherapy with 17beta-estradiol and progesterone prevents development of mouse experimental autoimmune encephalomyelitis. Horm. Mol. Biol. Clin. Investig. $1,43-51$.

Garcia-Estrada, J., Del Rio, J.A., Luquin, S., Soriano, E., Garcia-Segura, L.M., 1993 Gonadal hormones down-regulate reactive gliosis and astrocyte proliferation after a penetrating brain injury. Brain Res. 628, 271-278.

Garcia-Segura, L.M., Chowen, J.A., Parducz, A., Naftolin, F., 1994. Gonadal hormones as promoters of structural synaptic plasticity: cellular mechanisms. Prog. Neurobiol. 44, 279-307.

Garcia-Segura, L.M., Melcangi, R.C., 2006. Steroids and glial cell function. Glia 54, 485-498.

Garcia-Segura, L.M., Torres-Aleman, I., Naftolin, F., 1989. Astrocytic shape and glial fibrillary acidic protein immunoreactivity are modified by estradiol in primary rat hypothalamic cultures. Brain Res. Dev. Brain Res. 47, 298-302.

Geraldes, P., Gagnon, S., Hadjadj, S., Merhi, Y., Sirois, M.G., Cloutier, I., Tanguay, J.F. 2006. Estradiol blocks the induction of CD40 and CD40L expression on endothelia cells and prevents neutrophil adhesion: an ERalpha-mediated pathway. Cardiovasc. Res. 71, 566-573.

Ghisletti, S., Meda, C., Maggi, A., Vegeto, E., 2005. 17beta-estradiol inhibits inflammatory gene expression by controlling NF-kappaB intracellular localization. Mol. Cell. Biol. 25, 2957-2968.

Ghoumari, A.M., Baulieu, E.E., Schumacher, M., 2005. Progesterone increases oligodendroglial cell proliferation in rat cerebellar slice cultures. Neuroscience 135, 47-58.

Ghoumari, A.M., Ibanez, C., El-Etr, M., Leclerc, P., Eychenne, B., O'Malley, B.W., Baulieu, E.E., Schumacher, M., 2003. Progesterone and its metabolites increase myelin basic protein expression in organotypic slice cultures of rat cerebellum. J. Neurochem. 86, 848-859.

Giatti, S., Boraso, M., Melcangi, R., Viviani, B., 2012. Neuroactive steroids, their metabolites and neuroinflammation. J. Mol. Endocrinol. 49, R125-R134.

Giatti, S., D'Intino, G., Maschi, O., Pesaresi, M., Garcia-Segura, L.M., Calza, L., Caruso, D., Melcangi, R.C., 2010. Acute experimental autoimmune encephalomyelitis induces sex dimorphic changes in neuroactive steroid levels. Neurochem. Int. 56, 118-127.

Giatti, S., Diviccaro, S., Garcia-Segura, L.M., Melcangi, R.C., 2019. Sex differences in the brain expression of steroidogenic molecules under basal conditions and after gonadectomy. J. Neuroendocrinol. e12736.

Giatti, S., Diviccaro, S., Panzica, G., Melcangi, R.C., 2018a. Post-finasteride syndrome and post-SSRI sexual dysfunction: two sides of the same coin? Endocrine 2, 180-193.

Giatti, S., Foglio, B., Romano, S., Pesaresi, M., Panzica, G., Garcia-Segura, L.M., Caruso, D., Melcangi, R.C., 2016a. Effects of subchronic finasteride treatment and withdrawal on neuroactive steroid levels and their receptors in the male rat brain. Neuroendocrinology 103, 746-757.

Giatti, S., Garcia-Segura, L.M., Melcangi, R.C., 2015a. New steps forward in the neuroactive steroid field. J. Steroid Biochem. Mol. Biol. 153, 127-134.

Giatti, S., Mastrangelo, R., D'Antonio, M., Pesaresi, M., Romano, S., Diviccaro, S., Caruso, D., Mitro, N., Melcangi, R.C., 2018b. Neuroactive steroids and diabetic complications in the nervous system. Front. Neuroendocrinol. 48, 58-69.

Giatti, S., Melcangi, R.C., Pesaresi, M., 2016b. The other side of progestins: effects in the brain. J. Mol. Endocrinol. 57, R109-R126.

Giatti, S., Pesaresi, M., Cavaletti, G., Bianchi, R., Carozzi, V., Lombardi, R., Maschi, O., Lauria, G., Garcia-Segura, L.M., Caruso, D., Melcangi, R.C., 2009. Neuroprotective effects of a ligand of translocator protein-18kDa (Ro5-4864) in experimental diabetic neuropathy. Neuroscience 164, 520-529.

Giatti, S., Rigolio, R., Romano, S., Mitro, N., Viviani, B., Cavaletti, G., Caruso, D., GarciaSegura, L.M., Melcangi, R.C., 2015b. Dihydrotestosterone as a protective agent in chronic experimental autoimmune encephalomyelitis. Neuroendocrinology 101, 296-308.

Giatti, S., Romano, S., Pesaresi, M., Cermenati, G., Mitro, N., Caruso, D., Tetel, M.J., Garcia-Segura, L.M., Melcangi, R.C., 2015c. Neuroactive steroids and the peripheral nervous system: an update. Steroids 103, 23-30.

Gillies, G.E., Murray, H.E., Dexter, D., McArthur, S., 2004. Sex dimorphisms in the neuroprotective effects of estrogen in an animal model of Parkinson's disease. Pharmacol. Biochem. Behav. 78, 513-522.

Giltay, E.J., van der Mast, R.C., Lauwen, E., Heijboer, A.C., de Waal, M.W.M., Comijs, H.C., 2017. Plasma testosterone and the course of major depressive disorder in older men and women. Am. J. Geriatr. Psychiatry 25, 425-437.

Girard, C., Liu, S., Adams, D., Lacroix, C., Sineus, M., Boucher, C., Papadopoulos, V., Rupprecht, R., Schumacher, M., Groyer, G., 2012. Axonal regeneration and neuroinflammation: roles for the translocator protein $18 \mathrm{kDa}$. J. Neuroendocrinol. 24 71-81.

Girard, C., Liu, S., Cadepond, F., Adams, D., Lacroix, C., Verleye, M., Gillardin, J.M Baulieu, E.E., Schumacher, M., Schweizer-Groyer, G., 2008. Etifoxine improves peripheral nerve regeneration and functional recovery. Proc. Natl. Acad. Sci. U. S. A. 105, 20505-20510.

Gispen, W.H., Biessels, G.J., 2000. Cognition and synaptic plasticity in diabetes mellitus. Trends Neurosci. 23, 542-549.

Gleicher, N., Barad, D.H., 2007. Gender as risk factor for autoimmune diseases. J. Autoimmun. 28, 1-6.

Gold, S.M., Chalifoux, S., Giesser, B.S., Voskuhl, R.R., 2008. Immune modulation and increased neurotrophic factor production in multiple sclerosis patients treated with testosterone. J. Neuroinflammation 5, 32.

Goldstein, J.M., 2006. Sex, hormones and affective arousal circuitry dysfunction in schizophrenia. Horm. Behav. 50, 612-622.

Goldstein, J.M., Link, B.G., 1988. Gender and the expression of schizophrenia. J. Psychiatr. Res. 22, 141-155.

Goldstein, J.M., Seidman, L.J., Goodman, J.M., Koren, D., Lee, H., Weintraub, S., Tsuang, M.T., 1998. Are there sex differences in neuropsychological functions among patient with schizophrenia? Am. J. Psychiatry 155, 1358-1364.

Goldstein, J.M., Seidman, L.J., Makris, N., Ahern, T., O'Brien, L.M., Caviness Jr., V.S., Kennedy, D.N., Faraone, S.V., Tsuang, M.T., 2007. Hypothalamic abnormalities in schizophrenia: sex effects and genetic vulnerability. Biol. Psychiatry 61, 935-945.

Goldstein, J.M., Seidman, L.J., O'Brien, L.M., Horton, N.J., Kennedy, D.N., Makris, N., Caviness Jr., V.S., Faraone, S.V., Tsuang, M.T., 2002. Impact of normal sexual dimorphisms on sex differences in structural brain abnormalities in schizophrenia assessed by magnetic resonance imaging. Arch. Gen. Psychiatry 59, 154-164.

Gonzalez Deniselle, M.C., Liere, P., Pianos, A., Meyer, M., Aprahamian, F., Cambourg, A., Di Giorgio, N.P., Schumacher, M., De Nicola, A.F., Guennoun, R., 2016. Steroid profiling in male wobbler mouse, a model of amyotrophic lateral sclerosis. Endocrinology 157, 4446-4460.

Gonzalez Deniselle, M.C., Lopez-Costa, J.J., Saavedra, J.P., Pietranera, L., Gonzalez, S.L., Garay, L., Guennoun, R., Schumacher, M., De Nicola, A.F., 2002. Progesterone neuroprotection in the Wobbler mouse, a genetic model of spinal cord motor neuron disease. Neurobiol. Dis. 11, 457-468.

Groswasser, Z., Cohen, M., Keren, O., 1998. Female TBI patients recover better than males. Brain Inj. 12, 805-808.

Guennoun, R., Benmessahel, Y., Delespierre, B., Gouezou, M., Rajkowski, K.M., Baulieu, E.E., Schumacher, M., 2001. Progesterone stimulates Krox-20 gene expression in Schwann cells. Brain Res. Mol. Brain Res. 90, 75-82.

Guerra-Araiza, C., Amorim, M.A., Camacho-Arroyo, I., Garcia-Segura, L.M., 2007. Effects of progesterone and its reduced metabolites, dihydroprogesterone and tetrahydroprogesterone, on the expression and phosphorylation of glycogen synthase kinase- 3 and the microtubule-associated protein tau in the rat cerebellum. Dev. Neurobiol. 67, 510-520.

Guerra-Araiza, C., Coyoy-Salgado, A., Camacho-Arroyo, I., 2002. Sex differences in the regulation of progesterone receptor isoforms expression in the rat brain. Brain Res. Bull. 59, 105-109.

Gur, R.E., Kohler, C., Turetsky, B.I., Siegel, S.J., Kanes, S.J., Bilker, W.B., Brennan, A.R., Gur, R.C., 2004. A sexually dimorphic ratio of orbitofrontal to amygdala volume is altered in schizophrenia. Biol. Psychiatry 55, 512-517.

Haaxma, C.A., Bloem, B.R., Borm, G.F., Oyen, W.J., Leenders, K.L., Eshuis, S., Booij, J., 
Dluzen, D.E., Horstink, M.W., 2007. Gender differences in Parkinson's disease. J. Neurol. Neurosurg. Psychiatry 78, 819-824.

Hadj-Sahraoui, N., Frederic, F., Delhaye-Bouchaud, N., Mariani, J., 1996. Gender effect on Purkinje cell loss in the cerebellum of the heterozygous reeler mouse. J. Neurogenet. 11, 45-58.

Hadjimarkou, M.M., Vasudevan, N., 2018. GPER1/GPR30 in the brain: Crosstalk with classical estrogen receptors and implications for behavior. J. Steroid Biochem. Mol. Biol. 176, 57-64.

Hafner, H., 2003. Gender differences in schizophrenia. Psychoneuroendocrinology 28 (Suppl 2), 17-54.

Halbreich, U., Kahn, L.S., 2003. Hormonal aspects of schizophrenias: an overview. Psychoneuroendocrinology 28 (Suppl 2), 1-16.

Hall, E.D., Pazara, K.E., Linseman, K.L., 1991. Sex differences in postischemic neuronal necrosis in gerbils. J. Cereb. Blood Flow Metab. 11, 292-298.

Hammond, J., Le, Q., Goodyer, C., Gelfand, M., Trifiro, M., LeBlanc, A., 2001. Testosterone-mediated neuroprotection through the androgen receptor in human primary neurons. J. Neurochem. 77, 1319-1326.

Hanamsagar, R., Bilbo, S.D., 2016. Sex differences in neurodevelopmental and neurodegenerative disorders: Focus on microglial function and neuroinflammation during development. J. Steroid Biochem. Mol. Biol. 160, 127-133.

Hankin, B.L., Abramson, L.Y., 1999. Development of gender differences in depression: description and possible explanations. Ann. Med. 31, 372-379.

Harbuz, M.S., Perveen-Gill, Z., Lightman, S.L., Jessop, D.S., 1995. A protective role for testosterone in adjuvant-induced arthritis. Br. J. Rheumatol. 34, 1117-1122.

Hasan Mahmood, A.S.M., Uddin, M.M., Ibrahim, M.M.H., Mandal, S.K., Alhamami, H.N., Briski, K.P., 2018. Sex differences in forebrain estrogen receptor regulation of hypoglycemic patterns of counter-regulatory hormone secretion and ventromedial hypothalamic nucleus glucoregulatory neurotransmitter and astrocyte glycogen metabolic enzyme expression. Neuropeptides 72, 65-74.

Hasanpour, M., Nourazarian, A., Geranmayeh, M.H., Nikanfar, M., Khaki-Khatibi, F., Rahbarghazi, R., 2018. The dynamics of neurosteroids and sex-related hormones in the pathogenesis of Alzheimer's disease. Neuromol. Med. 20, 215-224.

Hasirci, A.S., Maldonado-Devincci, A.M., Beattie, M.C., O'Buckley, T.K., Morrow, A.L., 2017. Cellular GABAergic neuroactive steroid (3alpha,5alpha)-3-hydroxy-pregnan20-one (3alpha,5alpha-THP) immunostaining levels are increased in the ventral tegmental area of human alcohol use disorder patients: a postmortem study. Alcohol. Clin. Exp. Res. 41, 299-311.

Hawkins, S.A., McDonnell, G.V., 1999. Benign multiple sclerosis? Clinical course, long term follow up, and assessment of prognostic factors. J. Neurol. Neurosurg. Psychiatry 67, 148-152.

He, J., Evans, C.O., Hoffman, S.W., Oyesiku, N.M., Stein, D.G., 2004. Progesterone and allopregnanolone reduce inflammatory cytokines after traumatic brain injury. Exp. Neurol. 189, 404-412.

Hempel, R., Onopa, R., Convit, A., 2012. Type 2 diabetes affects hippocampus volume differentially in men and women. Diabetes Metab. Res. Rev. 28, 76-83.

Herz, J., Filiano, A.J., Smith, A., Yogev, N., Kipnis, J., 2017. Myeloid cells in the central nervous system. Immunity 46, 943-956.

Holroyd-Leduc, J.M., Kapral, M.K., Austin, P.C., Tu, J.V., 2000. Sex differences and similarities in the management and outcome of stroke patients. Stroke 31, 1833-1837.

Huang, Y.C., Hung, C.F., Lin, P.Y., Lee, Y., Wu, C.C., Hsu, S.T., Chen, C.C., Chong, M.Y., Lin, C.H., Wang, L.J., 2017. Gender differences in susceptibility to schizophrenia: Potential implication of neurosteroids. Psychoneuroendocrinology 84, 87-93.

Hudkins, K.L., Pichaiwong, W., Wietecha, T., Kowalewska, J., Banas, M.C., Spencer, M.W., Muhlfeld, A., Koelling, M., Pippin, J.W., Shankland, S.J., Askari, B., Rabaglia, M.E., Keller, M.P., Attie, A.D., Alpers, C.E., 2010. BTBR Ob/Ob mutant mice model progressive diabetic nephropathy. J. Am. Soc. Nephrol. 21, 1533-1542.

Huppenbauer, C.B., Tanzer, L., DonCarlos, L.L., Jones, K.J., 2005. Gonadal steroid attenuation of developing hamster facial motoneuron loss by axotomy: equal efficacy of testosterone, dihydrotestosterone, and 17-beta estradiol. J. Neurosci. 25, 4004-4013.

Hussain, R., Ghoumari, A.M., Bielecki, B., Steibel, J., Boehm, N., Liere, P., Macklin, W.B., Kumar, N., Habert, R., Mhaouty-Kodja, S., Tronche, F., Sitruk-Ware, R., Schumacher, M., Ghandour, M.S., 2013. The neural androgen receptor: a therapeutic target for myelin repair in chronic demyelination. Brain 136, 132-146.

Ibanez, C., Shields, S.A., El-Etr, M., Leonelli, E., Magnaghi, V., Li, W.W., Sim, F.J., Baulieu, E.E., Melcangi, R.C., Schumacher, M., Franklin, R.J., 2003. Steroids and the reversal of age-associated changes in myelination and remyelination. Prog. Neurobiol. 71, 49-56.

Irwig, M.S., 2012a. Depressive symptoms and suicidal thoughts among former users of finasteride with persistent sexual side effects. J. Clin. Psychiatry 73, 1220-1223.

Irwig, M.S., 2012b. Persistent sexual side effects of finasteride: could they be permanent? J. Sex. Med. 9, 2927-2932.

Ishihara, Y., Fujitani, N., Kawami, T., Adachi, C., Ishida, A., Yamazaki, T., 2014. Suppressive effects of 17beta-estradiol on tributyltin-induced neuronal injury via Akt activation and subsequent attenuation of oxidative stress. Life Sci. 99, 24-30.

Ishikawa, M., Yoshitomi, T., Covey, D.F., Zorumski, C.F., Izumi, Y., 2016. TSPO activation modulates the effects of high pressure in a rat ex vivo glaucoma model. Neuropharmacology 111, 142-159.

Jackson, G.L., Kuehl, D., Rhim, T.J., 1991. Testosterone inhibits gonadotropin-releasing hormone pulse frequency in the male sheep. Biol. Reprod. 45, 188-194.

Jacobson, A.M., Samson, J.A., Weinger, K., Ryan, C.M., 2002. Diabetes, the brain, and behavior: is there a biological mechanism underlying the association between diabetes and depression? Int. Rev. Neurobiol. 51, 455-479.

Jacobson, D.L., Gange, S.J., Rose, N.R., Graham, N.M., 1997. Epidemiology and estimated population burden of selected autoimmune diseases in the United States. Clin. Immunol. Immunopathol. 84, 223-243.

Jones, K.J., Brown, T.J., Damaser, M., 2001. Neuroprotective effects of gonadal steroids on regenerating peripheral motoneurons. Brain Res. Brain Res. Rev. 37, 372-382.

Joseph, E.K., Levine, J.D., 2003. Sexual dimorphism in the contribution of protein kinase $\mathrm{C}$ isoforms to nociception in the streptozotocin diabetic rat. Neuroscience 120 , 907-913.

Jung-Testas, I., Schumacher, M., Robel, P., Baulieu, E.E., 1996. The neurosteroid progesterone increases the expression of myelin proteins (MBP and CNPase) in rat oligodendrocytes in primary culture. Cell. Mol. Neurobiol. 16, 439-443.

Kalocayova, B., Mezesova, L., Bartekova, M., Vlkovicova, J., Jendruchova, V., Vrbjar, N. 2017. Properties of Na, K-ATPase in cerebellum of male and female rats: effects of acute and prolonged diabetes. Mol. Cell. Biochem. 425, 25-36.

Kancheva, R., Hill, M., Novak, Z., Chrastina, J., Kancheva, L., Starka, L., 2011. Neuroactive steroids in periphery and cerebrospinal fluid. Neuroscience 191, 22-27.

Kancheva, R., Hill, M., Novak, Z., Chrastina, J., Velikova, M., Kancheva, L., Riha, I., Starka, L., 2010. Peripheral neuroactive steroids may be as good as the steroids in the cerebrospinal fluid for the diagnostics of CNS disturbances. J. Steroid Biochem. Mol. Biol. 119, 35-44.

Kapral, M.K., Fang, J., Hill, M.D., Silver, F., Richards, J., Jaigobin, C., Cheung, A.M., 2005. Sex differences in stroke care and outcomes: results from the Registry of the Canadian Stroke Network. Stroke 36, 809-814.

Kastenberger, I., Schwarzer, C., 2014. GPER1 (GPR30) knockout mice display reduced anxiety and altered stress response in a sex and paradigm dependent manner. Horm. Behav. 66, 628-636.

Kaye, W., 2008. Neurobiology of anorexia and bulimia nervosa. Physiol. Behav. 94, 121-135.

Kelley, M.H., Kuroiwa, M., Taguchi, N., Herson, P.S., 2011. Sex difference in sensitivity to allopregnanolone neuroprotection in mice correlates with effect on spontaneous inhibitory post synaptic currents. Neuropharmacology 61, 724-729.

Khasnavis, S., Ghosh, A., Roy, A., Pahan, K., 2013. Castration induces Parkinson disease pathologies in young male mice via inducible nitric-oxide synthase. J. Biol. Chem. 288, 20843-20855.

Kimura, K., Minematsu, K., Kazui, S., Yamaguchi, T., 2005. Mortality and cause of death after hospital discharge in 10,981 patients with ischemic stroke and transient ischemic attack. Cerebrovasc. Dis. 19, 171-178.

Kipp, M., Karakaya, S., Johann, S., Kampmann, E., Mey, J., Beyer, C., 2007. Oestrogen and progesterone reduce lipopolysaccharide-induced expression of tumour necrosis factor-alpha and interleukin-18 in midbrain astrocytes. J. Neuroendocrinol. 19, 819-822.

Kiziltan, M.E., Benbir, G., 2008. Clinical and electrophysiological differences in male and female patients with diabetic foot. Diabetes Res. Clin. Pract. 79, e17-e18.

Kiziltan, M.E., Gunduz, A., Kiziltan, G., Akalin, M.A., Uzun, N., 2007. Peripheral neuropathy in patients with diabetic foot ulcers: clinical and nerve conduction study. J. Neurol. Sci. 258, 75-79.

Kodl, C.T., Seaquist, E.R., 2008. Cognitive dysfunction and diabetes mellitus. Endocr. Rev. 29, 494-511.

Koenig, H.L., Schumacher, M., Ferzaz, B., Thi, A.N., Ressouches, A., Guennoun, R., JungTestas, I., Robel, P., Akwa, Y., Baulieu, E.E., 1995. Progesterone synthesis and myelin formation by Schwann cells. Science 268, 1500-1503.

Koss, W.A., Haertel, J.M., Philippi, S.M., Frick, K.M., 2018. Sex differences in the rapid cell signaling mechanisms underlying the memory-enhancing effects of 17 beta-estradiol. eNeuro 5.

Kovacs, E.J., Messingham, K.A., Gregory, M.S., 2002. Estrogen regulation of immune responses after injury. Mol. Cell. Endocrinol. 193, 129-135.

Kovats, S., Carreras, E., Agrawal, H., 2010. Sex steroid receptors in immune cells. Sex Horm. Immun. Infect. 53-91.

Koverech, A., Cicione, C., Lionetto, L., Maestri, M., Passariello, F., Sabbatini, E., Capi, M., De Marco, C.M., Guglielmetti, M., Negro, A., Di Menna, L., Simmaco, M., Nicoletti, F., Martelletti, P., 2019. Migraine and cluster headache show impaired neurosteroids patterns. J. Headache Pain 20, 61.

Kramar, E.A., Babayan, A.H., Gall, C.M., Lynch, G., 2013. Estrogen promotes learningrelated plasticity by modifying the synaptic cytoskeleton. Neuroscience $239,3-16$.

Kramer, P.R., Kramer, S.F., Guan, G., 2004. 17 beta-estradiol regulates cytokine release through modulation of CD16 expression in monocytes and monocyte-derived macrophages. Arthritis Rheum. 50, 1967-1975.

Kraszpulski, M., Soininen, H., Helisalmi, S., Alafuzoff, I., 2001. The load and distribution of beta-amyloid in brain tissue of patients with Alzheimer's disease. Acta Neurol. Scand. 103, 88-92.

Kraus, J.F., Peek-Asa, C., McArthur, D., 2000. The independent effect of gender on outcomes following traumatic brain injury: a preliminary investigation. Neurosurg. Focus 8, e5.

Kumar, P., Khan, A., Deshmukh, R., Lal Sharma, P., 2014. Role of neurosteroids in ex perimental 3-nitropropionic acid induced neurotoxicity in rats. Eur. J. Pharmacol. 723, 38-45.

Kumsar, S., Kumsar, N.A., Saglam, H.S., Kose, O., Budak, S., Adsan, O., 2014 Testosterone levels and sexual function disorders in depressive female patients: effects of antidepressant treatment. J. Sex. Med. 11, 529-535.

Kurth, F., Luders, E., Sicotte, N.L., Gaser, C., Giesser, B.S., Swerdloff, R.S., Montag, M.J., Voskuhl, R.R., Mackenzie-Graham, A., 2014. Neuroprotective effects of testosterone treatment in men with multiple sclerosis. Neuroimage Clin. 4, 454-460.

Labombarda, F., Gonzalez, S., Gonzalez Deniselle, M.C., Garay, L., Guennoun, R., Schumacher, M., De Nicola, A.F., 2006a. Progesterone increases the expression of myelin basic protein and the number of cells showing NG2 immunostaining in the lesioned spinal cord. J. Neurotrauma 23, 181-192.

Labombarda, F., Gonzalez, S.L., Lima, A., Roig, P., Guennoun, R., Schumacher, M., de Nicola, A.F., 2009. Effects of progesterone on oligodendrocyte progenitors, oligodendrocyte transcription factors, and myelin proteins following spinal cord injury. Glia 57, 884-897. 
Labombarda, F., González, S., Lima, A., Roig, P., Guennoun, R., Schumacher, M., De Nicola, A.F., 2011. Progesterone attenuates astro- and microgliosis and enhances oligodendrocyte differentiation following spinal cord injury. Exp. Neurol. 231, $135-146$.

Labombarda, F., Pianos, A., Liere, P., Eychenne, B., Gonzalez, S., Cambourg, A., De Nicola, A.F., Schumacher, M., Guennoun, R., 2006b. Injury elicited increase in spinal cord neurosteroid content analyzed by gas chromatography mass spectrometry. Endocrinology 147, 1847-1859.

Lagunas, N., Calmarza-Font, I., Diz-Chaves, Y., Garcia-Segura, L.M., 2010. Long-term ovariectomy enhances anxiety and depressive-like behaviors in mice submitted to chronic unpredictable stress. Horm. Behav. 58, 786-791.

Larson, T.A., 2018. Sex steroids, adult neurogenesis, and inflammation in CNS homeostasis, degeneration, and repair. Front. Endocrinol. (Lausanne) 9, 205

Lavaque, E., Mayen, A., Azcoitia, I., Tena-Sempere, M., Garcia-Segura, L.M., 2006a. Sex differences, developmental changes, response to injury and cAMP regulation of the mRNA levels of steroidogenic acute regulatory protein, cytochrome p450scc, and aromatase in the olivocerebellar system. J. Neurobiol. 66, 308-318.

Lavaque, E., Sierra, A., Azcoitia, I., Garcia-Segura, L.M., 2006b. Steroidogenic acute regulatory protein in the brain. Neuroscience 138, 741-747.

Lee, J.H., Byun, M.S., Yi, D., Choe, Y.M., Choi, H.J., Baek, H., Sohn, B.K., Lee, J.Y., Kim, H.J., Kim, J.W., Lee, Y., 2017. Sex-specific association of sex hormones and gonadotropins, with brain amyloid and hippocampal neurodegeneration. Neurobiol. Aging 58, 34-40.

Lei, B., Mace, B., Dawson, H.N., Warner, D.S., Laskowitz, D.T., James, M.L., 2014. Antiinflammatory effects of progesterone in lipopolysaccharide-stimulated BV-2 microglia. PLoS ONE 9, e103969.

Lei, Z.B., Fu, X.J., Lu, Z.T., Wang, B.C., Liu, X.L., You, N.Z., 2003. Effect of estradiol on chemokine receptor CXCR2 expression in rats: implications for atherosclerosis. Acta Pharmacol. Sin. 24, 670-674.

Leicaj, M.L., Pasquini, L.A., Lima, A., Gonzalez Deniselle, M.C., Pasquini, J.M., De Nicola, A.F., Garay, L.I., 2018. Changes in neurosteroidogenesis during demyelination and remyelination in cuprizone-treated mice. J. Neuroendocrinol. 30, e12649.

Leonelli, E., Bianchi, R., Cavaletti, G., Caruso, D., Crippa, D., Garcia-Segura, L.M., Lauria, G., Magnaghi, V., Roglio, I., Melcangi, R.C., 2007. Progesterone and its derivatives are neuroprotective agents in experimental diabetic neuropathy: a multimodal analysis. Neuroscience 144, 1293-1304.

Leonelli, E., Yague, J.G., Ballabio, M., Azcoitia, I., Magnaghi, V., Schumacher, M., GarciaSegura, L.M., Melcangi, R.C., 2005. Ro5-4864, a synthetic ligand of peripheral benzodiazepine receptor, reduces aging-associated myelin degeneration in the sciatic nerve of male rats. Mech. Ageing Dev. 126, 1159-1163.

Leva, G., Klein, C., Benyounes, J., Halle, F., Bihel, F., Collongues, N., De Seze, J., MensahNyagan, A.G., Patte-Mensah, C., 2017. The translocator protein ligand XBD173 improves clinical symptoms and neuropathological markers in the SJL/J mouse model of multiple sclerosis. Biochim. Biophys. Acta, Mol. Basis Dis. 1863, 3016-3027.

Lewis, C., Dluzen, D.E., 2008. Testosterone enhances dopamine depletion by methamphetamine in male, but not female, mice. Neurosci. Lett. 448, 130-133.

Lewis, J., Dickson, D.W., Lin, W.L., Chisholm, L., Corral, A., Jones, G., Yen, S.H., Sahara, N., Skipper, L., Yager, D., Eckman, C., Hardy, J., Hutton, M., McGowan, E., 2001. Enhanced neurofibrillary degeneration in transgenic mice expressing mutant tau and APP. Science 293, 1487-1491.

Li, J., Yu, Y., Wang, B., Wu, H., Xue, G., Hou, Y., 2016. Selective regulation of neurosteroid biosynthesis under ketamine-induced apoptosis of cortical neurons in vitro. Mol. Med. Rep. 13, 1586-1592.

Litim, N., Bourque, M., Al Sweidi, S., Morissette, M., Di Paolo, T., 2015. The 5alphareductase inhibitor Dutasteride but not Finasteride protects dopamine neurons in the MPTP mouse model of Parkinson's disease. Neuropharmacology 97, 86-94.

Litim, N., Morissette, M., Caruso, D., Melcangi, R.C., Di Paolo, T., 2017. Effect of the 5alpha-reductase enzyme inhibitor dutasteride in the brain of intact and parkinsonian mice. J. Steroid Biochem. Mol. Biol. 174, 242-256.

Liu, A., Margaill, I., Zhang, S., Labombarda, F., Coqueran, B., Delespierre, B., Liere, P., Marchand-Leroux, C., O'Malley, B.W., Lydon, J.P., De Nicola, A.F., Sitruk-Ware, R., Mattern, C., Plotkine, M., Schumacher, M., Guennoun, R., 2012. Progesterone receptors: a key for neuroprotection in experimental stroke. Endocrinology 153, 3747-3757.

Liu, M., Hurn, P.D., Roselli, C.E., Alkayed, N.J., 2007. Role of P450 aromatase in sexspecific astrocytic cell death. J. Cereb. Blood Flow Metab. 27, 135-141.

Liu, S., Wu, H., Xue, G., Ma, X., Wu, J., Qin, Y., Hou, Y., 2013. Metabolic alteration of neuroactive steroids and protective effect of progesterone in Alzheimer's disease-like rats. Neural Regen. Res. 8, 2800-2810.

Liu, S.B., Han, J., Zhang, N., Tian, Z., Li, X.B., Zhao, M.G., 2011. Neuroprotective effects of oestrogen against oxidative toxicity through activation of G-protein-coupled receptor 30 receptor. Clin. Exp. Pharmacol. Physiol. 38, 577-585.

Locci, A., Pinna, G., 2019. Stimulation of peroxisome proliferator-activated receptoralpha by N-palmitoylethanolamine engages allopregnanolone biosynthesis to modulate emotional behavior. Biol. Psychiatry.

Lopez Rodriguez, A.B., Mateos Vicente, B., Romero-Zerbo, S.Y., Rodriguez-Rodriguez, N., Bellini, M.J., Rodriguez de Fonseca, F., Bermudez-Silva, F.J., Azcoitia, I., GarciaSegura, L.M., Viveros, M.P., 2011. Estradiol decreases cortical reactive astrogliosis after brain injury by a mechanism involving cannabinoid receptors. Cereb. Cortex 21, 2046-2055.

Lopez-Rodriguez, A.B., Acaz-Fonseca, E., Giatti, S., Caruso, D., Viveros, M.P., Melcangi, R.C., Garcia-Segura, L.M., 2015. Correlation of brain levels of progesterone and dehydroepiandrosterone with neurological recovery after traumatic brain injury in female mice. Psychoneuroendocrinology 56, 1-11.

Lopez-Rodriguez, A.B., Acaz-Fonseca, E., Spezzano, R., Giatti, S., Caruso, D., Viveros, M.P., Melcangi, R.C., Garcia-Segura, L.M., 2016. Profiling neuroactive steroid levels after traumatic brain injury in male mice. Endocrinology 157, 3983-3993.

Luchetti, S., Bossers, K., Frajese, G.V., Swaab, D.F., 2010. Neurosteroid biosynthetic pathway changes in substantia nigra and caudate nucleus in Parkinson's disease. Brain Pathol. 20, 945-951.

Luchetti, S., Bossers, K., Van de Bilt, S., Agrapart, V., Morales, R.R., Frajese, G.V., Swaab, D.F., 2011a. Neurosteroid biosynthetic pathways changes in prefrontal cortex in Alzheimer's disease. Neurobiol. Aging 32, 1964-1976.

Luchetti, S., Huitinga, I., Swaab, D.F., 2011b. Neurosteroid and GABA-A receptor alterations in Alzheimer's disease, Parkinson's disease and multiple sclerosis. Neuroscience 191, 6-21.

Luchetti, S., van Eden, C.G., Schuurman, K., van Strien, M.E., Swaab, D.F., Huitinga, I., 2014. Gender differences in multiple sclerosis: induction of estrogen signaling in male and progesterone signaling in female lesions. J. Neuropathol. Exp. Neurol. 73, 123-135.

Luquin, S., Naftolin, F., Garcia-Segura, L.M., 1993. Natural fluctuation and gonadal hormone regulation of astrocyte immunoreactivity in dentate gyrus. J. Neurobiol. 24, 913-924.

Lv, W., Du, N., Liu, Y., Fan, X., Wang, Y., Jia, X., Hou, X., Wang, B., 2016. Low testosterone level and risk of Alzheimer's disease in the elderly men: a systematic review and meta-analysis. Mol. Neurobiol. 53, 2679-2684.

Ma, L., Zhang, H., Liu, N., Wang, P.Q., Guo, W.Z., Fu, Q., Jiao, L.B., Ma, Y.Q., Mi, W.D., 2016. TSPO ligand PK11195 alleviates neuroinflammation and beta-amyloid generation induced by systemic LPS administration. Brain Res. Bull. 121, 192-200.

Magnaghi, V., Ballabio, M., Gonzalez, L.C., Leonelli, E., Motta, M., Melcangi, R.C., 2004. The synthesis of glycoprotein Po and peripheral myelin protein 22 in sciatic nerve of male rats is modulated by testosterone metabolites. Brain Res. Mol. Brain Res. 126, 67-73.

Magnaghi, V., Ballabio, M., Roglio, I., Melcangi, R.C., 2007. Progesterone derivatives increase expression of Krox-20 and Sox-10 in rat Schwann cells. J. Mol. Neurosci. 31, $149-157$.

Magnaghi, V., Cavarretta, I., Zucchi, I., Susani, L., Rupprecht, R., Hermann, B., Martini, L., Melcangi, R.C., 1999. Po gene expression is modulated by androgens in the sciatic nerve of adult male rats. Brain Res. Mol. Brain Res. 70, 36-44.

Magnaghi, V., Veiga, S., Ballabio, M., Gonzalez, L.C., Garcia-Segura, L.M., Melcangi, R.C., 2006. Sex-dimorphic effects of progesterone and its reduced metabolites on gene expression of myelin proteins by rat Schwann cells. J. Peripher. Nerv. Syst. 11, $111-118$.

Maguire, J., 2019. Neuroactive steroids and GABAergic involvement in the neuroendocrine dysfunction associated with major depressive disorder and postpartum depression. Front. Cell. Neurosci. 13, 83.

Mannix, R., Berglass, J., Berkner, J., Moleus, P., Qiu, J., Jantzie, L.L., Meehan 3rd, W.P., Stanley, R.M., Robinson, S., 2014. Sex differences in the effect of progesterone after controlled cortical impact in adolescent mice: a preliminary study. J. Neurosurg. 121, 1337-1341.

Mantovani, A., Sica, A., Locati, M., 2005. Macrophage polarization comes of age. Immunity 23, 344-346.

Manwani, B., Bentivegna, K., Benashski, S.E., Venna, V.R., Xu, Y., Arnold, A.P., McCullough, L.D., 2015. Sex differences in ischemic stroke sensitivity are influenced by gonadal hormones, not by sex chromosome complement. J. Cereb. Blood Flow Metab. 35, 221-229.

Manwani, B., Liu, F., Scranton, V., Hammond, M.D., Sansing, L.H., McCullough, L.D., 2013. Differential effects of aging and sex on stroke induced inflammation across the lifespan. Exp. Neurol. 249, 120-131.

Marcus, S.M., Kerber, K.B., Rush, A.J., Wisniewski, S.R., Nierenberg, A., Balasubramani, G.K., Ritz, L., Kornstein, S., Young, E.A., Trivedi, M.H., 2008. Sex differences in depression symptoms in treatment-seeking adults: confirmatory analyses from the Sequenced Treatment Alternatives to Relieve Depression study. Compr. Psychiatry $49,238-246$.

Martinez-Cerdeno, V., Noctor, S.C., Kriegstein, A.R., 2006. Estradiol stimulates progenitor cell division in the ventricular and subventricular zones of the embryonic neocortex. Eur. J. Neurosci. 24, 3475-3488.

Marx, C.E., Bradford, D.W., Hamer, R.M., Naylor, J.C., Allen, T.B., Lieberman, J.A., Strauss, J.L., Kilts, J.D., 2011. Pregnenolone as a novel therapeutic candidate in schizophrenia: emerging preclinical and clinical evidence. Neuroscience 191, 78-90.

Marx, C.E., Keefe, R.S., Buchanan, R.W., Hamer, R.M., Kilts, J.D., Bradford, D.W., Strauss, J.L., Naylor, J.C., Payne, V.M., Lieberman, J.A., Savitz, A.J., Leimone, L.A., Dunn, L., Porcu, P., Morrow, A.L., Shampine, L.J., 2009. Proof-of-concept trial with the neurosteroid pregnenolone targeting cognitive and negative symptoms in schizophrenia. Neuropsychopharmacology 34, 1885-1903.

Marx, C.E., Trost, W.T., Shampine, L.J., Stevens, R.D., Hulette, C.M., Steffens, D.C., Ervin, J.F., Butterfield, M.I., Blazer, D.G., Massing, M.W., Lieberman, J.A., 2006. The neurosteroid allopregnanolone is reduced in prefrontal cortex in Alzheimer's disease. Biol. Psychiatry 60, 1287-1294.

Massa, M.G., David, C., Jorg, S., Berg, J., Gisevius, B., Hirschberg, S., Linker, R.A., Gold, R., Haghikia, A., 2017. Testosterone differentially affects T cells and neurons in murine and human models of neuroinflammation and neurodegeneration. Am. J. Pathol. 187, 1613-1622.

Massella, A., D'Intino, G., Fernandez, M., Sivilia, S., Lorenzini, L., Giatti, S., Melcangi, R.C., Calza, L., Giardino, L., 2012. Gender effect on neurodegeneration and myelin markers in an animal model for multiple sclerosis. BMC Neurosci. 13, 12.

Matarese, G., Sanna, V., Di Giacomo, A., Lord, G.M., Howard, J.K., Bloom, S.R., Lechler, R.I., Fontana, S., Zappacosta, S., 2001. Leptin potentiates experimental autoimmune encephalomyelitis in SJL female mice and confers susceptibility to males. Eur. J. Immunol. 31, 1324-1332.

Maydych, V., 2019. The interplay between stress, inflammation, and emotional attention: relevance for depression. Front. Neurosci. 13, 384. 
McCarthy, M.M., Schwarz, J.M., Wright, C.L., Dean, S.L., 2008. Mechanisms mediating oestradiol modulation of the developing brain. J. Neuroendocrinol. 20, 777-783.

McCarthy, M.M., Todd, B.J., Amateau, S.K., 2003. Estradiol modulation of astrocytes and the establishment of sex differences in the brain. Ann. N. Y. Acad. Sci. 1007, 283-297.

McEwen, B.S., Woolley, C.S., 1994. Estradiol and progesterone regulate neuronal structure and synaptic connectivity in adult as well as developing brain. Exp. Gerontol. 29, 431-436.

McHenry, J., Carrier, N., Hull, E., Kabbaj, M., 2014. Sex differences in anxiety and depression: Role of testosterone. Front. Neuroendocrinol. 35, 42-57.

McIntyre, R.S., Mancini, D., Eisfeld, B.S., Soczynska, J.K., Grupp, L., Konarski, J.Z. Kennedy, S.H., 2006. Calculated bioavailable testosterone levels and depression in middle-aged men. Psychoneuroendocrinology 31, 1029-1035.

Meffre, D., Pianos, A., Liere, P., Eychenne, B., Cambourg, A., Schumacher, M., Stein, D.G., Guennoun, R., 2007. Steroid profiling in brain and plasma of male and pseudopregnant female rats after traumatic brain injury: analysis by gas chromatography/ mass spectrometry. Endocrinology 148, 2505-2517.

Melcangi, R.C., Azcoitia, I., Ballabio, M., Cavarretta, I., Gonzalez, L.C., Leonelli, E. Magnaghi, V., Veiga, S., Garcia-Segura, L.M., 2003. Neuroactive steroids influence peripheral myelination: a promising opportunity for preventing or treating age-dependent dysfunctions of peripheral nerves. Prog. Neurobiol. 71, 57-66.

Melcangi, R.C., Caruso, D., Abbiati, F., Giatti, S., Calabrese, D., Piazza, F., Cavaletti, G. 2013. Neuroactive steroid levels are modified in cerebrospinal fluid and plasma of post-finasteride patients showing persistent sexual side effects and anxious/depressive symptomatology. J. Sex. Med. 10, 2598-2603.

Melcangi, R.C., Caruso, D., Levandis, G., Abbiati, F., Armentero, M.T., Blandini, F., 2012. Modifications of neuroactive steroid levels in an experimental model of nigrostriatal degeneration: potential relevance to the pathophysiology of Parkinson's disease. J. Mol. Neurosci. 46, 177-183.

Melcangi, R.C., Cavarretta, I.T., Ballabio, M., Leonelli, E., Schenone, A., Azcoitia, I., Miguel Garcia-Segura, L., Magnaghi, V., 2005. Peripheral nerves: a target for the action of neuroactive steroids. Brain Res. Brain Res. Rev. 48, 328-338.

Melcangi, R.C., Garcia-Segura, L.M., Mensah-Nyagan, A.G., 2008. Neuroactive steroids: state of the art and new perspectives. Cell. Mol. Life Sci. 65, 777-797.

Melcangi, R.C., Magnaghi, V., Cavarretta, I., Martini, L., Piva, F., 1998. Age-induced decrease of glycoprotein Po and myelin basic protein gene expression in the rat sciatic nerve. Repair by steroid derivatives. Neuroscience 85, 569-578.

Melcangi, R.C., Magnaghi, V., Cavarretta, I., Zucchi, I., Bovolin, P., D'Urso, D., Martini, L., 1999. Progesterone derivatives are able to influence peripheral myelin protein 22 and P0 gene expression: possible mechanisms of action. J. Neurosci. Res. 56, 349-357.

Melcangi, R.C., Magnaghi, V., Galbiati, M., Ghelarducci, B., Sebastiani, L., Martini, L., 2000a. The action of steroid hormones on peripheral myelin proteins: a possible new tool for the rebuilding of myelin? J. Neurocytol. 29, 327-339.

Melcangi, R.C., Magnaghi, V., Martini, L., 2000b. Aging in peripheral nerves: regulation of myelin protein genes by steroid hormones. Prog. Neurobiol. 60, 291-308.

Melcangi, R.C., Panzica, G., Garcia-Segura, L.M., 2011. Neuroactive steroids: focus on human brain. Neuroscience 191, 1-5.

Melcangi, R.C., Santi, D., Spezzano, R., Grimoldi, M., Tabacchi, T., Fusco, M.L., Diviccaro, S., Giatti, S., Carra, G., Caruso, D., Simoni, M., Cavaletti, G., 2017. Neuroactive steroid levels and psychiatric and andrological features in post-finasteride patients. J. Steroid Biochem. Mol. Biol. 171, 229-235.

Mensah-Nyagan, A.G., Meyer, L., Schaeffer, V., Kibaly, C., Patte-Mensah, C., 2009. Evidence for a key role of steroids in the modulation of pain. Psychoneuroendocrinology 34 (Suppl 1), S169-S177.

Mercier, G., Turque, N., Schumacher, M., 2001. Early activation of transcription factor expression in Schwann cells by progesterone. Brain Res. Mol. Brain Res. 97, 137-148.

Meyer, L., Patte-Mensah, C., Taleb, O., Mensah-Nyagan, A.G., 2010. Cellular and functional evidence for a protective action of neurosteroids against vincristine chemotherapy-induced painful neuropathy. Cell. Mol. Life Sci. 67, 3017-3034.

Meyer, L., Patte-Mensah, C., Taleb, O., Mensah-Nyagan, A.G., 2011. Allopregnanolone prevents and suppresses oxaliplatin-evoked painful neuropathy: multi-parametric assessment and direct evidence. Pain 152, 170-181.

Miao, Y.L., Guo, W.Z., Shi, W.Z., Fang, W.W., Liu, Y., Liu, J., Li, B.W., Wu, W., Li, Y.F., 2014. Midazolam ameliorates the behavior deficits of a rat posttraumatic stress disorder model through dual $18 \mathrm{kDa}$ translocator protein and central benzodiazepine receptor and neurosteroidogenesis. PLoS ONE 9, e101450.

Micevych, P., Sinchak, K., 2008. Synthesis and function of hypothalamic neuroprogesterone in reproduction. Endocrinology 149, 2739-2742.

Milivojevic, V., Kranzler, H.R., Gelernter, J., Burian, L., Covault, J., 2011. Variation in genes encoding the neuroactive steroid synthetic enzymes 5alpha-reductase type 1 and 3alpha-reductase type 2 is associated with alcohol dependence. Alcohol. Clin. Exp. Res. 35, 946-952.

Miller, A.P., Feng, W., Xing, D., Weathington, N.M., Blalock, J.E., Chen, Y.F., Oparil, S., 2004. Estrogen modulates inflammatory mediator expression and neutrophil chemotaxis in injured arteries. Circulation 110, 1664-1669.

Mishra, S., Chaube, R., 2017. Distribution and localization of 3beta-hydroxysteroid dehydrogenase (3beta-HSD) in the brain and its regions of the catfish Heteropneustes fossilis. Gen. Comp. Endocrinol. 241, 80-88.

Misiak, B., Frydecka, D., Loska, O., Moustafa, A.A., Samochowiec, J., Kasznia, J., Stanczykiewicz, B., 2018. Testosterone, DHEA and DHEA-S in patients with schizophrenia: A systematic review and meta-analysis. Psychoneuroendocrinology 89, 92-102.

Misiak, M., Beyer, C., Arnold, S., 2010. Gender-specific role of mitochondria in the vulnerability of 6-hydroxydopamine-treated mesencephalic neurons. BBA 1797 , 1178-1188.

Mitro, N., Cermenati, G., Audano, M., Giatti, S., Pesaresi, M., Pedretti, S., Spezzano, R., Caruso, D., Melcangi, R.C., 2017. Sterol regulatory element binding protein-1C knockout mice show altered neuroactive steroid levels in sciatic nerve. J. Neurochem. $142,420-428$.

Mitro, N., Cermenati, G., Brioschi, E., Abbiati, F., Audano, M., Giatti, S., Crestani, M., De Fabiani, E., Azcoitia, I., Garcia-Segura, L.M., Caruso, D., Melcangi, R.C., 2014. Neuroactive steroid treatment modulates myelin lipid profile in diabetic peripheral neuropathy. J. Steroid Biochem. Mol. Biol. 143, 115-121.

Mitro, N., Cermenati, G., Giatti, S., Abbiati, F., Pesaresi, M., Calabrese, D., Garcia-Segura, L.M., Caruso, D., Melcangi, R.C., 2012. LXR and TSPO as new therapeutic targets to increase the levels of neuroactive steroids in the central nervous system of diabetic animals. Neurochem. Int. 60, 616-621.

Mogi, K., Takanashi, H., Nagasawa, M., Kikusui, T., 2015. Sex differences in spatiotemporal expression of AR, ERalpha, and ERbeta mRNA in the perinatal mouse brain. Neurosci. Lett. 584, 88-92.

Moldovan, I.R., Cotleur, A.C., Zamor, N., Butler, R.S., Pelfrey, C.M., 2008. Multiple sclerosis patients show sexual dimorphism in cytokine responses to myelin antigens. J. Neuroimmunol. 193, 161-169.

Moriarty, P.J., Lieber, D., Bennett, A., White, L., Parrella, M., Harvey, P.D., Davis, K.L., 2001. Gender differences in poor outcome patients with lifelong schizophrenia. Schizophr. Bull. 27, 103-113.

Morohaku, K., Pelton, S.H., Daugherty, D.J., Butler, W.R., Deng, W., Selvaraj, V., 2014. Translocator protein/peripheral benzodiazepine receptor is not required for steroid hormone biosynthesis. Endocrinology 155, 89-97.

Mosher, L.J., Godar, S.C., Morissette, M., McFarlin, K.M., Scheggi, S., Gambarana, C., Fowler, S.C., Di Paolo, T., Bortolato, M., 2018. Steroid 5alpha-reductase 2 deficiency leads to reduced dominance-related and impulse-control behaviors. Psychoneuroendocrinology 91, 95-104.

Mosquera, L., Colon, J.M., Santiago, J.M., Torrado, A.I., Melendez, M., Segarra, A.C., Rodriguez-Orengo, J.F., Miranda, J.D., 2014. Tamoxifen and estradiol improved locomotor function and increased spared tissue in rats after spinal cord injury: their antioxidant effect and role of estrogen receptor alpha. Brain Res. 1561, 11-22.

Mottron, L., Duret, P., Mueller, S., Moore, R.D., Forgeot d'Arc, B., Jacquemont, S., Xiong, L., 2015. Sex differences in brain plasticity: a new hypothesis for sex ratio bias in autism. Mol. Autism. 6, 33.

Murphy, A.J., Guyre, P.M., Pioli, P.A., 2010. Estradiol suppresses NF-kappa B activation through coordinated regulation of let-7a and miR-125b in primary human macrophages. J. Immunol. 184, 5029-5037.

Murphy, D.D., Segal, M., 2000. Progesterone prevents estradiol-induced dendritic spine formation in cultured hippocampal neurons. Neuroendocrinology 72, 133-143.

Murray, H.E., Pillai, A.V., McArthur, S.R., Razvi, N., Datla, K.P., Dexter, D.T., Gillies, G.E., 2003. Dose- and sex-dependent effects of the neurotoxin 6-hydroxydopamine on the nigrostriatal dopaminergic pathway of adult rats: differential actions of estrogen in males and females. Neuroscience 116, 213-222.

Nagarajan, G., Aruna, A., Chang, C.F., 2015. Neuropeptide Arginine Vasotocin Positively Affects Neurosteroidogenesis in the Early Brain of Grouper, Epinephelus coioides. J. Neuroendocrinol. 27, 718-736.

Nelson, L.H., Saulsbery, A.I., Lenz, K.M., 2019. Small cells with big implications: Microglia and sex differences in brain development, plasticity and behavioral health. Prog. Neurobiol. 176, 103-119.

Ng, I., Lee, K.K., Lim, J.H., Wong, H.B., Yan, X.Y., 2006. Investigating gender differences in outcome following severe traumatic brain injury in a predominantly Asian population. Br. J. Neurosurg. 20, 73-78.

Nguyen, T.V., Jayaraman, A., Quaglino, A., Pike, C.J., 2010. Androgens selectively protect against apoptosis in hippocampal neurones. J. Neuroendocrinol. 22, 1013-1022.

Niemeier, J.P., Marwitz, J.H., Lesher, K., Walker, W.C., Bushnik, T., 2007. Gender differences in executive functions following traumatic brain injury. Neuropsychol. Rehabil. 17, 293-313.

Niewada, M., Kobayashi, A., Sandercock, P.A., Kaminski, B., Czlonkowska, A., 2005. Influence of gender on baseline features and clinical outcomes among 17,370 patients with confirmed ischaemic stroke in the international stroke trial. Neuroepidemiology 24, 123-128.

Noorbakhsh, F., Ellestad, K.K., Maingat, F., Warren, K.G., Han, M.H., Steinman, L., Baker, G.B., Power, C., 2011. Impaired neurosteroid synthesis in multiple sclerosis. Brain 134, 2703-2721.

O'Brien, P.D., Hur, J., Robell, N.J., Hayes, J.M., Sakowski, S.A., Feldman, E.L., 2016. Gender-specific differences in diabetic neuropathy in BTBR ob/ob mice. J. Diabet. Complic. 30, 30-37.

Oberlander, J.G., Woolley, C.S., 2016. 17beta-Estradiol acutely potentiates glutamatergic synaptic transmission in the hippocampus through distinct mechanisms in males and females. J. Neurosci. 36, 2677-2690.

Ohashi, K., Ando, Y., Munetsuna, E., Yamada, H., Yamazaki, M., Nagura, A., Taromaru, N., Ishikawa, H., Suzuki, K., Teradaira, R., 2015. Maternal fructose consumption alters messenger RNA expression of hippocampal StAR, PBR, P450(11beta), 11betaHSD, and 17beta-HSD in rat offspring. Nutr. Res. 35, 259-264.

Ooishi, Y., Kawato, S., Hojo, Y., Hatanaka, Y., Higo, S., Murakami, G., Komatsuzaki, Y., Ogiue-Ikeda, M., Kimoto, T., Mukai, H., 2012. Modulation of synaptic plasticity in the hippocampus by hippocampus-derived estrogen and androgen. J. Steroid Biochem. Mol. Biol. 131, 37-51.

Osborne, D.M., Edinger, K., Frye, C.A., 2009. Chronic administration of androgens with actions at estrogen receptor beta have anti-anxiety and cognitive-enhancing effects in male rats. Age (Dordr.) 31, 119-126.

Ozacmak, V.H., Sayan, H., 2009. The effects of 17 beta estradiol, 17alpha estradiol and progesterone on oxidative stress biomarkers in ovariectomized female rat brain subjected to global cerebral ischemia. Physiol. Res. 58, 909-912.

Palaszynski, K.M., Liu, H., Loo, K.K., Voskuhl, R.R., 2004a. Estriol treatment ameliorates disease in males with experimental autoimmune encephalomyelitis: implications for multiple sclerosis. J. Neuroimmunol. 149, 84-89. 
Palaszynski, K.M., Loo, K.K., Ashouri, J.F., Liu, H.B., Voskuhl, R.R., 2004b. Androgens are protective in experimental autoimmune encephalomyelitis: implications for multiple sclerosis. J. Neuroimmunol. 146, 144-152.

Panzica, G.C., Melcangi, R.C., 2008. The endocrine nervous system: source and target for neuroactive steroids. Brain Res. Rev. 57, 271-276.

Papadopoulos, V., 2014. On the role of the translocator protein (18-kDa) TSPO in steroid hormone biosynthesis. Endocrinology 155, 15-20.

Papadopoulos, V., Fan, J., Zirkin, B., 2018. Translocator protein (18 kDa): an update on its function in steroidogenesis. J. Neuroendocrinol. 30.

Pariante, C.M., Vassilopoulou, K., Velakoulis, D., Phillips, L., Soulsby, B., Wood, S.J., Brewer, W., Smith, D.J., Dazzan, P., Yung, A.R., Zervas, I.M., Christodoulou, G.N., Murray, R., McGorry, P.D., Pantelis, C., 2004. Pituitary volume in psychosis. Br. J. Psychiatry 185, 5-10.

Park, C., Rosenblat, J.D., Brietzke, E., Pan, Z., Lee, Y., Cao, B., Zuckerman, H., Kalantarova, A., McIntyre, R.S., 2019. Stress, epigenetics and depression: a systematic review. Neurosci. Biobehav, Rev. 102, 139-152.

Parmenter, B.A., Denney, D.R., Lynch, S.G., Middleton, L.S., Harlan, L.M., 2007. Cognitive impairment in patients with multiple sclerosis: association with the APOE gene and promoter polymorphisms. Mult. Scler. 13, 25-32.

Patel, D., Kas, M.J., Chattarji, S., Buwalda, B., 2019. Rodent models of social stress and neuronal plasticity: Relevance to depressive-like disorders. Behav. Brain Res. 369, 111900 .

Patte-Mensah, C., Meyer, L., Taleb, O., Mensah-Nyagan, A.G., 2014. Potential role of allopregnanolone for a safe and effective therapy of neuropathic pain. Prog. Neurobiol. 113, 70-78.

Pelfrey, C.M., Cotleur, A.C., Lee, J.C., Rudick, R.A., 2002. Sex differences in cytokine responses to myelin peptides in multiple sclerosis. J. Neuroimmunol. 130, 211-223.

Pelletier, G., 2010. Steroidogenic enzymes in the brain: morphological aspects. Prog. Brain Res. 181, 193-207.

Pesaresi, M., Giatti, S., Calabrese, D., Maschi, O., Caruso, D., Melcangi, R.C., 2010a. Dihydroprogesterone increases the gene expression of myelin basic protein in spinal cord of diabetic rats. J. Mol. Neurosci. 42, 135-139.

Pesaresi, M., Giatti, S., Cavaletti, G., Abbiati, F., Calabrese, D., Bianchi, R., Caruso, D., Garcia-Segura, L.M., Melcangi, R.C., 2011a. Sex differences in the manifestation of peripheral diabetic neuropathy in gonadectomized rats: a correlation with the levels of neuroactive steroids in the sciatic nerve. Exp. Neurol. 228, 215-221.

Pesaresi, M., Giatti, S., Cavaletti, G., Abbiati, F., Calabrese, D., Lombardi, R., Bianchi, R., Lauria, G., Caruso, D., Garcia-Segura, L.M., Melcangi, R.C., 2011b. Sex-dimorphic effects of dehydroepiandrosterone in diabetic neuropathy. Neuroscience 199, 401-409.

Pesaresi, M., Giatti, S., Spezzano, R., Romano, S., Diviccaro, S., Borsello, T., Mitro, N., Caruso, D., Garcia-Segura, L.M., Melcangi, R.C., 2018. Axonal transport in a peripheral diabetic neuropathy model: sex-dimorphic features. Biol. Sex Differ. 9, 6.

Pesaresi, M., Maschi, O., Giatti, S., Garcia-Segura, L.M., Caruso, D., Melcangi, R.C., 2010b. Sex differences in neuroactive steroid levels in the nervous system of diabetic and non-diabetic rats. Horm. Behav. 57, 46-55.

Peterson, B.L., Won, S., Geddes, R.I., Sayeed, I., Stein, D.G., 2015. Sex-related differences in effects of progesterone following neonatal hypoxic brain injury. Behav. Brain Res. 286, 152-165.

Pike, C.J., Carroll, J.C., Rosario, E.R., Barron, A.M., 2009. Protective actions of sex steroid hormones in Alzheimer's disease. Front. Neuroendocrinol. 30, 239-258.

Platania, P., Seminara, G., Aronica, E., Troost, D., Vincenza Catania, M., Angela Sortino, M., 2005. 17beta-estradiol rescues spinal motoneurons from AMPA-induced toxicity: a role for glial cells. Neurobiol. Dis. 20, 461-470.

Plaven-Sigray, P., Matheson, G.J., Collste, K., Ashok, A.H., Coughlin, J.M., Howes, O.D., Mizrahi, R., Pomper, M.G., Rusjan, P., Veronese, M., Wang, Y., Cervenka, S., 2018. Positron emission tomography studies of the glial cell marker translocator protein in patients with psychosis: a meta-analysis using individual participant data. Biol. Psychiatry 84, 433-442.

Poling, M.C., Luo, E.Y., Kauffman, A.S., 2017. Sex Differences in Steroid Receptor Coexpression and Circadian-Timed Activation of Kisspeptin and RFRP-3 Neurons May Contribute to the Sexually Dimorphic Basis of the LH Surge. Endocrinology 158, 3565-3578.

Porcu, P., Barron, A.M., Frye, C.A., Walf, A.A., Yang, S.Y., He, X.Y., Morrow, A.L., Panzica, G.C., Melcangi, R.C., 2016. Neurosteroidogenesis today: novel targets for neuroactive steroid synthesis and action and their relevance for translational research. J. Neuroendocrinol. 28.

Pozzilli, C., Tomassini, V., Marinelli, F., Paolillo, A., Gasperini, C., Bastianello, S., 2003. 'Gender gap' in multiple sclerosis: magnetic resonance imaging evidence. Eur. J. Neurol. 10, 95-97.

Quast, C., Reif, A., Bruckl, T., Pfister, H., Weber, H., Mattheisen, M., Cichon, S., Lang, T., Hamm, A., Fehm, L., Strohle, A., Arolt, V., Domschke, K., Kircher, T., Wittchen, H.U., Pauli, P., Gerlach, A.L., Alpers, G.W., Deckert, J., Rupprecht, R., Binder, E.B., Erhardt, A., 2014. Gender-specific association of variants in the AKR1C1 gene with dimensional anxiety in patients with panic disorder: additional evidence for the importance of neurosteroids in anxiety? Depress Anxiety 31, 843-850.

Quillinan, N., Deng, G., Grewal, H., Herson, P.S., 2014. Androgens and stroke: good, bad or indifferent? Exp. Neurol. 259, 10-15.

Ramachandran, B., Ahmed, S., Zafar, N., Dean, C., 2015. Ethanol inhibits long-term potentiation in hippocampal CA1 neurons, irrespective of lamina and stimulus strength, through neurosteroidogenesis. Hippocampus 25, 106-118.

Ramsden, M., Shin, T.M., Pike, C.J., 2003. Androgens modulate neuronal vulnerability to kainate lesion. Neuroscience 122, 573-578.

Rao, M.L., Kolsch, H., 2003. Effects of estrogen on brain development and neuroprotection-implications for negative symptoms in schizophrenia.

Psychoneuroendocrinology 28 (Suppl 2), 83-96.
Rasmusson, A.M., King, M.W., Valovski, I., Gregor, K., Scioli-Salter, E., Pineles, S.L., Hamouda, M., Nillni, Y.I., Anderson, G.M., Pinna, G., 2019. Relationships between cerebrospinal fluid GABAergic neurosteroid levels and symptom severity in men with PTSD. Psychoneuroendocrinology 102, 95-104.

Rasmusson, A.M., Pinna, G., Paliwal, P., Weisman, D., Gottschalk, C., Charney, D., Krystal, J., Guidotti, A., 2006. Decreased cerebrospinal fluid allopregnanolone levels in women with posttraumatic stress disorder. Biol. Psychiatry 60, 704-713.

Ratcliff, J.J., Greenspan, A.I., Goldstein, F.C., Stringer, A.Y., Bushnik, T., Hammond, F.M., Novack, T.A., Whyte, J., Wright, D.W., 2007. Gender and traumatic brain injury: do the sexes fare differently? Brain Inj. 21, 1023-1030.

Reddy, D.S., Carver, C.M., Clossen, B., Wu, X., 2019. Extrasynaptic gamma-aminobutyric acid type A receptor-mediated sex differences in the antiseizure activity of neurosteroids in status epilepticus and complex partial seizures. Epilepsia 60, 730-743.

Reddy, J., Waldner, H., Zhang, X., Illes, Z., Wucherpfennig, K.W., Sobel, R.A., Kuchroo, V.K., 2005. Cutting edge: CD $4+C D 25+$ regulatory T cells contribute to gender differences in susceptibility to experimental autoimmune encephalomyelitis. J. Immunol. 175, 5591-5595.

Reeves, M.J., Bushnell, C.D., Howard, G., Gargano, J.W., Duncan, P.W., Lynch, G., Khatiwoda, A., Lisabeth, L., 2008. Sex differences in stroke: epidemiology, clinical presentation, medical care, and outcomes. Lancet Neurol. 7, 915-926.

Reite, M., Sheeder, J., Teale, P., Adams, M., Richardson, D., Simon, J., Jones, R.H., Rojas, D.C., 1997. Magnetic source imaging evidence of sex differences in cerebral lateralization in schizophrenia. Arch. Gen. Psychiatry 54, 433-440.

Reyna-Neyra, A., Camacho-Arroyo, I., Ferrera, P., Arias, C., 2002. Estradiol and progesterone modify microtubule associated protein 2 content in the rat hippocampus. Brain Res. Bull. 58, 607-612.

Riecher-Rossler, A., Hafner, H., 2000. Gender aspects in schizophrenia: bridging the border between social and biological psychiatry. Acta Psychiatr. Scand. Suppl. 58-62.

Rodriguez-Navarro, J.A., Solano, R.M., Casarejos, M.J., Gomez, A., Perucho, J., de Yebenes, J.G., Mena, M.A., 2008. Gender differences and estrogen effects in parkin null mice. J. Neurochem. 106, 2143-2157.

Rodriguez-Perez, A.I., Dominguez-Meijide, A., Lanciego, J.L., Guerra, M.J., LabandeiraGarcia, J.L., 2013. Inhibition of Rho kinase mediates the neuroprotective effects of estrogen in the MPTP model of Parkinson's disease. Neurobiol. Dis. 58, 209-219.

Roglio, I., Bianchi, R., Camozzi, F., Carozzi, V., Cervellini, I., Crippa, D., Lauria, G., Cavaletti, G., Melcangi, R.C., 2009. Docetaxel-induced peripheral neuropathy: protective effects of dihydroprogesterone and progesterone in an experimental model. J. Peripher. Nerv. Syst. 14, 36-44.

Roglio, I., Bianchi, R., Giatti, S., Cavaletti, G., Caruso, D., Scurati, S., Crippa, D., GarciaSegura, L.M., Camozzi, F., Lauria, G., Melcangi, R.C., 2007. Testosterone derivatives are neuroprotective agents in experimental diabetic neuropathy. Cell. Mol. Life Sci. 64, 1158-1168.

Roglio, I., Bianchi, R., Gotti, S., Scurati, S., Giatti, S., Pesaresi, M., Caruso, D., Panzica, G.C., Melcangi, R.C., 2008. Neuroprotective effects of dihydroprogesterone and progesterone in an experimental model of nerve crush injury. Neuroscience 155, 673-685.

Romano, S., Mitro, N., Diviccaro, S., Spezzano, R., Audano, M., Garcia-Segura, L.M. Caruso, D., Melcangi, R.C., 2017. Short-term effects of diabetes on neurosteroidogenesis in the rat hippocampus. J. Steroid Biochem. Mol. Biol. 167, 135-143.

Romano, S., Mitro, N., Giatti, S., Diviccaro, S., Pesaresi, M., Spezzano, R., Audano, M. Garcia-Segura, L.M., Caruso, D., Melcangi, R.C., 2018. Diabetes induces mitochondrial dysfunction and alters cholesterol homeostasis and neurosteroidogenesis in the rat cerebral cortex. J. Steroid Biochem. Mol. Biol. 178, 108-116.

Romeo, E., Brancati, A., De Lorenzo, A., Fucci, P., Furnari, C., Pompili, E., Sasso, G.F., Spalletta, G., Troisi, A., Pasini, A., 1996. Marked decrease of plasma neuroactive steroids during alcohol withdrawal. Clin. Neuropharmacol. 19, 366-369.

Romeo, E., Strohle, A., Spalletta, G., di Michele, F., Hermann, B., Holsboer, F., Pasini, A. Rupprecht, R., 1998. Effects of antidepressant treatment on neuroactive steroids in major depression. Am. J. Psychiatry 155, 910-913.

Roof, R.L., Hall, E.D., 2000. Gender differences in acute CNS trauma and stroke: neuroprotective effects of estrogen and progesterone. J. Neurotrauma 17, 367-388.

Roquer, J., Campello, A.R., Gomis, M., 2003. Sex differences in first-ever acute stroke. Stroke 34, 1581-1585.

Rosamond, W., Flegal, K., Friday, G., Furie, K., Go, A., Greenlund, K., Haase, N., Ho, M. Howard, V., Kissela, B., Kittner, S., Lloyd-Jones, D., McDermott, M., Meigs, J., Moy, C., Nichol, G., O'Donnell, C.J., Roger, V., Rumsfeld, J., Sorlie, P., Steinberger, J., Thom, T., Wasserthiel-Smoller, S., Hong, Y., 2007. Heart disease and stroke statistics-2007 update: a report from the American Heart Association Statistics Committe and Stroke Statistics Subcommittee. Circulation 115, e69-e171.

Rosario, E.R., Carroll, J., Pike, C.J., 2010. Testosterone regulation of Alzheimer-like neuropathology in male 3xTg-AD mice involves both estrogen and androgen path ways. Brain Res. 1359, 281-290.

Rosario, E.R., Carroll, J.C., Pike, C.J., 2012. Evaluation of the effects of testosterone and luteinizing hormone on regulation of beta-amyloid in male 3xTg-AD mice. Brain Res. $1466,137-145$.

Rosario, E.R., Chang, L., Head, E.H., Stanczyk, F.Z., Pike, C.J., 2011. Brain levels of sex steroid hormones in men and women during normal aging and in Alzheimer's disease. Neurobiol. Aging 32, 604-613.

Ruiz-Palmero, I., Ortiz-Rodriguez, A., Melcangi, R.C., Caruso, D., Garcia-Segura, L.M., Rune, G.M., Arevalo, M.A., 2016. Oestradiol synthesized by female neurons generates sex differences in neuritogenesis. Sci. Rep. 6, 31891.

Rupprecht, R., Holsboer, F., 1999. Neuropsychopharmacological properties of neuroactive steroids. Steroids 64, 83-91.

Rupprecht, R., Papadopoulos, V., Rammes, G., Baghai, T.C., Fan, J., Akula, N., Groyer, G., Adams, D., Schumacher, M., 2010. Translocator protein (18 kDa) (TSPO) as a therapeutic target for neurological and psychiatric disorders. Nat Rev Drug Discov 9, 
971-988.

Russi, A.E., Ebel, M.E., Yang, Y., Brown, M.A., 2018. Male-specific IL-33 expression regulates sex-dimorphic EAE susceptibility. Proc. Natl. Acad. Sci. U. S. A. 115 E1520-E1529.

Sacher, J., Wilson, A.A., Houle, S., Rusjan, P., Hassan, S., Bloomfield, P.M., Stewart, D.E., Meyer, J.H., 2010. Elevated brain monoamine oxidase A binding in the early postpartum period. Arch. Gen. Psychiatry 67, 468-474.

Sakata, A., Mogi, M., Iwanami, J., Tsukuda, K., Min, L.J., Jing, F., Iwai, M., Ito, M., Horiuchi, M., 2010. Female exhibited severe cognitive impairment in type 2 diabetes mellitus mice. Life Sci. 86, 638-645.

Sakata, A., Mogi, M., Iwanami, J., Tsukuda, K., Min, L.J., Jing, F., Ohshima, K., Ito, M., Horiuchi, M., 2011. Female type 2 diabetes mellitus mice exhibit severe ischemic brain damage. J Am Soc Hypertens 5, 7-11.

Sanchez, P., Torres, J.M., Olmo, A., O'Valle, F., Ortega, E., 2009. Effects of environmental stress on mRNA and protein expression levels of steroid 5alpha-Reductase isozymes in adult rat brain. Horm. Behav. 56, 348-353.

Santillo, A., Falvo, S., Di Fiore, M.M., Chieffi Baccari, G., 2017. Seasonal changes and sexual dimorphism in gene expression of StAR protein, steroidogenic enzymes and sex hormone receptors in the frog brain. Gen. Comp. Endocrinol. 246, 226-232.

Santoro, A., Mattace Raso, G., Taliani, S., Da Pozzo, E., Simorini, F., Costa, B., Martini, C., Laneri, S., Sacchi, A., Cosimelli, B., Calignano, A., Da Settimo, F., Meli, R., 2016. TSPO-ligands prevent oxidative damage and inflammatory response in C6 glioma cells by neurosteroid synthesis. Eur. J. Pharm. Sci. 88, 124-131.

Sarzi, E., Seveno, M., Angebault, C., Milea, D., Ronnback, C., Quiles, M., Adrian, M., Grenier, J., Caignard, A., Lacroux, A., Lavergne, C., Reynier, P., Larsen, M., Hamel, C.P., Delettre, C., Lenaers, G., Muller, A., 2017. Increased steroidogenesis promotes early-onset and severe vision loss in females with OPA1 dominant optic atrophy. Hum. Mol. Genet. 26, 4764

Savettieri, G., Messina, D., Andreoli, V., Bonavita, S., Caltagirone, C., Cittadella, R., Farina, D., Fazio, M.C., Girlanda, P., Le Pira, F., Liguori, M., Lugaresi, A., Nocentini, U., Reggio, A., Salemi, G., Tedeschi, G., Trojano, M., Valentino, P., Quattrone, A., 2004. Gender-related effect of clinical and genetic variables on the cognitive impairment in multiple sclerosis. J. Neurol. 251, 1208-1214.

Sayeed, I., Guo, Q., Hoffman, S.W., Stein, D.G., 2006. Allopregnanolone, a progesterone metabolite, is more effective than progesterone in reducing cortical infarct volume after transient middle cerebral artery occlusion. Ann. Emerg. Med. 47, 381-389.

Sayeed, I., Wali, B., Stein, D.G., 2007. Progesterone inhibits ischemic brain injury in a rat model of permanent middle cerebral artery occlusion. Restor. Neurol. Neurosci. 25, 151-159.

Schneider, T., Roman, A., Basta-Kaim, A., Kubera, M., Budziszewska, B., Schneider, K., Przewlocki, R., 2008. Gender-specific behavioral and immunological alterations in an animal model of autism induced by prenatal exposure to valproic acid. Psychoneuroendocrinology 33, 728-740.

Schoenle, E.J., Schoenle, D., Molinari, L., Largo, R.H., 2002. Impaired intellectual development in children with Type I diabetes: association with $\mathrm{HbA}(1 \mathrm{c})$, age at diagnosis and sex. Diabetologia 45, 108-114.

Schule, C., Nothdurfter, C., Rupprecht, R., 2014. The role of allopregnanolone in depression and anxiety. Prog. Neurobiol. 113, 79-87.

Schwarz, J.M., Sholar, P.W., Bilbo, S.D., 2012. Sex differences in microglial colonization of the developing rat brain. J. Neurochem. 120, 948-963.

Scotland, R.S., Stables, M.J., Madalli, S., Watson, P., Gilroy, D.W., 2011. Sex differences in resident immune cell phenotype underlie more efficient acute inflammatory responses in female mice. Blood 118, 5918-5927.

Segatto, M., Di Giovanni, A., Marino, M., Pallottini, V., 2013. Analysis of the protein network of cholesterol homeostasis in different brain regions: an age and sex dependent perspective. J. Cell. Physiol. 228, 1561-1567.

Seidman, L.J., Goldstein, J.M., Goodman, J.M., Koren, D., Turner, W.M., Faraone, S.V. Tsuang, M.T., 1997. Sex differences in olfactory identification and Wisconsin Card Sorting performance in schizophrenia: relationship to attention and verbal ability. Biol. Psychiatry 42, 104-115.

Selvamani, A., Williams, M.H., Miranda, R.C., Sohrabji, F., 2014. Circulating miRNA profiles provide a biomarker for severity of stroke outcomes associated with age and sex in a rat model. Clin Sci (Lond) 127, 77-89.

Selvaraj, V., Stocco, D.M., 2015. The changing landscape in translocator protein (TSPO) function. Trends Endocrinol. Metab. 26, 341-348.

Selvaraj, V., Stocco, D.M., Tu, L.N., 2015. Minireview: translocator protein (TSPO) and steroidogenesis: a reappraisal. Mol. Endocrinol. 29, 490-501.

Setiawan, E., Attwells, S., Wilson, A.A., Mizrahi, R., Rusjan, P.M., Miler, L., Xu, C., Sharma, S., Kish, S., Houle, S., Meyer, J.H., 2018. Association of translocator protein total distribution volume with duration of untreated major depressive disorder: a cross-sectional study. Lancet Psychiatry 5, 339-347.

Shores, M.M., Sloan, K.L., Matsumoto, A.M., Moceri, V.M., Felker, B., Kivlahan, D.R., 2004. Increased incidence of diagnosed depressive illness in hypogonadal older men. Arch. Gen. Psychiatry 61, 162-167.

Sicotte, N.L., Giesser, B.S., Tandon, V., Klutch, R., Steiner, B., Drain, A.E., Shattuck, D.W., Hull, L., Wang, H.J., Elashoff, R.M., Swerdloff, R.S., Voskuhl, R.R., 2007. Testosterone treatment in multiple sclerosis: a pilot study. Arch. Neurol. 64, 683-688.

Simonds, V.M., Whiffen, V.E., 2003. Are gender differences in depression explained by gender differences in co-morbid anxiety? J. Affect. Disord. 77, 197-202.

Singh, M., Su, C., Ng, S., 2013. Non-genomic mechanisms of progesterone action in the brain. Front. Neurosci. 7, 159.

Siriphorn, A., Dunham, K.A., Chompoopong, S., Floyd, C.L., 2012. Postinjury administration of 17beta-estradiol induces protection in the gray and white matter with associated functional recovery after cervical spinal cord injury in male rats. J. Comp. Neurol. 520, 2630-2646.

Skinner, D.C., Evans, N.P., Delaleu, B., Goodman, R.L., Bouchard, P., Caraty, A., 1998.
The negative feedback actions of progesterone on gonadotropin-releasing hormone secretion are transduced by the classical progesterone receptor. Proc. Natl. Acad. Sci. U. S. A. 95, 10978-10983.

Slewa-Younan, S., Green, A.M., Baguley, I.J., Gurka, J.A., Marosszeky, J.E., 2004. Sex differences in injury severity and outcome measures after traumatic brain injury. Arch. Phys. Med. Rehabil. 85, 376-379.

Sohrabji, F., 2015. Estrogen-IGF-1 interactions in neuroprotection: ischemic stroke as a case study. Front. Neuroendocrinol. 36, 1-14.

Spanic, T., Fabjan, T., Majdic, G., 2015. Expression levels of mRNA for neurosteroidogenic enzymes 17beta-HSD, 5alpha-reductase, 3alpha-HSD and cytochrome P450 aromatase in the fetal wild type and SF-1 knockout mouse brain. Endocr. Res. 40, 44-48.

Spence, R.D., Voskuhl, R.R., 2012. Neuroprotective effects of estrogens and androgens in CNS inflammation and neurodegeneration. Front. Neuroendocrinol. 33, 105-115.

Sribnick, E.A., Wingrave, J.M., Matzelle, D.D., Wilford, G.G., Ray, S.K., Banik, N.L., 2005 Estrogen attenuated markers of inflammation and decreased lesion volume in acute spinal cord injury in rats. J. Neurosci. Res. 82, 283-293.

Stanic, D., Dubois, S., Chua, H.K., Tonge, B., Rinehart, N., Horne, M.K., Boon, W.C., 2014. Characterization of aromatase expression in the adult male and female mouse brain. I. Coexistence with oestrogen receptors alpha and beta, and androgen receptors. PLoS ONE 9, e90451.

Steiner, R.A., Bremner, W.J., Clifton, D.K., 1982. Regulation of luteinizing hormone pulse frequency and amplitude by testosterone in the adult male rat. Endocrinology 111, 2055-2061.

Sze, Y., Gill, A.C., Brunton, P.J., 2018. Sex-dependent changes in neuroactive steroid concentrations in the rat brain following acute swim stress. J. Neuroendocrinol. 30, e12644.

Szymanski, S., Lieberman, J.A., Alvir, J.M., Mayerhoff, D., Loebel, A., Geisler, S., Chakos, M., Koreen, A., Jody, D., Kane, J., et al., 1995. Gender differences in onset of illness, treatment response, course, and biologic indexes in first-episode schizophrenic patients. Am. J. Psychiatry 152, 698-703.

Tabatadze, N., Huang, G., May, R.M., Jain, A., Woolley, C.S., 2015. Sex Differences in Molecular Signaling at Inhibitory Synapses in the Hippocampus. J. Neurosci. 35, 11252-11265.

Takahashi, T., Suzuki, M., Kawasaki, Y., Hagino, H., Yamashita, I., Nohara, S., Nakamura, K., Seto, H., Kurachi, M., 2003. Perigenual cingulate gyrus volume in patients with schizophrenia: a magnetic resonance imaging study. Biol. Psychiatry 53, 593-600.

Tam, H., Schlinger, B.A., 2007. Activities of 3beta-HSD and aromatase in slices of developing and adult zebra finch brain. Gen. Comp. Endocrinol. 150, 26-33.

Tanaka, M., Ogaeri, T., Samsonov, M., Sokabe, M., 2019. The 5alpha-Reductase Inhibitor Finasteride Exerts Neuroprotection Against Ischemic Brain Injury in Aged Male Rats. Transl Stroke Res 10, 67-77.

Tanzer, L., Jones, K.J., 2004. Neurotherapeutic action of testosterone on hamster facial nerve regeneration: temporal window of effects. Horm. Behav. 45, 339-344.

Taylor, L.C., Puranam, K., Gilmore, W., Ting, J.P., Matsushima, G.K., 2010. 17beta-estradiol protects male mice from cuprizone-induced demyelination and oligodendrocyte loss. Neurobiol. Dis. 39, 127-137.

Tomas-Camardiel, M., Sanchez-Hidalgo, M.C., Sanchez del Pino, M.J., Navarro, A., Machado, A., Cano, J., 2002. Comparative study of the neuroprotective effect of dehydroepiandrosterone and 17beta-estradiol against 1-methyl-4-phenylpyridium toxicity on rat striatum. Neuroscience $109,569-584$.

Torres-Aleman, I., Rejas, M.T., Pons, S., Garcia-Segura, L.M., 1992. Estradiol promotes cell shape changes and glial fibrillary acidic protein redistribution in hypothalamic astrocytes in vitro: a neuronal-mediated effect. Glia 6, 180-187.

Traish, A.M., Melcangi, R.C., Bortolato, M., Garcia-Segura, L.M., Zitzmann, M., 2015. Adverse effects of 5alpha-reductase inhibitors: What do we know, don't know, and need to know? Rev. Endocr. Metab. Disord. 16, 177-198.

Tsutsui, K., Ukena, K., Sakamoto, H., Okuyama, S., Haraguchi, S., 2011. Biosynthesis, mode of action, and functional significance of neurosteroids in the purkinje cell. Front Endocrinol (Lausanne) 2, 61.

Tuisku, J., Plaven-Sigray, P., Gaiser, E.C., Airas, L., Al-Abdulrasul, H., Bruck, A., Carson, R.E., Chen, M.K., Cosgrove, K.P., Ekblad, L., Esterlis, I., Farde, L., Forsberg, A. Halldin, C., Helin, S., Kosek, E., Lekander, M., Lindgren, N., Marjamaki, P., Rissanen, E., Sucksdorff, M., Varrone, A., Hrrt Pbr, Study Group, Collste, K., Gallezot, J.D., Hillmer, A., Huang, Y., Hoglund, C.O., Johansson, J., Jucaite, A., Lampa, J., Nabulsi, N., Pittman, B., Sandiego, C.M., Stenkrona, P., Rinne, J., Matuskey, D., Cervenka, S. 2019. Effects of age, BMI and sex on the glial cell marker TSPO - a multicentre [(11)C]PBR28 HRRT PET study. Eur. J. Nucl. Med. Mol. Imaging 46, 2329-2338.

Tunez, I., Collado, J.A., Medina, F.J., Pena, J., Del, C.M.M., Jimena, I., Franco, F., Rueda, I., Feijoo, M., Muntane, J., Montilla, P., 2006. 17 beta-Estradiol may affect vulnerability of striatum in a 3-nitropropionic acid-induced experimental model of Huntington's disease in ovariectomized rats. Neurochem. Int. 48, 367-373.

Turtzo, L.C., McCullough, L.D., 2008. Sex differences in stroke. Cerebrovasc. Dis. 26, $462-474$.

Uban, K.A., Herting, M.M., Wozniak, J.R., Sowell, E.R., Cifasd, 2017. Sex differences in associations between white matter microstructure and gonadal hormones in children and adolescents with prenatal alcohol exposure. Psychoneuroendocrinology 83, $111-121$.

Uzunova, V., Sheline, Y., Davis, J.M., Rasmusson, A., Uzunov, D.P., Costa, E., Guidotti, A. 1998. Increase in the cerebrospinal fluid content of neurosteroids in patients with unipolar major depression who are receiving fluoxetine or fluvoxamine. Proc. Natl. Acad. Sci. U. S. A. 95, 3239-3244.

Van Den Eeden, S.K., Tanner, C.M., Bernstein, A.L., Fross, R.D., Leimpeter, A., Bloch, D.A., Nelson, L.M., 2003. Incidence of Parkinson's disease: variation by age, gender, and race/ethnicity. Am. J. Epidemiol. 157, 1015-1022.

VanLandingham, J.W., Cekic, M., Cutler, S., Hoffman, S.W., Stein, D.G.C.P., 2007. 
Neurosteroids reduce inflammation after TBI through CD55 induction. Neurosci. Lett. 425, 94-98.

Vannucci, S.J., Willing, L.B., Goto, S., Alkayed, N.J., Brucklacher, R.M., Wood, T.L., Towfighi, J., Hurn, P.D., Simpson, I.A., 2001. Experimental stroke in the female diabetic, db/db, mouse. J. Cereb. Blood Flow Metab. 21, 52-60.

Vega-Vela, N.E., Osorio, D., Avila-Rodriguez, M., Gonzalez, J., Garcia-Segura, L.M., Echeverria, V., Barreto, G.E., 2017. L-Type Calcium Channels Modulation by Estradiol. Mol. Neurobiol. 54, 4996-5007.

Vegeto, E., Bonincontro, C., Pollio, G., Sala, A., Viappiani, S., Nardi, F., Brusadelli, A. Viviani, B., Ciana, P., Maggi, A., 2001. Estrogen prevents the lipopolysaccharideinduced inflammatory response in microglia. J. Neurosci. 21, 1809-1818.

Veiga, S., Leonelli, E., Beelke, M., Garcia-Segura, L.M., Melcangi, R.C., 2006. Neuroactive steroids prevent peripheral myelin alterations induced by diabetes. Neurosci. Lett. 402, 150-153.

Velazquez-Zamora, D.A., Garcia-Segura, L.M., Gonzalez-Burgos, I., 2012. Effects of selective estrogen receptor modulators on allocentric working memory performance and on dendritic spines in medial prefrontal cortex pyramidal neurons of ovariectomized rats. Horm. Behav. 61, 512-517.

Veliskova, J., 2006. The role of estrogens in seizures and epilepsy: the bad guys or the good guys? Neuroscience 138, 837-844.

Vieira-Marques, C., Arbo, B.D., Cozer, A.G., Hoefel, A.L., Cecconello, A.L., Zanini, P., Niches, G., Kucharski, L.C., Ribeiro, M.F.M., 2017. Sex-specific effects of dehydroepiandrosterone (DHEA) on glucose metabolism in the CNS. J. Steroid Biochem. Mol. Biol. 171, 1-10.

Vierk, R., Brandt, N., Rune, G.M., 2014. Hippocampal estradiol synthesis and its significance for hippocampal synaptic stability in male and female animals. Neuroscience 274, 24-32.

Vierk, R., Glassmeier, G., Zhou, L., Brandt, N., Fester, L., Dudzinski, D., Wilkars, W., Bender, R.A., Lewerenz, M., Gloger, S., Graser, L., Schwarz, J., Rune, G.M., 2012. Aromatase inhibition abolishes LTP generation in female but not in male mice. J. Neurosci. 32, 8116-8126.

Villa, A., Gelosa, P., Castiglioni, L., Cimino, M., Rizzi, N., Pepe, G., Lolli, F., Marcello, E., Sironi, L., Vegeto, E., Maggi, A., 2018. Sex-Specific Features of Microglia from Adult Mice. Cell Rep 23, 3501-3511.

Vina, J., Sastre, J., Pallardo, F., Borras, C., 2003. Mitochondrial theory of aging: importance to explain why females live longer than males. Antioxid. Redox Signal. 5, $549-556$.

Vita, G., Dattola, R., Girlanda, P., Oteri, G., Lo Presti, F., Messina, C., 1983. Effects of steroid hormones on muscle reinnervation after nerve crush in rabbit. Exp. Neurol. 80, 279-287.

Viviani, B., Corsini, E., Binaglia, M., Lucchi, L., Galli, C.L., Marinovich, M., 2002. The anti- inflammatory activity of estrogen in glial cells is regulated by the PKC- anchoring protein RACK-1. J. Neurochem. 83, 1180-1187.

Wagner, A.K., Bayir, H., Ren, D., Puccio, A., Zafonte, R.D., Kochanek, P.M., 2004. Relationships between cerebrospinal fluid markers of excitotoxicity, ischemia, and oxidative damage after severe TBI: the impact of gender, age, and hypothermia. J. Neurotrauma 21, 125-136.

Walf, A.A., Frye, C.A., 2010. Estradiol reduces anxiety- and depression-like behavior of aged female mice. Physiol. Behav. 99, 169-174.

Walf, A.A., Frye, C.A., 2012. Gestational or acute restraint in adulthood reduces levels of 5alpha-reduced testosterone metabolites in the hippocampus and produces behavioral inhibition of adult male rats. Front. Cell. Neurosci. 6, 40.

Walf, A.A., Frye, C.A., 2014. Estradiol reduces anxiety- and depression-like behavior of aged female mice. Physiol. Behav. 99, 169-174.

Walf, A.A., Paris, J.J., Frye, C.A., 2009. Chronic estradiol replacement to aged female rats reduces anxiety-like and depression-like behavior and enhances cognitive performance. Psychoneuroendocrinology 34, 909-916.

Wali, B., Ishrat, T., Stein, D.G., Sayeed, I., 2016. Progesterone improves long-term functional and histological outcomes after permanent stroke in older rats. Behav. Brain Res. 305, 46-56.

Wang, J.M., Liu, L., Irwin, R.W., Chen, S., Brinton, R.D., 2008. Regenerative potential of allopregnanolone. Brain Res. Rev. 57, 398-409.

Weger, M., Diotel, N., Weger, B.D., Beil, T., Zaucker, A., Eachus, H.L., Oakes, J.A., do
Rego, J.L., Storbeck, K.H., Gut, P., Straehle, U., 2018. Expression and activity profiling of the steroidogenic enzymes of glucocorticoid biosynthesis and the fdx1 cofactors in zebrafish. J Neuroendocrinol 30.

Weinshenker, B.G., 1994. Natural history of multiple sclerosis. Ann. Neurol. 36 (Suppl), S6-S11.

Wirth, M.M., 2011. Beyond the HPA axis: progesterone-derived neuroactive steroids in human stress and emotion. Front. Endocrinol. (Lausanne) 2, 19.

Wolf, L., Bauer, A., Melchner, D., Hallof-Buestrich, H., Stoertebecker, P., Haen, E., Kreutz, M., Sarubin, N., Milenkovic, V.M., Wetzel, C.H., Rupprecht, R., Nothdurfter, C., 2015 Enhancing neurosteroid synthesis-relationship to the pharmacology of translocator protein (18 kDa) (TSPO) ligands and benzodiazepines. Pharmacopsychiatry 48, $72-77$.

Wooten, G.F., Currie, L.J., Bovbjerg, V.E., Lee, J.K., Patrie, J., 2004. Are men at greater risk for Parkinson's disease than women? J. Neurol. Neurosurg. Psychiatry 75, 637-639.

Xin, F., Fischer, E., Krapp, C., Krizman, E.N., Lan, Y., Mesaros, C., Snyder, N.W., Bansal, A., Robinson, M.B., Simmons, R.A., Bartolomei, M.S., 2018. Mice exposed to bisphenol A exhibit depressive-like behavior with neurotransmitter and neuroactive steroid dysfunction. Horm. Behav. 102, 93-104.

Xu, P., Li, D., Tang, X., Bao, X., Huang, J., Tang, Y., Yang, Y., Xu, H., Fan, X., 2013. LXR agonists: new potential therapeutic drug for neurodegenerative diseases. Mol. Neurobiol. 48, 715-728.

Yao, P.L., Zhuo, S., Mei, H., Chen, X.F., Li, N., Zhu, T.F., Chen, S.T., Wang, J.M., Hou, R.X., Le, Y.Y., 2017. Androgen alleviates neurotoxicity of beta-amyloid peptide (Abeta) by promoting microglial clearance of Abeta and inhibiting microglial inflammatory response to Abeta. CNS Neurosci. Ther. 23, 855-865.

Yorek, M.A., Coppey, L.J., Gellett, J.S., Davidson, E.P., Bing, X., Lund, D.D., Dillon, J.S. 2002. Effect of treatment of diabetic rats with dehydroepiandrosterone on vascular and neural function. Am. J. Physiol. Endocrinol. Metab. 283, E1067-E1075.

Yu, W.H., 1982. Effect of testosterone on the regeneration of the hypoglossal nerve in rats. Exp. Neurol. 77, 129-141.

Yu, W.H., 1989. Survival of motoneurons following axotomy is enhanced by lactation or by progesterone treatment. Brain Res. 491, 379-382.

Yue, X., Lu, M., Lancaster, T., Cao, P., Honda, S., Staufenbiel, M., Harada, N., Zhong, Z. Shen, Y., Li, R., 2005. Brain estrogen deficiency accelerates Abeta plaque formation in an Alzheimer's disease animal model. Proc. Natl. Acad. Sci. U. S. A. 102, 19198-19203.

Zettergren, A., Jonsson, L., Johansson, D., Melke, J., Lundstrom, S., Anckarsater, H., Lichtenstein, P., Westberg, L., 2013. Associations between polymorphisms in sex steroid related genes and autistic-like traits. Psychoneuroendocrinology 38, 2575-2584.

Zhang, Q.G., Raz, L., Wang, R., Han, D., De Sevilla, L., Yang, F., Vadlamudi, R.K., Brann, D.W., 2009. Estrogen attenuates ischemic oxidative damage via an estrogen receptor alpha-mediated inhibition of NADPH oxidase activation. J. Neurosci. 29, 13823-13836.

Zhang, Q.G., Wang, R., Tang, H., Dong, Y., Chan, A., Sareddy, G.R., Vadlamudi, R.K., Brann, D.W., 2014. Brain-derived estrogen exerts anti-inflammatory and neuroprotective actions in the rat hippocampus. Mol. Cell. Endocrinol. 389, 84-91.

Zhang, Y., Champagne, N., Beitel, L.K., Goodyer, C.G., Trifiro, M., LeBlanc, A., 2004. Estrogen and androgen protection of human neurons against intracellular amyloid beta1-42 toxicity through heat shock protein 70. J. Neurosci. 24, 5315-5321.

Zhong, Y.H., Wu, H.Y., He, R.H., Zheng, B.E., Fan, J.Z., 2019. Sex Differences in sex hormone profiles and prediction of consciousness recovery after severe traumatic brain injury. Front Endocrinol (Lausanne) 10, 261.

Zhu, H., Han, X., Ji, D., Lv, G., Xu, M., 2012. Estrogen inhibits lipid peroxidation after hypoxic-ischemic brain damage in neonatal rats. Neural. Regen. Res. 7, 2424-2431.

Zhu, X., Frechou, M., Liere, P., Zhang, S., Pianos, A., Fernandez, N., Denier, C., Mattern, C., Schumacher, M., Guennoun, R., 2017. A role of endogenous progesterone in stroke cerebroprotection revealed by the neural-specific deletion of its intracellular receptors. J. Neurosci. 37, 10998-11020.

Zup, S.L., Edwards, N.S., McCarthy, M.M., 2014. Sex- and age-dependent effects of androgens on glutamate-induced cell death and intracellular calcium regulation in the developing hippocampus. Neuroscience 281C, 77-87. 